\title{
PREDICTION OF THE DEGRADATION OF EMERGING CONTAMINANTS DURING OXIDATIVE TREATMENT VIA ANALYSIS OF REACTION RATE CONSTANTS
}

\author{
A Thesis \\ presented to \\ the Faculty of California Polytechnic State University, \\ San Luis Obispo
}

In Partial Fulfillment of the Requirements for the Degree

Master of Science in Civil and Environmental Engineering

by

Kellie Cochran

June 2018 
(C) 2018

Kellie Cochran

ALL RIGHTS RESERVED 


\title{
COMMITTEE MEMBERSHIP
}

TITLE: Prediction of the Degradation of Emerging Contaminants During Oxidative Treatment via Analysis of Reaction Rate Constants

\author{
AUTHOR: Kellie Cochran
}

DATE SUBMITTED: June 2018

COMMITTEE CHAIR: Rebekah Oulton, Ph. D., P.E.

Assistant Professor of Civil and

Environmental Engineering

COMMITTEE MEMBER: Amro El Badawy, Ph. D.

Lecturer of Civil and Environmental

Engineering

COMMITTEE MEMBER: $\quad$ Tryg Lundquist, Ph. D., P.E.

Professor of Civil and Environmental

Engineering 


\begin{abstract}
Prediction of the Degradation of Emerging Contaminants During Oxidative Treatment via Analysis of Reaction Rate Constants
\end{abstract}

\title{
Kellie Cochran
}

Globally, water supplies are diminishing in quality while demand is continually increasing. The municipal water and wastewater sector has been paying increased attention to unregulated emerging organic contaminants. Advanced oxidation processes (AOPs), which produce hydroxyl radicles $(\cdot \mathrm{OH})$, have been developed and implemented to remove recalcitrant emerging contaminants left by conventional treatment processes. The current understanding of the removal efficacy of AOPs for emerging contaminants is limited. This study analyzes the ability of an AOP involving ozone and multi-walled carbon nanotubes (MWCNTs) in removing three specific emerging contaminants: caffeine, atrazine, and phenytoin, which were selected based on their persistence and ubiquity in the environment and their potential to serve as AOP efficacy indicator compounds. Reaction rate constants were determined from batch reactor data and compared to the degradation trends observed for the different compounds after exposure to treatment. During exposure to ozone alone, caffeine degraded quickly $\left(\mathrm{K}_{\mathrm{O} 3}=334\right.$ $\left.\pm 67 \mathrm{M}^{-1} \mathrm{~s}^{-1}\right)$, atrazine degraded slightly $\left(\mathrm{K}_{\mathrm{O} 3}=8.3 \pm 1.0 \mathrm{M}^{-1} \mathrm{~s}^{-1}\right)$, and phenytoin did not respond to the treatment. Atrazine and phenytoin were exposed to $\cdot \mathrm{OH}$ in the AOP treatment process, and the contaminants displayed greater removal 
compared to ozone only. To simulate more realistic water systems, a mixture of caffeine and atrazine was subjected to ozone only and the AOP with ozone and CNTs. Competition for ozone and $\bullet \mathrm{OH}$ resulted in lower atrazine degradation. This result reflects the expected degradation of these compounds based on their individually determined reaction rate constants. Atrazine behaved as expected when exposed to ozone and the AOP, and the reaction rate constants determined for atrazine reflect the observed degradation trend which qualifies atrazine as a potential indicator compound. Overall, this study demonstrates the ability of the AOP combining ozone and CNTs to degrade recalcitrant compounds, the potential for atrazine to serve as an indicator compound for AOPs, and the reliability of reaction rate constants to predict the degradation of contaminants in increasingly complex water systems. 


\section{ACKNOWLEDGMENTS}

I would like to acknowledge the following people for their continued support and encouragement throughout this research project: Dr. Rebekah Oulton for sharing your excitement and extensive knowledge in this field of research, and for helping me develop a project centered around my interests and guiding me through every step in the process. I am grateful for the professional development and personal growth I have experienced through this project. Dr. Amro El Badawy for helping me develop my research question and for your guidance over the past year. Dr. Tryg Lundquist for your recommendations and support for my project throughout. The faculty, students, and staff of the Civil and Environmental Engineering Department for giving me countless opportunities and memorable experiences over the past five years. Dr. Eric Jones and the Chemistry and Biochemistry Department for allowing me to use your HPLC to analyze my samples. Emily Miller and all of the students who assisted for their time and help working in the lab. My family and friends for their unending love and support. I am grateful for the encouragement I received every step of the way that has allowed me to see this project to completion. 


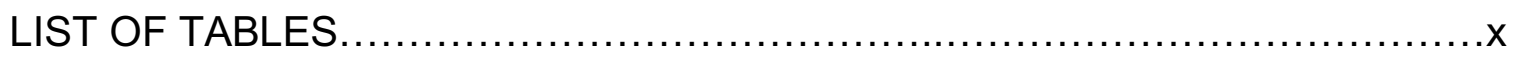

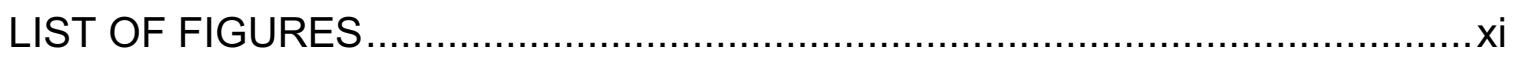

CHAPTER

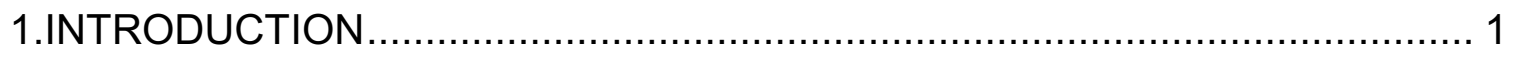

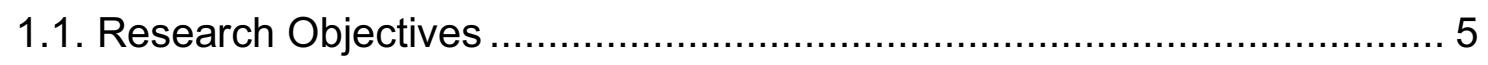

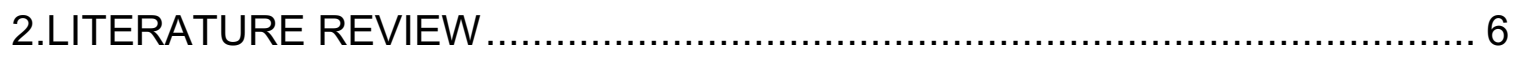

2.1.Emerging Contaminants and Breakdown Products ................................ 6

2.2.Conventional Treatment Processes ........................................................ 10

2.3.Tertiary Treatment Processes ............................................................. 12

2.3.1.Pressure Driven Membrane Filtration .............................................. 13

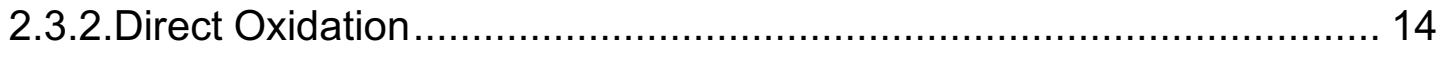

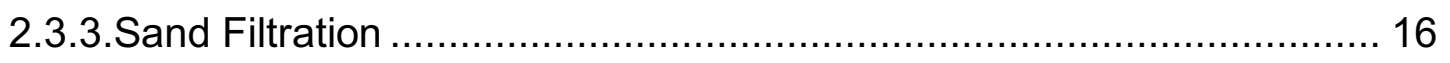

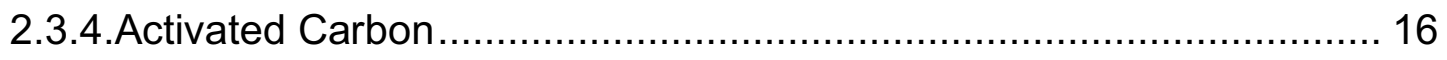

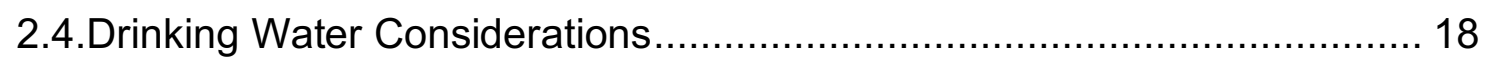

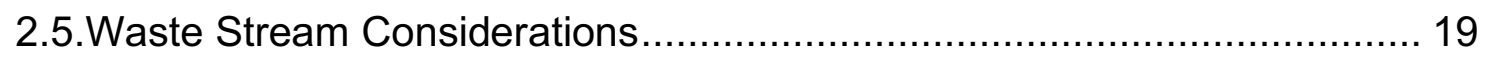

2.6.Advanced Oxidation Processes..................................................... 20

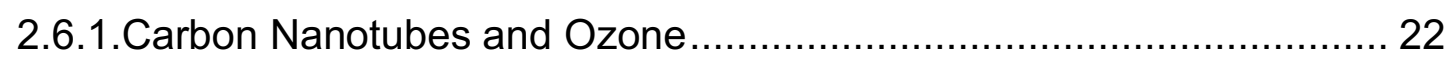

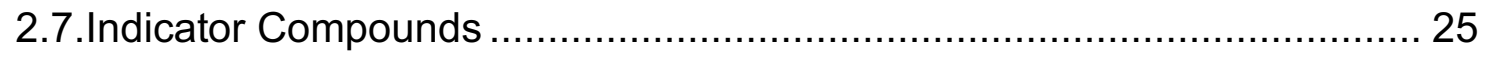

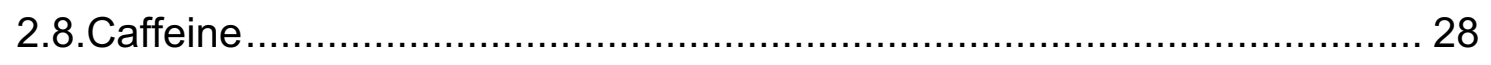

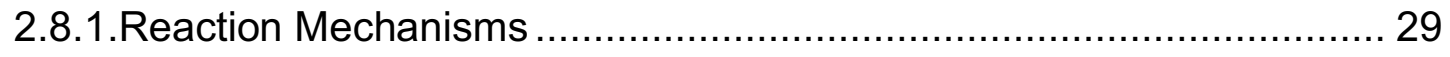




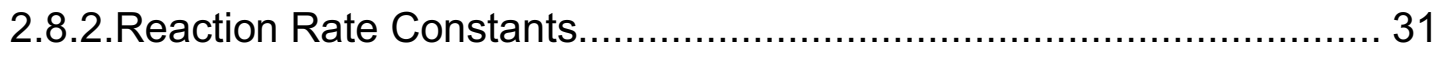

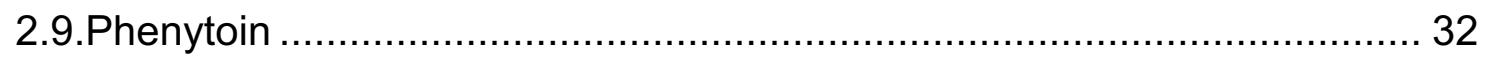

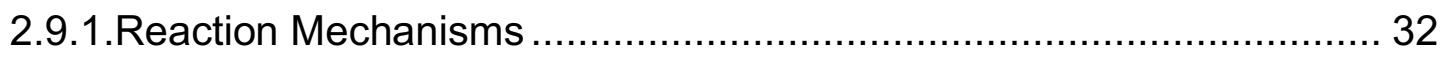

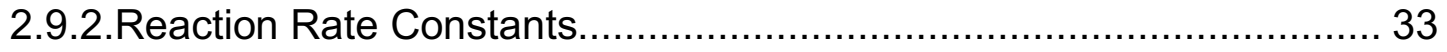

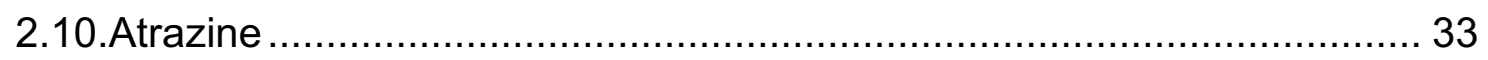

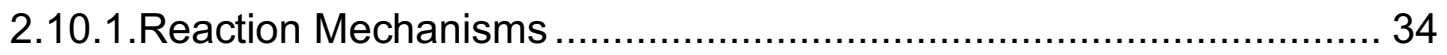

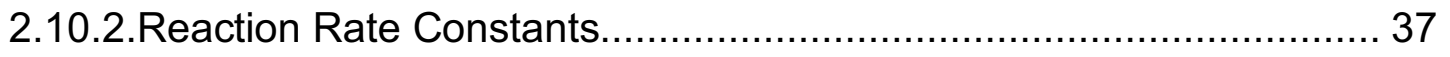

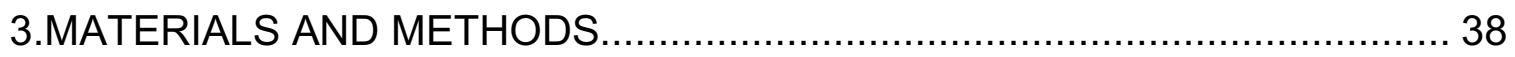

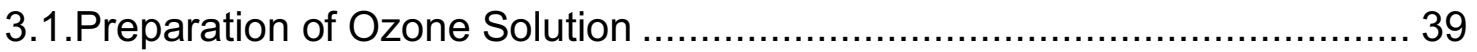

3.2.Preparation of Carbon Nanotubes ...................................................... 40

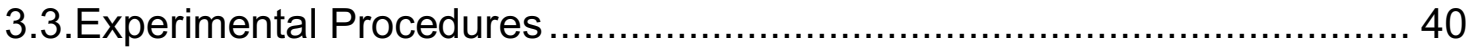

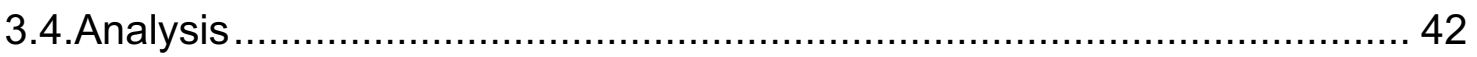

3.5.Quality Assurance and Quality Control............................................... 43

3.6. Determination of Reaction Rate Constants ......................................... 45

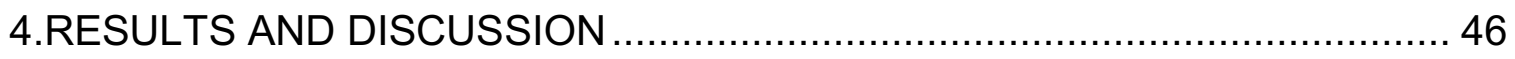

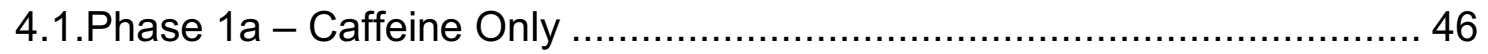

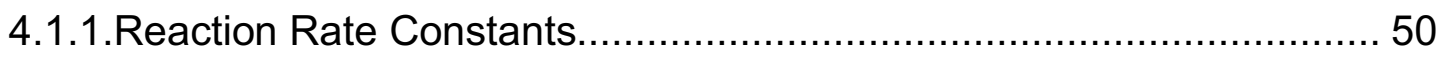

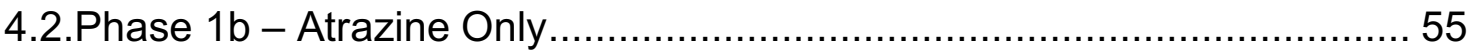

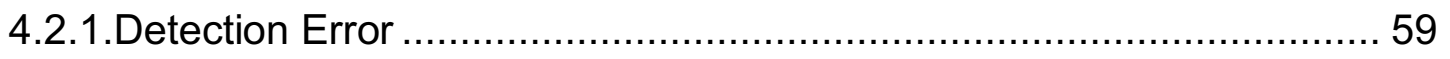

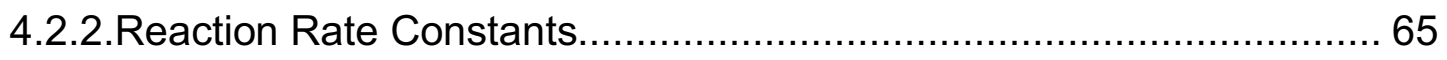

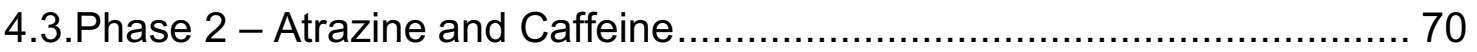

4.3.1.Reaction Rate Constants......................................................... 75

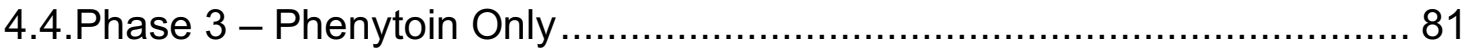


5.1.Conclusions

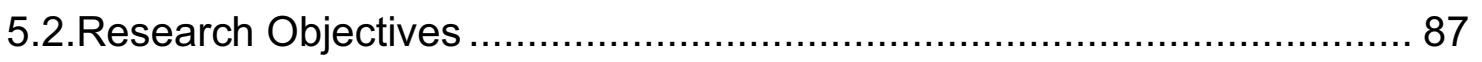

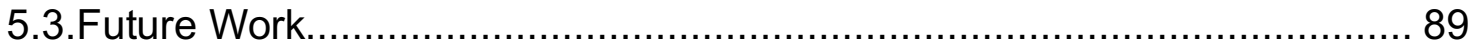

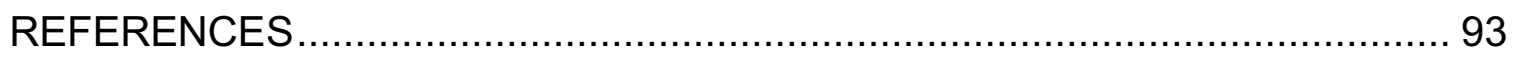
APPENDICES

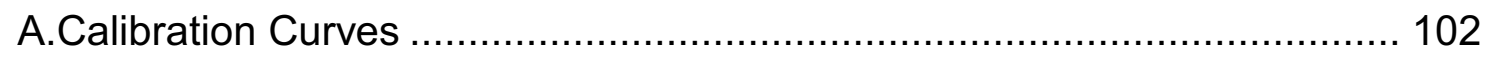

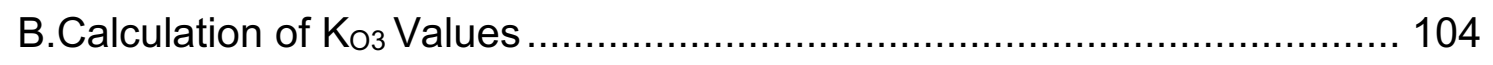

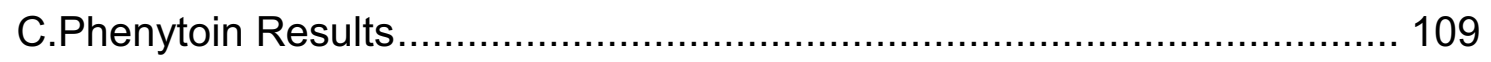




\section{LIST OF TABLES}

Table

Page

1. Second-order $\mathrm{K}_{\mathrm{o}}$ values $\left(\mathrm{M}^{-1} \mathrm{~s}^{-1}\right)$ for caffeine exposed to ozone 53

2. Second-order $\mathrm{K}_{\mathrm{o}}$ values $\left(\mathrm{M}^{-1} \mathrm{~s}^{-1}\right)$ for atrazine exposed to ozone 67

3. Second-order $\mathrm{K}^{\prime}$ values $\left(\mathrm{M}^{-1} \mathrm{~s}^{-1}\right)$ for atrazine exposed to $\bullet \mathrm{OH} \ldots \ldots \ldots \ldots \ldots \ldots \ldots . \ldots . \ldots . \ldots . \ldots$

4. Second-order $\mathrm{K}_{\mathrm{O}}$ values $\left(\mathrm{M}^{-1} \mathrm{~s}^{-1}\right)$ for atrazine and caffeine exposed to ozone

5. Second-order $\mathrm{K}^{\prime}$ values $\left(\mathrm{M}^{-1} \mathrm{~S}^{-1}\right)$ for atrazine and caffeine exposed to

$\cdot \mathrm{OH}$ 


\section{LIST OF FIGURES}

$\begin{array}{lll}\text { Figure } & \text { Page }\end{array}$

1. Proposed reaction mechanism of caffeine exposed to ozone in (a) acidic conditions at $\mathrm{pH} 3$ and (b) alkaline conditions at $\mathrm{pH} 8$ from Rosal et al. (2009).

2. Structure of phenytoin and its breakdown products from Ohnmacht et al. (2006).

3. Structure of atrazine and its breakdown products from Fan et al. (2014)...... 35

4. Proposed reaction mechanism of atrazine exposed to ozone and MWCNTs from Fan et al. (2014)....

5. Caffeine concentration as a function of time in Experiment 1 (standard competition ratio), 2 (double competition), and 3 (triple competition) 48

6. Ozone concentration as a function of time in Experiment 1 (standard competition ratio), 2 (double competition), and 3 (triple competition)

7. Atrazine concentration as a function of time in Experiment 4 (ozone only), 5 (CNTs only), and 6 (AOP with ozone and CNTs), and the removal achieved by the $\mathrm{AOP}$ via $\cdot \mathrm{OH}$ 57

8. Chromatograph of atrazine sample blank (not exposed to treatment) 59

9. Chromatograph of atrazine in Experiment 4 (ozone only) after 5 seconds 60

10. Chromatograph of atrazine in Experiment 4 (ozone only) after 5 minutes 
11. Chromatograph of atrazine in Experiment 6 (AOP with ozone and CNTs) after 5 seconds.

12. Chromatograph of atrazine in Experiment 6 (AOP with ozone and CNTs) after 5 minutes 62

13. Atrazine concentration added to unknown identified breakdown products in Experiment 4 (ozone only) and 6 (AOP with ozone and CNTs)

14. Ozone concentration as a function of time in Experiment 4 (ozone only) and 6 (AOP with ozone and CNTs). 66

15. Atrazine concentration as a function of time in Experiment 7 (ozone only), 8 (CNTs only), and 9 (AOP with ozone and CNTs), and the removal achieved by the AOP via $\cdot \mathrm{OH}$ with increased competition.

16. Ozone concentration as a function of time in Experiment 7 (ozone only) and 9 (AOP with ozone and CNTs) with increased competition. 76

17. Atrazine and caffeine concentration as a function of time in Experiment 7 (ozone only) with increased competition. 80

A.1. Calibration curve for known caffeine concentrations and absorbance measured by the HPLC

A.2. Calibration curve for known atrazine concentrations and absorbance measured by the HPLC 103

A.3. Calibration curve for known phenytoin concentrations and absorbance measured by the HPLC 
B.1. Natural log of removal of caffeine versus the time integrated ozone concentration for (a) Trial 1, (b) Trial 2, and (c) Trial 3 in Experiment 1 ....104

B.2. Natural log of removal of caffeine versus the time integrated ozone concentration for (a) Trial 1 and (b) Trial 2 in Experiment $2 \ldots \ldots \ldots \ldots \ldots \ldots . \ldots 105$

B.3. Natural log of removal of caffeine versus the time integrated ozone concentration for (a) Trial 1 and (b) Trial 2 in Experiment 3 105

B.4. Natural log of removal of atrazine versus the time integrated ozone concentration for (a) Trial 1 and (b) Trial 2 in Experiment 4 106

B.5. Natural log of removal of atrazine versus the time integrated ozone concentration for (a) Trial 1 and (b) Trial 2 in Experiment 6

B.6. Natural log of removal of atrazine versus the time integrated ozone concentration for (a) Trial 1 and (b) Trial 2 in Experiment 7 107

B.7. Natural log of removal of atrazine versus the time integrated ozone concentration for (a) Trial 1 and (b) Trial 2 in Experiment 9 108

C.1. Phenytoin concentration as a function of time in Experiment 10 (ozone only), 11 (CNTs only), and 12 (AOP with ozone and CNTs) 109 


\section{Chapter 1 - Introduction}

As the global population continues to grow and urbanize, supplying a sufficient amount of clean water is becoming a challenge (Pal, He, Jekel, Reinhard, \& Yew-Hoong Gin, 2014). Water supplies from surface water and groundwater are diminishing and can no longer meet the increasing demands of expanding urban cities (Pal et al., 2014). In addition to experiencing a reduction in water supply, the quality of the available water has been degraded as a result of wastewater effluent discharge and the compounding of contaminants in water through repeated indirect reuse (Pal et al., 2014). Cities are proposing and implementing advanced treatment processes in drinking water and wastewater treatment facilities to improve the effluent quality and allow for direct reuse (Pal et al., 2014).

Growing concern over the presence of unregulated emerging organic contaminants in water has also prompted the development of more advanced treatment technologies (Garcia-Ivars et al., 2017; Glassmeyer et al., 2017). Emerging contaminants are increasingly prevalent in water sources as a result of use of pharmaceuticals, personal care products (PCPs), pesticides, and other chemicals, and they pose a challenge for treatment and limit the opportunities for reuse (Garcia-Ivars et al., 2017; Petrie, Barden, \& Kasprzyk-Hordern, 2014). Some of these contaminants can be removed or partially degraded through conventional water and wastewater treatment processes, while other contaminants resist treatment and are classified as persistent environmental 
pollutants (Garcia-Ivars et al., 2017). Treatment techniques referred to as advanced oxidation processes (AOPs) have been developed to target recalcitrant emerging contaminants (Klavarioti, Mantzavinos, \& Kassinos, 2009; Oulton, Kohn, \& Cwiertny, 2010; Rey et al., 2011; Schaar, Clara, Gans, \& Kreuzinger, 2010). This study analyzes the efficacy of an AOP developed by Oulton et al. to degrade three ubiquitous and recalcitrant emerging contaminants (Oulton, 2013).

To better understand the improved removal achieved by AOPs, conventional and tertiary treatment methods were first studied. Conventional (primary and secondary) treatment processes have proven to be effective at removing biologically degradable compounds, but they do not target emerging contaminants (Garcia-Ivars et al., 2017; Knopp, Prasse, Ternes, \& Cornel, 2016; Liu, Kanjo, \& Mizutani, 2009; Oulton, 2013; Schaar et al., 2010). Tertiary treatment with pressure driven membrane filtration, direct oxidation, sand filtration, or activated carbon has also been incorporated into treatment processes to improve effluent water quality (Esplugas, Bila, Krause, \& Dezotti, 2007; Karelid, Larsson, \& Bjorlenius, 2017; Liu et al., 2009; Oulton et al., 2010; Schaar et al., 2010; Schonherr, Buchheim, Scholz, \& Stelter, 2017). However, these tertiary treatment processes are limited in their ability to remove many emerging contaminants which necessitates an AOP or combined treatment process to achieve a higher level of contaminant removal (Garcia-Ivars et al., 2017). 
AOPs promote the production of highly reactive species, primarily hydroxyl radicals $(\cdot \mathrm{OH})$, to target emerging contaminants and compounds that are resistant to other treatment methods (Klavarioti et al., 2009; Oulton et al., 2010; Rey et al., 2011; Schaar et al., 2010). Currently, various combinations of reactive species such as ozone, hydrogen peroxide $\left(\mathrm{H}_{2} \mathrm{O}_{2}\right)$, UV irradiation, and others are used to generate $\cdot \mathrm{OH}$, but current methods have limitations including high energy demand and high chemical use (Klavarioti et al., 2009; Liu et al., 2009; Oulton et al., 2010; Schonherr et al., 2017). Achieving greater concentrations of $\bullet \mathrm{OH}$ in a treatment system is expected to further remove emerging contaminants (Fan, Restivo, Órfão, Pereira, \& Lapkin, 2014; Oulton et al., 2015; Schonherr et al., 2017). Recent studies have been conducted on the use of ozone in combination with other materials such as activated carbon and carbon nanotubes (CNTs) to promote the increased production of $\cdot \mathrm{OH}$ (Fan et al., 2014; Oulton et al., 2015; Restivo, Garcia-bordejé, Órfão, \& Pereira, 2016; Schonherr et al., 2017; Sotelo et al., 2012). Oulton et al. studied the use of ozone and multi-walled carbon nanotubes (MWCNTs) functionalized with nitric acid, and found the process to be effective in the production of $\cdot \mathrm{OH}$ (Oulton et al., 2015). The study by Oulton et al. (2015) found the AOP tested to be a promising treatment for emerging contaminants.

Another challenge with treatment of emerging contaminants is analysis. The wide range of classes of emerging contaminants and the variety of properties associated with them present a challenge for measuring emerging contaminant 
levels in water systems (Petrie et al., 2014). There is a need for a simpler and more reliable method of quantifying emerging contaminants that will allow for accurate measurement of concentrations in drinking water and wastewater (Petrie et al., 2014). The use of indicator compounds to represent the efficacy of a treatment process for removing emerging contaminants has been recommended in several studies (Benotti et al., 2009; Broséus et al., 2009; Huerta-Fontela, Galceran, \& Ventura, 2011; Oulton et al., 2010). In addition to using indicator compounds, the reaction rate constant of a compound may also be used to predict the removal of emerging contaminants by a treatment process.

Three emerging contaminants known to be recalcitrant to direct oxidation were exposed to treatment in this study, and the level of degradation achieved by the AOP was evaluated. From previous studies, caffeine, phenytoin (anti-epileptic drug), and atrazine (herbicide) were found to be resistant to direct oxidation and were recommended as indicator compounds for AOPs (Benotti et al., 2009; Broséus et al., 2009; Oulton et al., 2015). The contaminants for this study were also selected based on their widespread presence in drinking water, wastewater, and surface water (Benotti et al., 2009; Ohnmacht, Chen, Tong, \& Hage, 2006; Rosal et al., 2009). In this study, the AOP from Oulton et al. (2015) was replicated and used as a treatment process. To determine the efficacy of the AOP developed by Oulton et al. (2015), several emerging contaminants were exposed to the treatment process, and the reduction in their concentration was measured. The reaction mechanisms, formation of breakdown products, and 
reaction rate constants for caffeine, phenytoin, and atrazine were studied to predict how the contaminants will respond to treatment.

\subsection{Research Objectives}

There are three main research objectives for this study. First, this study aims to explore the ability and limitations of the AOP developed by Oulton et al. (2015) to remove recalcitrant emerging contaminants from water. The goal is to better understand the functioning of this treatment process and the potential it has for improving effluent water quality. The second objective is to determine if specific ubiquitous and recalcitrant contaminants can serve as indicator compounds that represent the efficacy of an AOP for removing a wide range of emerging contaminants. Third, this study aims to determine if the reaction rate constant for a compound reflects how it will respond to treatment in complex water mixtures. The results of this study will help determine whether reaction rate constants can be used to predict how a compound will react in a system where a variety of contaminants are present (i.e. real water systems).

To achieve these research objectives, a literature review was conducted and the findings are summarized in Chapter 2. A series of experiments were developed, and the materials and methods are outlined in Chapter 3. In Chapter 4, the findings of this study are presented. Finally, the conclusions and recommendations for future work are included in Chapter 5. 


\section{Chapter 2 - Literature Review}

The existing literature surrounding this area of research was reviewed and summarized in this chapter. The current body of knowledge and identified gaps in research were used to inform and develop this study.

\subsection{Emerging Contaminants and Breakdown Products}

Emerging contaminants are a relatively new class of contaminants that are increasingly present in wastewater effluents, environmental waters, and source waters for drinking water treatment. These emerging contaminants can include endocrine disrupting compounds (EDCs), pharmaceuticals, pesticides, disinfection byproducts (DBPs), and PCPs (Garcia-Ivars et al., 2017). In surface water, the concentration of these emerging contaminants typically ranges from one nanogram per liter to a few micrograms per liter (Almomani, Shawaqfah, Bhosale, \& Kumar, 2016; Clara et al., 2005; Knopp et al., 2016; Quintana, Weiss, \& Reemtsma, 2005). Some pharmaceuticals have also been detected within a similar concentration range in drinking water (Huerta-Fontela et al., 2011). Even at these trace concentrations, emerging contaminants have the potential to harm human, animal, and ecological health (Garcia-Ivars et al., 2017).

While their overall health effect is unknown, emerging contaminants are a cause for concern in environmental and drinking water. Some emerging contaminants (i.e. certain types of pharmaceuticals and pesticides) are classified as EDCs because they disturb the normal functioning of the endocrine systems (Belgiorno 
et al., 2007; Broséus et al., 2009; Liu et al., 2009). EDCs typically exist in trace concentrations in the environment but can persist and bioaccumulate in larger species and humans which can have negative reproductive and health effects (Bolong, Ismail, Salim, \& Matsuura, 2009; Esplugas et al., 2007; Garcia-Ivars et al., 2017; Liu et al., 2009; Mompelat, Le Bot, \& Thomas, 2009). In addition to the potential health impacts, the prevalence of pharmaceuticals in water has promoted the development of antibiotic resistant bacteria (Esplugas et al., 2007; Garcia-Ivars et al., 2017). As the presence of emerging contaminants in environmental and drinking water continues to increase, unforeseen impacts and compounding effects from these contaminants may be discovered.

Many of these contaminants are commonly introduced into environmental waters through wastewater treatment plant effluents (Almomani et al., 2016; Belgiorno et al., 2007; Clara et al., 2005; Deeb, Stephan, Schmitz, \& Schmidt, 2017; Schaar et al., 2010). Wastewater collected from domestic sewers, hospitals, and industrial processes is the main source of emerging contaminants entering the water system (Boleda, Galceran, \& Ventura, 2011). During wastewater treatment, some emerging contaminants are not completely eliminated or transformed which allows them to enter surface waters where they then might enter drinking water treatment plants (Boleda et al., 2011; Broséus et al., 2009; Deeb et al., 2017; Oulton et al., 2010). Improved methods for detection and removal of emerging contaminants from wastewater and drinking water are needed to 
prevent the circulation and accumulation of emerging contaminants in water systems.

Pharmaceuticals and other emerging contaminants are difficult to remove from water because they can be biologically active, retain their chemical structure for a long time, and resist chemical and biological degradation (Klavarioti et al., 2009). Removing emerging contaminants from water is also challenging because of the wide range of properties associated with each compound. Therefore, more than one type of treatment is usually required to remove a variety of contaminants. In wastewater treatment plant effluents and environmental waters, treatment and biological processes including oxidation, photolysis, hydrolysis, and microbial metabolism reduce the concentrations of emerging contaminants (Aymerich et al., 2016; Deeb et al., 2017). Emerging contaminants are also removed by natural processes occurring in environmental waters such as biodegradation, photodegradation, and adsorption by sediments (Aymerich et al., 2016; Mompelat et al., 2009). These treatment processes facilitate the partial degradation of the original (or parent) compounds and result in the formation of breakdown (or degradation) products (Aymerich et al., 2016; Deeb et al., 2017).

As emerging contaminants are degraded, they are transformed into intermediate breakdown products before being completely destroyed (or mineralized) (Aymerich et al., 2016). Oftentimes, complete mineralization of a contaminant is not achieved through a treatment process or natural degradation, meaning the 
breakdown products are able to persist. There is limited research surrounding the microbial degradation of contaminants such as pharmaceuticals, the breakdown products that are formed, and the environmental fate of these compounds (Deeb et al., 2017; Quintana et al., 2005). The properties and toxicity of most breakdown products are unknown, but these breakdown products have the potential to be more active and toxic than their parent compounds (Deeb et al., 2017; Knopp et al., 2016). Breakdown products can also retain their biochemical activity and be resistant to biodegradation (Deeb et al., 2017; Jelic et al., 2011; Oulton et al., 2010). To ensure complete removal of emerging contaminants from water, the presence of breakdown products must be addressed by treatment processes (Quintana et al., 2005).

Breakdown products also pose a challenge for treating wastewater and promoting environmental water quality because in some cases the breakdown products of a contaminant have been found to be in higher concentrations in wastewater and environmental waters than the parent compound (Hernández, Sancho, Ibáñez, \& Grimalt, 2008; Quintana et al., 2005). A study conducted by Deeb et al. (2017) found a low concentration of breakdown products in wastewater before ozonation and an increase in breakdown product concentration after ozonation. The increase in breakdown product concentration corresponds to a decreasing concentration of parent compounds in treated wastewater and environmental water. After the increase in breakdown product concentration following ozonation, the concentration was significantly reduced in 
surface water (Deeb et al., 2017). However, the reduction in breakdown product concentration in surface water may be a result of dilution rather than contaminant degradation. Overall, the results of this study highlight the gaps in understanding of emerging contaminant removal and the limited ability to predict the total effect these contaminants, including their breakdown products, have on water systems. The reduction of emerging contaminant levels alone cannot be equated to removal of ecotoxicological concern (Oulton, 2013). Therefore, all forms of emerging contaminants, including breakdown products, must be considered in the development of water and wastewater treatment processes.

\subsection{Conventional Treatment Processes}

Conventional wastewater treatment systems are designed to remove physical and biological contaminants such as suspended solids, nitrogen, phosphorus, biological oxygen demand (BOD), and pathogens, but they do not directly address emerging contaminants (Garcia-Ivars et al., 2017; Knopp et al., 2016; Liu et al., 2009; Oulton, 2013; Schaar et al., 2010). After being treated by conventional processes, emerging contaminants often are only partially degraded and remain in the effluent (Oulton et al., 2010).

The removal of the constituents in wastewater occurs through primary and secondary treatment processes. A study by Oulton et al. (2010) identified fifteen emerging contaminants found to be the most susceptible to removal through conventional wastewater treatment from previous studies. However, primary 
treatment methods alone including coagulation, flocculation, and sedimentation have not proven to be effective at removing a wide range of emerging contaminants from water (Bolong et al., 2009; Esplugas et al., 2007; Oulton et al., 2010). For secondary treatment, traditional processes including conventional activated sludge (CAS) and trickling filters are able to remove some level of emerging contaminants from water. CAS is commonly used as a secondary treatment process, and studies have shown that some contaminants are removed through biodegradation in activated sludge treatment (Belgiorno et al., 2007; Liu et al., 2009; Oulton et al., 2010). Longer hydraulic retention times (HRTs) and solid retention times (SRTs) allow for sorption and biodegradation which is thought to improve the removal of emerging contaminants in CAS wastewater treatment plants (Belgiorno et al., 2007; Bolong et al., 2009). However, a study conducted by Oulton et al. (2010) found no trend in adjusting the operating parameters of secondary treatment processes to improve removal efficiency of emerging contaminants. The study also determined CAS to be ineffective at achieving a high level of emerging contaminant removal in wastewater for many contaminants (Oulton et al., 2010). Similar to CAS, trickling filters used for secondary treatment have not been found to effectively remove emerging contaminants except for specific classes of compounds (Bolong et al., 2009; Oulton et al., 2010).

The removal efficiency of newer technologies, such as a membrane bioreactor (MBR) system, for emerging contaminants is higher but not significantly improved 
compared to more conventional technologies (i.e. CAS and trickling filters) (Clara et al., 2005; Oulton et al., 2010; Quintana et al., 2005; Radjenović, Petrović, \& Barceló, 2009). For pharmaceuticals and PCPs, MBRs have shown to have a slightly higher removal efficiency than CAS (Oulton et al., 2010). MBRs operate with longer HRTs and SRTs than other treatment methods; therefore, more biodegradation occurs which helps remove a greater level of easily biodegradable emerging contaminants (Belgiorno et al., 2007; Sipma et al., 2010).

The mechanisms within conventional wastewater treatment that contribute to the partial removal of emerging contaminants include adsorption onto suspended solids, aerobic and anaerobic degradation, chemical degradation, and volatilization (Belgiorno et al., 2007; Liu et al., 2009; Sipma et al., 2010). However, the removal efficiency of emerging contaminants by CAS, trickling filters, and MBRs is limited by the biodegradability of the contaminant (Oulton et al., 2010; Sipma et al., 2010). Additional treatment processes are required to achieve higher levels of removal.

\subsection{Tertiary Treatment Processes}

It is unlikely that the performance of conventional treatment processes can be improved to achieve sufficient removal of emerging contaminants to ensure human and environmental health are protected (Oulton et al., 2010). Therefore, tertiary treatment is required and has been implemented to some extent in newer 
wastewater treatment systems (Garcia-Ivars et al., 2017). Tertiary treatment processes include pressure driven membrane filtration, direct oxidation, sand filtration, and activated carbon adsorption (Garcia-Ivars et al., 2017).

\subsubsection{Pressure Driven Membrane Filtration}

Pressure driven membrane filtration is a tertiary treatment method for removing emerging contaminants (Liu et al., 2009; Schaar et al., 2010). These membrane filtration processes use pressure to force water through semi-permeable membranes against the concentration gradient (Oulton, 2013). The membranes physically remove contaminants by pore size restrictions or electrostatic repulsion (Oulton et al., 2010). The removal efficiency of various membranes is highest for reverse osmosis (RO), followed by nanofiltration, ultrafiltration, and microfiltration (Liu et al., 2009; Oulton et al., 2010). Microfiltration and ultrafiltration provide pretreatment for nanofiltration and RO (Oulton et al., 2010). $\mathrm{RO}$ and nanofiltration are commonly used to remove micropollutants for high quality drinking water or industrial process water, and they are increasingly implemented in newer advanced wastewater treatment systems (Oulton, 2013). The benefit of these tertiary treatment processes is their capability of achieving a high level of emerging contaminant removal (Garcia-Ivars et al., 2017; Oulton, 2013). 


\subsubsection{Direct Oxidation}

Treatment via direct oxidation can eliminate emerging contaminants from water by chemically degrading the compounds into their core molecular components, such as carbon dioxide $\left(\mathrm{CO}_{2}\right)$ through the process called mineralization (Esplugas et al., 2007; Liu et al., 2009; Schonherr et al., 2017). Chemical oxidants such as chlorine, chlorine dioxide, and ozone are used for disinfection of drinking water and wastewater, and in higher concentrations they can achieve removal of emerging contaminants (Lee \& von Gunten, 2010). However, at higher concentrations, chlorination and ozonation can produce potentially harmful byproducts such as bromate and $\mathrm{N}$-nitrosodimethlyamine (NDMA), that can be more toxic than the original compound (Almomani et al., 2016; Bolong et al., 2009; Knopp et al., 2016; Liu et al., 2009). Therefore, the toxicity of water before and after chemical treatment must be monitored or an additional treatment process following direct oxidation must be implemented to ensure the complete removal of emerging contaminants and byproducts (Almomani et al., 2016; Knopp et al., 2016). Additionally, the efficacy of chlorination and ozonation can be reduced by organic material and other constituents in the water which are also the precursors for byproduct formation (Oulton et al., 2010).

When compared, ozone is more effective at removing emerging contaminants than chlorine and chlorine dioxide and therefore is becoming more commonly used for direct oxidation in newer treatment systems (Almomani et al., 2016; Liu et al., 2009). Ozone is also capable of removing taste, odor, color, and 
pathogens from water (Broséus et al., 2009; Klavarioti et al., 2009; Knopp et al., 2016). Additionally, ozone generates $\cdot \mathrm{OH}$ as a result of the degradation of ozone in water (Oulton et al., 2010; Schonherr et al., 2017). $\bullet \mathrm{OH}$ are highly reactive and can react with and degrade a broad range of organic compounds such as emerging contaminants (Broséus et al., 2009; Huerta-Fontela et al., 2011; Oulton et al., 2010; Rosal et al., 2010; Wert, Rosario-Ortiz, \& Snyder, 2009). Compared to ozone, $\cdot \mathrm{OH}$ react less selectively with other compounds which improves the removal efficiency for contaminants (Almomani et al., 2016; Lee \& von Gunten, 2010; Oulton et al., 2010; Wert et al., 2009). A sufficient ozone dose combined with the appropriate HRT has the potential to eliminate a wide range of micropollutants and reduce their emission into the environment (Knopp et al., 2016; Rosal et al., 2010; Schaar et al., 2010).

However, some emerging contaminants have shown to be resistant to ozone treatment and are considered to be ozone recalcitrant compounds (Oulton, 2013; Oulton et al., 2010; Rosal et al., 2010). During direct oxidation using ozone, $\bullet \mathrm{OH}$ can react with ozone recalcitrant compounds which can reduce their concentration slightly (Oulton et al., 2015; Wert et al., 2009). Ozonation does not achieve complete mineralization of these recalcitrant contaminants because they are often transformed into breakdown products that may be less susceptible to further oxidation (Almomani et al., 2016; Knopp et al., 2016). To target ozone recalcitrant compounds, AOPs that promote the production of $\bullet \mathrm{OH}$ are needed (Oulton, 2013). 
While emerging contaminants such as pharmaceuticals are not completely removed by ozonation, the direct oxidation process can significantly reduce their pharmacological effect (Almomani et al., 2016). In a study conducted by Broséus et al. (2009), ozone removed greater than $80 \%$ of the 13 PCPs and EDCs tested. An additional study conducted by Almomani et al. (2016) found that ozonation significantly degraded a majority of the pharmaceuticals studied. However, the total mineralization of the organic matter was less than $39 \%$ for treated surface water and less than $30 \%$ for treated wastewater which indicates a need for further treatment if complete contaminant removal is desired.

\subsubsection{Sand Filtration}

Sand filters are commonly used for drinking water treatment and can be used for tertiary wastewater treatment to remove suspended solids. The biological activity of the filter can aid in the degradation and removal of emerging contaminants (Oulton et al., 2010). To help achieve complete removal of emerging contaminants (parent compounds and breakdown products), sand filters can be added after a chemical treatment step such as direct oxidation (Klavarioti et al., 2009; Knopp et al., 2016).

\subsubsection{Activated Carbon}

Adsorption onto activated carbon is commonly used for tertiary treatment to promote the removal of emerging contaminants (Karelid et al., 2017; Liu et al., 2009; Oulton et al., 2010; Schaar et al., 2010). Activated carbon is incorporated 
into the treatment process through granular activated carbon (GAC) contained in a column or powdered activated carbon (PAC) which is added and recirculated internally (Karelid et al., 2017). When compared in a study conducted by Karelid et al. (2017), PAC achieved a higher removal rate of pharmaceutically active compounds than GAC for the same amount of carbon consumed. However, both forms of activated carbon are capable of removing a high level of emerging contaminants and are an alternative to chemical tertiary treatment processes (Karelid et al., 2017). GAC filters have also demonstrated the ability to reduce the concentration of emerging contaminants and breakdown products following chemical processes (Knopp et al., 2016).

In addition to GAC and PAC, biological activated carbon (BAC) can be used for tertiary treatment and is effective because it contains a biofilm on the material surface that both biodegrades and sorbs contaminants (Oulton et al., 2010). In general, activated carbon adsorption combined with a chemical process achieves a promising removal rate of emerging contaminants, but the removal efficiency depends on the adsorption capacity of the activated carbon (Esplugas et al., 2007; Liu et al., 2009). This limits the functionality of activated carbon because the adsorption capacity is known to decrease throughout operation (Liu et al., 2009). 


\subsection{Drinking Water Considerations}

In addition to establishing methods for removing emerging contaminants from wastewater, there is a need for detection and removal of emerging contaminants in drinking water. If emerging contaminants are not removed through wastewater treatment and persist in the environment, they have the potential to enter drinking water treatment plants and be consumed by humans if not fully treated (Glassmeyer et al., 2017). A number of emerging contaminants are not removed through drinking water treatment which allows for direct exposure to humans through potable water use and consumption (Glassmeyer et al., 2017).

Developing the ability to remove emerging contaminants through drinking water treatment is important for providing high quality and safe drinking water (Boleda et al., 2011; Huerta-Fontela et al., 2011).

For drinking water treatment, conventional methods such as coagulation, flocculation, and sand filtration have poor removal efficiency of emerging contaminants, while direct oxidation through chlorination and ozonation have improved performance (Broséus et al., 2009; Huerta-Fontela et al., 2011; Klavarioti et al., 2009). Tertiary treatment using RO, nanofiltration, and adsorption on activated carbon have shown to be effective for removing some level of emerging contaminants (Almomani et al., 2016; Broséus et al., 2009; Esplugas et al., 2007; Radjenović, Petrović, Ventura, \& Barceló, 2008). Despite exposure to various treatment methods, a number of contaminants are not completely eliminated and remain in trace levels in drinking water (Almomani et 
al., 2016; Boleda et al., 2011; Huerta-Fontela et al., 2011; Mompelat et al., 2009).

The overall removal of emerging contaminants from wastewater and drinking water by conventional treatment plants is unknown, inconsistent, or incomplete, which establishes the need for more advanced treatment techniques (Liu et al., 2009; Oulton et al., 2010).

\subsection{Waste Stream Considerations}

The waste streams generated by a treatment processes must also be considered because contaminants can be transferred into a solid phase or a concentrated liquid waste both requiring further treatment and disposal (Almomani et al., 2016). For example, sludge produced by conventional treatment processes contains the contaminants removed from the water including some emerging contaminants that were adsorbed (Aymerich et al., 2016; Esplugas et al., 2007; Klavarioti et al., 2009; Radjenović et al., 2009). Contaminants in waste sludge pose a threat to environmental health because the contaminants can desorb from the sludge under the correct conditions and re-enter the environment (Radjenović et al., 2009). Dried sludge from wastewater treatment plants is often used for agricultural applications or at landfills which serves as an additional pathway for introducing emerging contaminants into the environment (Jelic et al., 2011).

Additionally, treatment processes that use membranes for filtration produce large waste streams of concentrated brine which requires treatment and disposal (Radjenović et al., 2008). The brine from filtration processes can contain 
pharmaceuticals in concentrations in the range of several hundred nanograms per liter (Radjenović et al., 2008). Producing high quality effluent with filtration processes like RO has the consequence of generating large waste streams of brine that present permitting challenges associated with their disposal (Bell et al., 2016; Oulton et al., 2015). Justification for developing advanced treatment processes, such as RO and other membrane treatments, includes limiting costs, improving energy consumption, and reducing brine generation (Bell et al., 2016; Oulton, 2013).

\subsection{Advanced Oxidation Processes}

To ensure the complete removal of emerging contaminants from water, AOPs have been studied as an alternative to membrane treatment (Garcia-Ivars et al., 2017; Oulton, 2013). AOPs focus on chemically degrading contaminants rather than physically removing them which reduces their concentration and avoids the generation of a waste stream (Oulton, 2013). Compared to direct oxidation processes that use an oxidant like chlorine or ozone alone, AOPs target the production of highly reactive species, primarily $\cdot \mathrm{OH}$, to destroy contaminants and recalcitrant compounds (Klavarioti et al., 2009; Oulton et al., 2010; Rey et al., 2011; Schaar et al., 2010; Schonherr et al., 2017). A number of AOPs are used to generate reactive species include ozone combined with $\mathrm{UV}$ irradiation or $\mathrm{H}_{2} \mathrm{O}_{2}$, UV combined with $\mathrm{H}_{2} \mathrm{O}_{2}$, Fenton's and photo-Fenton's reagent, $\mathrm{TiO}_{2}$ combined with UV, and others (Klavarioti et al., 2009; Liu et al., 2009; Oulton et al., 2010; Schonherr et al., 2017). When used in AOPs, oxidizers with greater redox 
potentials are expected to have a higher removal efficiency of contaminants (Liu et al., 2009).

The goal of incorporating AOPs in treatment systems is to achieve complete removal or mineralization of emerging contaminants; however, complete mineralization is not consistently achieved because breakdown products can form during oxidation (Klavarioti et al., 2009). Prior to treatment by an AOP, biological pre-treatment can be used to remove biodegradable compounds that compete for the chemical oxidant and have the potential to form breakdown products (Klavarioti et al., 2009). AOPs can also be coupled with other treatment processes to degrade emerging contaminants and remove breakdown products, to further improve treatment efficiencies (Klavarioti et al., 2009).

Combined treatment processes such as catalytic ozonation have been used to remove emerging contaminants (Fan et al., 2014). Catalytic ozonation is a process in which a surface promotes the degradation of ozone into $\cdot \mathrm{OH}$ (Sánchez-Polo, Salhi, Rivera-Utrilla, \& Von Gunten, 2006). Carbon materials have been used for catalytic ozonation because studies suggest that the formation of $\cdot \mathrm{OH}$ from ozone in water is catalyzed by activated carbon and CNTs (Fan et al., 2014; Oulton et al., 2015; Schonherr et al., 2017). The combined treatment process of CNTs and ozone has demonstrated the ability to remove emerging contaminants making it a feasible alternative AOP (Oulton et al., 2015). 


\subsubsection{Carbon Nanotubes and Ozone}

Previous studies including one conducted by Sánchez-Polo et al. (2006) that used GAC to generate $\cdot \mathrm{OHs}$ motivated additional reseach with CNTs and ozone. The results of the Sánchez-Polo et al. (2006) study found ozone combined with activated carbon to have potential for water treatment based on the oxidation capability of ozone and sorption capacity of activated carbon (Sánchez-Polo et al., 2006). Compared to activated carbon, the properties and functionality of nanostructured carbon materials such as CNTs improve the sorption of emerging contaminants achieved by carbon (Fan et al., 2014). While activated carbon is widely used in water and wastewater treatment and has the potential to remove emerging contaminants, the material has limited application in processes that use ozone (Oulton et al., 2015). A majority of the surface area of activated carbon is internal and cannot react with ozone, and after repeated ozonation, the structural integrity of activated carbon is degraded (Oulton et al., 2015). CNTs have high thermal and mechanical stability, high surface area, and high electrical conductivity which allows them to be used as semiconductors, composite materials, and catalysts (Fan et al., 2014; Oulton, 2013; Schonherr et al., 2017). During ozonation, CNTs can encourage the formation of $\bullet \mathrm{OH}$ (Oulton et al., 2015). CNTs must be oxidized prior to use to most effectively generate active species, and they can be functionalized to increase the density of surface sites that perform $\bullet \mathrm{OH}$ formation (Oulton et al., 2015; Schonherr et al., 2017). The catalytic activity of carbon materials can also be improved by modifying surface 
properties through treatment with nitrogenizing agents (Fan et al., 2014; Restivo et al., 2016).

A study using ozonation and MWCNTs functionalized with nitric acid was conducted by Oulton et al. (2015) to analyze the production of reactive $\cdot \mathrm{OH}$ species and removal of emerging contaminants. From the study, it was concluded that highly oxidized MWCNTs are as reactive as commercial AOPs such as ozone and $\mathrm{H}_{2} \mathrm{O}_{2}$. The oxidized MWCNTs were able to maintain their level of reactivity after long term exposure to ozone and ozone recalcitrant compounds. The study also found that oxidizing CNTs changed their nature from a sorbent to a substrate with carboxyl, hydroxyl, and carbonyl groups for generating $\bullet \mathrm{OH}$ (Oulton et al., 2015). The increased production of $\bullet \mathrm{OH}$ from the reaction between ozone and CNTs has the potential to remove ozone recalcitrant emerging contaminants and their associated breakdown products. The results of the experiment show promise for use as an alternative and possibly more effective AOP for advanced water and wastewater treatment (Oulton et al., 2015).

Additional studies have also demonstrated the efficacy of ozonation and functionalized CNTs for emerging contaminant removal. In a study conducted by Restivo et al. (2016), carbon functionalized with ammonia enhanced the reaction rate on the nanomaterial surface. According to Restivo et al. (2016), functionalized carbon materials have the potential to change the degradation 
pathways of organic micropollutants which can improve their removal rate but can also increase the toxicity of the effluent.

In a study conducted by Fan et al. (2014), catalytic ozonation using MWCNTs was tested for its ability to degrade atrazine. Four reaction systems were used to isolate and analyze the effect of direct oxidation with ozone compared to combined treatment with ozone and MWCNTs. Each treatment process was tested with and without the addition of tert-butanol to act as $a \cdot \mathrm{OH}$ scavenger. Several key findings resulted from the Fan et al. (2014) study including the observation of an increase in atrazine degradation in basic conditions $(\mathrm{pH} 9)$ compared to acidic conditions $(\mathrm{pH} 3)$ because of the increased presence of $\cdot \mathrm{OH}$ at higher $\mathrm{pH}$. As expected, increasing the ozone concentration and temperature of the reaction caused atrazine to degrade more rapidly. Additionally, Fan et al. (2014) found a correlation between increasing MWCNTs and reducing ozone concentration which confirms the theory that carbon materials cause ozone to degrade and produce $\cdot \mathrm{OH}$. In the experiment, the concentration of atrazine was reduced by $40 \%$ to $50 \%$ after 5 minutes of exposure to ozone, ozone with tertbutanol, ozone with MWCNTs, and ozone with tert-butanol and MWCNTs. After 10 minutes of exposure, the concentration of atrazine was reduced by approximately $85 \%$ by ozone, $75 \%$ by ozone and MWCNTs, $72 \%$ by ozone with tert-butanol, and $60 \%$ by ozone with tert-butanol and MWCNTs. The atrazine concentration was reduced to zero after 60 minutes of exposure to all of the different treatment combinations. Total organic carbon (TOC) removal for 
atrazine was also measured, and sorption to MWCNTs reduced atrazine by $78 \%$ while combined treatment with ozone and MWCNTs reduced atrazine concentration by $53 \%$. TOC was measured and compared to the concentrations of atrazine and its breakdown products to determine the amount of atrazine removed and the amount of breakdown products formed after exposure to treatment. The amount of the atrazine breakdown products were found to constitute a significant portion of the TOC measured from the different reactions (Fan et al., 2014).

According to another study by Schonherr et al. (2017), ozone was found to be the most effective oxidant for functionalized CNTs. Sotelo et al. (2012) found activated carbon, MWCNTs, and carbon nanofilters to be effective for removing atenolol, caffeine, diclofenac, and isoproturon. The study also suggests the use of MWCNTs and carbon nanofilters as alternative adsorbents for water treatment (Sotelo et al., 2012). Overall, the findings of previous studies suggest the use of CNTs and ozone as a promising alternative AOPs for removing recalcitrant compounds from water (Oulton et al., 2010). However, the overall efficacy of the treatment process and the direct benefit over other more conventional methods is undetermined and in need of further study (Oulton et al., 2010).

\subsection{Indicator Compounds}

To determine the ability of a treatment technology to reliably remove emerging contaminants, compounds that are widely prevalent in water and wastewater 
which display certain behavior towards treatment methods can be used as indicators (Benotti et al., 2009). The study conducted by Oulton et al. (2010), suggests the use of three sets of indicator compounds to represent the removal efficiency at different stages in treatment processes. The recommended indicator compounds include an emerging contaminant that is biodegradable (acetaminophen or ibuprofen), resistant to biodegradation but oxidatively degradable (carbamazepine or diclofenac), and resistant to biodegration and oxidation (iopromide or caffeine) (Oulton et al., 2010). To determine the removal efficiency of a tertiary treatment process or AOP, contaminants that are resistant to treatment by direct oxidation should be tested to indicate if any level of removal is achieved (Oulton et al., 2010). Caffeine, phenytoin, and atrazine have been found to be resistant to direct oxidation with ozone (Benotti et al., 2009; Broséus et al., 2009; Oulton et al., 2010) and may serve as good indicator compounds for the removal efficiency of an AOP targeting recalcitrant compounds such as the combined process of ozone and functionalized MWCNTs (Huerta-Fontela et al., 2011; Oulton et al., 2015; Rosal et al., 2009).

A study by Broséus et al. (2009) suggests that caffeine be used as an indicator compound for determining the efficacy of ozone treatment because of its high frequency of detection and persistence in wastewater and surface water (Broséus et al., 2009; Rosal et al., 2009). In the study by Broséus et al. (2009), caffeine was exposed to ozone and the measured removal ranged from $23 \%$ to $80 \%$ depending on the ozone concentration and contact time. This study 
suggests that, because caffeine is not fully removed by direct oxidation with ozone, caffeine can represent the effects of ozone treatment on a variety of compounds including pharmaceuticals, EDCs, and ozone-recalcitrant hormones (Broséus et al., 2009).

Several studies have identified phenytoin as a widely prevalent and persistent contaminant in water and wastewater, making it well suited to be used as an indicator compound (Benotti et al., 2009; Huerta-Fontela et al., 2011). In a study conducted by Benotti et al. (2009), phenytoin was detected in more than half of the source and treated water samples taken from 19 water treatment facilities. Another study by Huerta-Fontela et al. (2011) found phenytoin present in water at a concentration of approximately $10 \mathrm{ng} / \mathrm{L}$ after exposure to treatment with sand filtration, ozone, GAC filtration, and chlorine (Huerta-Fontela et al., 2011). Phenytoin has been found to be resistant to ozonation and therefore is recommended for use as an indicator compound for determining the efficacy of tertiary treatment processes (Oulton et al., 2010).

A study by Benotti et al. (2009) selected six indicator compounds based on their frequency of detection and response to removal by direct oxidation with chlorine and ozone. Benotti et al. (2009) recommended atrazine and meprobamate as indicator compounds to represent contaminants that are not responsive to removal by chlorine or ozone. Since meprobamate is in the same class of emerging contaminants as phenytoin, atrazine was selected as an ozone 
recalcitrant compound representing a different class of emerging contaminants to be tested in this study (Benotti et al., 2009). The study by Broséus et al. (2009) also suggests the use of atrazine as an oxidation indicator compound.

\subsection{Caffeine}

Caffeine is a ubiquitous contaminant in wastewater effluent and surface water because of its wide use globally (Rosal et al., 2009). Caffeine has been detected in tertiary effluent from wastewater treatment plants at concentrations ranging from 25 - 93 ng/L (Wert et al., 2009). A study by Glassmeyer et al. (2017) found caffeine in surface water at a maximum concentration of $124 \mathrm{ng} / \mathrm{L}$. In tap water, caffeine has been found at concentrations ranging from $60-119 \mathrm{ng} / \mathrm{L}$ (Mompelat et al., 2009). When consumed by humans, caffeine is metabolized, but the discharge of unconsumed caffeinated beverages allows caffeine to persist in high concentrations in wastewater influent, effluent, and surface water (Rosal et al., 2009). Caffeine has a high solubility and low octanol-water partition coefficient which allows it to persist in surface water (Rosal et al., 2009). Conventional treatment processes have not proven to be capable of completely removing caffeine and other emerging contaminants from water (Broséus et al., 2009). However, a study by Broséus et al. (2009) found caffeine responded to treatment with ozone but was not completely removed. 


\subsubsection{Reaction Mechanisms}

Rosal et al. (2009) studied the reaction mechanisms of caffeine when exposed to ozone in acidic and alkaline conditions. From the results of the study, the degradation pathway for the ozonation of caffeine in acidic and alkaline conditions was proposed (Figure 1). In the experiments performed by Rosal et al. (2009), caffeine was completely degraded, but breakdown products resulted from the reaction. The breakdown products of caffeine have been previously identified from different studies and include N,N-dimethylparabanic acid; 1,3,7-trimethyluric acid; 1,3-dimethyluric acid; and 1,7-dimethylxanthine (Mompelat et al., 2009;

Rosal et al., 2009). The breakdown products of caffeine are known to be resistant to further oxidation which prevents their complete removal (Dalmazio, Santos, Lopez, Eberlin, \& Augusti, 2005). Rosal et al. (2009) identified the breakdown product P3 in Figure 1 as 6-amino-5-( $\mathrm{N}$-formylmethylamino)-1,3dimethyluracil, which is another known metabolite of caffeine. Additionally, the P4 breakdown product in the proposed pathway was identified as the most abundant and oxidized product (Rosal et al., 2009). 

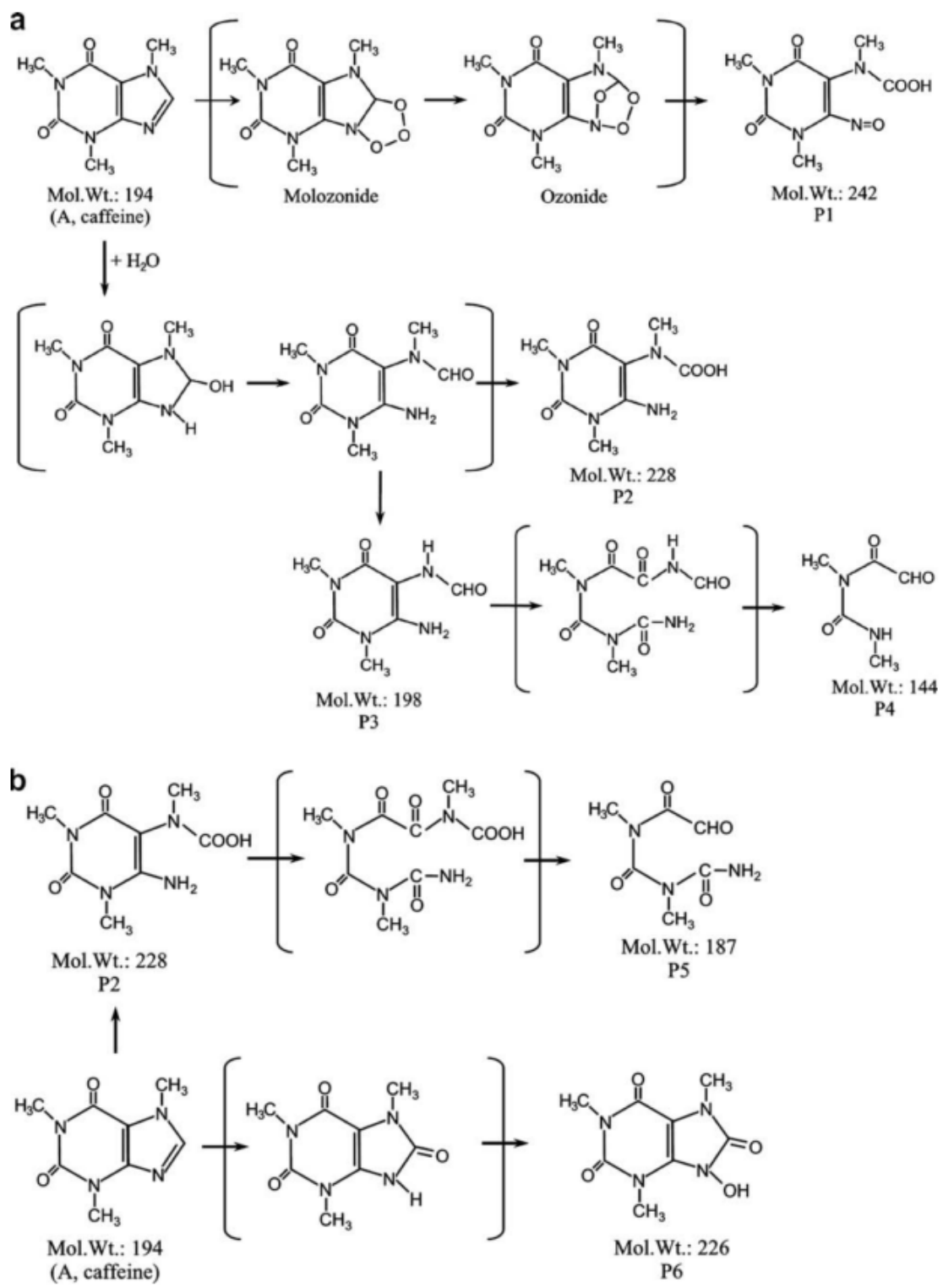

Figure 1: Proposed reaction mechanism of caffeine exposed to ozone in (a) acidic conditions at $\mathrm{pH} 3$ and (b) alkaline conditions at pH 8 from Rosal et al. (2009).

Rosal et al. (2009) also measured TOC and determined full mineralization was not achieved in experiments which indicated the presence of breakdown products. After ozonation, formic, acetic, oxalic, and short-chain carboxylic acids were detected and contributed to the remaining TOC. From the experiment, Rosal et al. (2009) concluded that caffeine exposed to varying ozone conditions 
degrades by different pathways but results in the formation of breakdown products regardless.

\subsubsection{Reaction Rate Constants}

The reaction rate constants for caffeine have been determined experimentally through various studies. The second-order rate constant for caffeine exposed to ozone ( $\mathrm{K}_{03}$ value) was found from one study to be between from $0.25-1.05 \mathrm{M}^{-1} \mathrm{~s}^{-1}$ for pH 3-10 (Rosal et al., 2009). The $\mathrm{K}_{03}$ values determined by Rosal et al. (2009) do not vary significantly despite the large difference in $\mathrm{pH}$ for the reaction conditions which is not consistent with the expected effect of $\mathrm{pH}$ on the reaction with ozone. An additional study found the $\mathrm{K}_{03}$ value for caffeine to be $2.3 \times 10^{5}$ $\mathrm{M}^{-1} \mathrm{~s}^{-1}$ (Almomani et al., 2016). Other reaction conditions such as $\mathrm{pH}$ and temperature were not given by Almomani et al. (2016) which raises a question of the validity of their results. A third study found the $\mathrm{K}_{03}$ value for caffeine to be 573-650 $\mathrm{M}^{-1} \mathrm{~s}^{-1}$ for $\mathrm{pH} 8.10$ at $20^{\circ} \mathrm{C}$ (Broséus et al., 2009). The reaction conditions used by Broséus et al. (2009) are similar to the conditions used in this study. Therefore, the $\mathrm{K}_{03}$ values determined in this experiment will most likely be comparable to the results obtained by Broséus et al. (2009). The literature Ko3 values for caffeine vary by multiple orders of magnitude which can be attributed to the different reaction conditions and procedure used to measure the reaction rate constant. The wide range of $\mathrm{K}_{\mathrm{O} 3}$ values found in literature indicate the need for further study to verify the results of previous experiments and to determine the actual Ko3 value for caffeine. 


\subsection{Phenytoin}

Phenytoin is the most commonly prescribed anti-epileptic drug which contributes to its frequent detection in drinking water, wastewater effluent, and surface water (Benotti et al., 2009; Ohnmacht et al., 2006). Phenytoin has been detected at a maximum concentration of $1.3 \mathrm{ng} / \mathrm{L}$ in tap water (Mompelat et al., 2009). In a case study, phenytoin was found in tertiary effluent from a wastewater treatment plant in concentrations ranging from $180-290 \mathrm{ng} / \mathrm{L}$ (Wert et al., 2009). Phenytoin is known to be recalcitrant to ozonation which allows the compound to persist in water sources (Benotti et al., 2009; Oulton et al., 2010).

\subsubsection{Reaction Mechanisms}

The reaction mechanisms of phenytoin were studied and the breakdown products were identified by Ohnmacht et al. (2006). When consumed by humans, phenytoin is metabolized and excreted in bile (Ohnmacht et al., 2006). The phenytoin metabolites are then reabsorbed from the intestinal tract and are excreted in urine (Ohnmacht et al., 2006). The primary breakdown products of human metabolism of phenytoin are 5-(3-hydroxyphenyl)-5-phenylhydantoin (mHPPH) and 5-(4-hydroxyphenyl)-5-phenylhydantoin (p-HPPH) (Figure 2). As displayed in Figure 2, the breakdown products of phenytoin have similar structures as their parent compound. Through human metabolism, $60-80 \%$ of the parent compound is transformed into the breakdown products m-HPPH and pHPPH (Ohnmacht et al., 2006). 


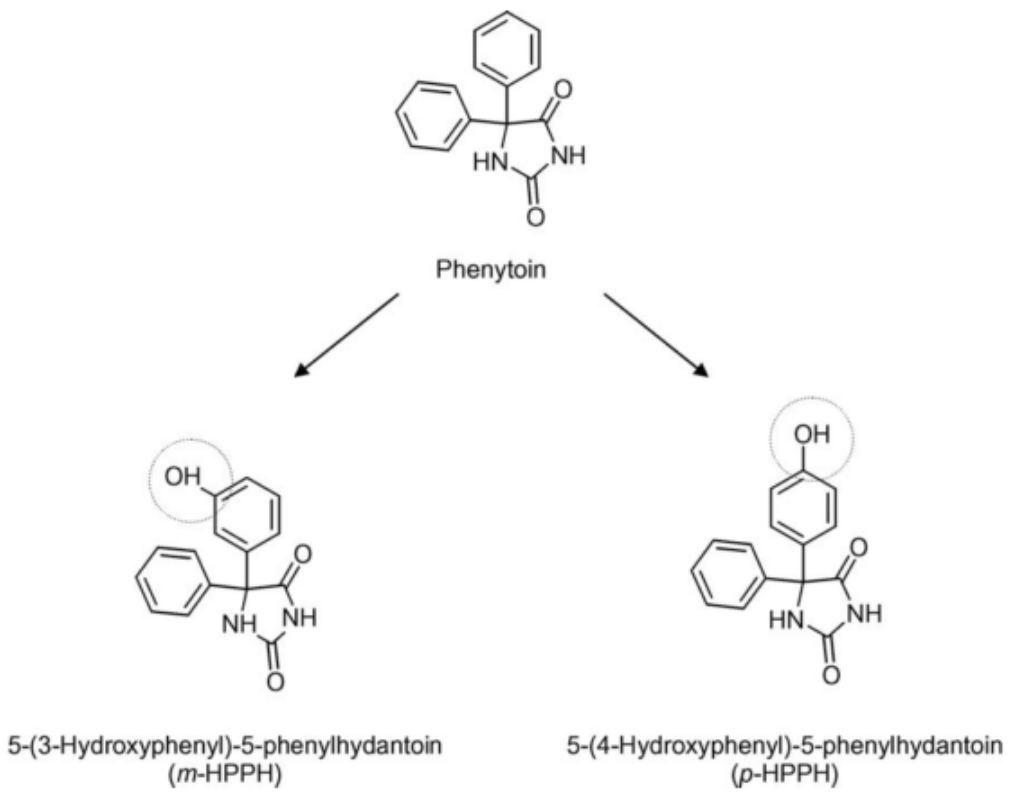

Figure 2: Structure of phenytoin and its breakdown products from Ohnmacht et al. (2006).

\subsubsection{Reaction Rate Constants}

Since phenytoin is not degraded by ozone, a second-order Koз value cannot be experimentally determined. The second-order reaction rate constant for phenytoin exposed to $\cdot \mathrm{OH}$ ( $\mathrm{K}_{\mathrm{OH}}$ value) has been estimated. In a study by Yuan et al. (2009), phenytoin was exposed to $\cdot \mathrm{OH}$ formed by the reaction between UV and $\mathrm{H}_{2} \mathrm{O}_{2}$, and the resulting $\mathrm{K}_{\mathrm{OH}}$ value was $6.28 \times 10^{9} \mathrm{M}^{-1} \mathrm{~s}^{-1}$ (Yuan, $\mathrm{Hu}, \mathrm{Hu}, \mathrm{Qu}$, \& Yang, 2009).

\subsection{Atrazine}

Atrazine is a commonly used herbicide that persists in the environment (Fan et al., 2014). A study conducted in the United States that analyzed contaminants in the drinking water for over 28 million people found atrazine at an average concentration of $32 \mathrm{ng} / \mathrm{L}$ in surface water and $49 \mathrm{ng} / \mathrm{L}$ in drinking water (Benotti 
et al., 2009). In tertiary effluent from a wastewater treatment plant, atrazine was found at a concentration ranging from 1.3 - $430 \mathrm{ng} / \mathrm{L}$ in a case study (Wert et al., 2009). Atrazine has been detected in water that its directly influenced by wastewater effluent but not by agricultural operations which demonstrates its ubiquity in wastewater and surface water (Benotti et al., 2009).

\subsubsection{Reaction Mechanisms}

Fan et al. (2014) studied the reaction mechanism of atrazine exposed to ozone, MWCNTs, and a combination of ozone and MWCNTs to determine the response of atrazine to oxidation and $\cdot \mathrm{OH}$. The common breakdown products resulting from ozonation of atrazine (ATZ) include desethylatrazine (DEA),

desisopropylatrazine (DIA), desisopropylatrazine (DEIA), 2-chloro-4-acetamido6-isopropylamino-1,3,5-triazine (CDIT), 2-chloro-4-ethylamino-6-acetamido-1,3,5triazine (CDET), and 2-chloro-4-acet-amido-6-amino-1,3,5-triazine (CDAT).

Figure 3 depicts the structure of atrazine and its breakdown products identified from various studies (Fan et al., 2014). 

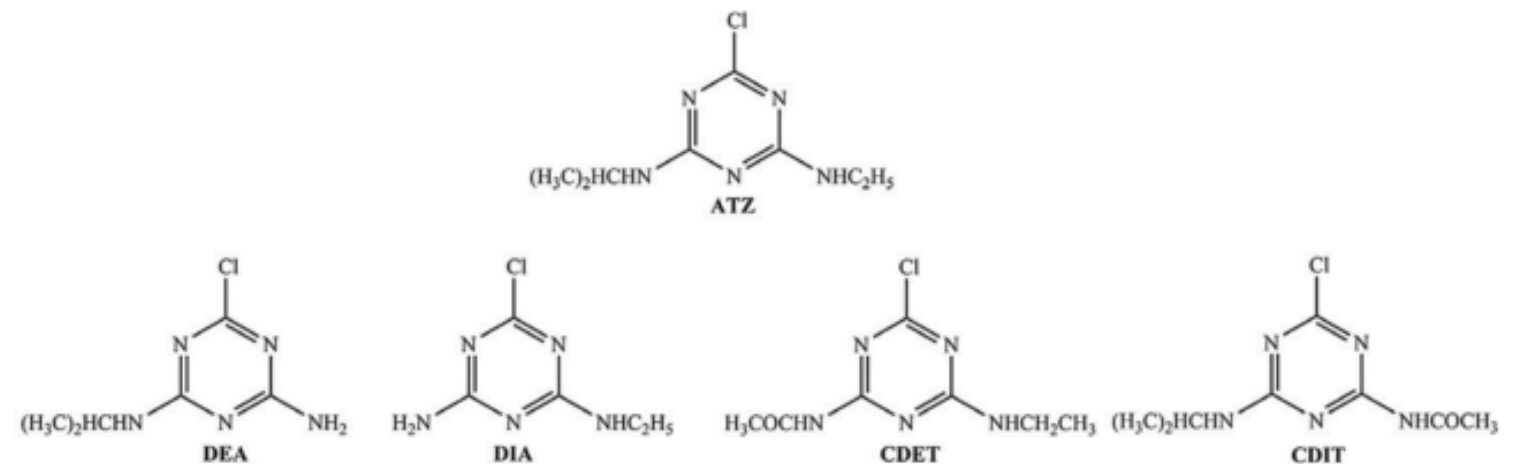

IA

CDET

CDIT
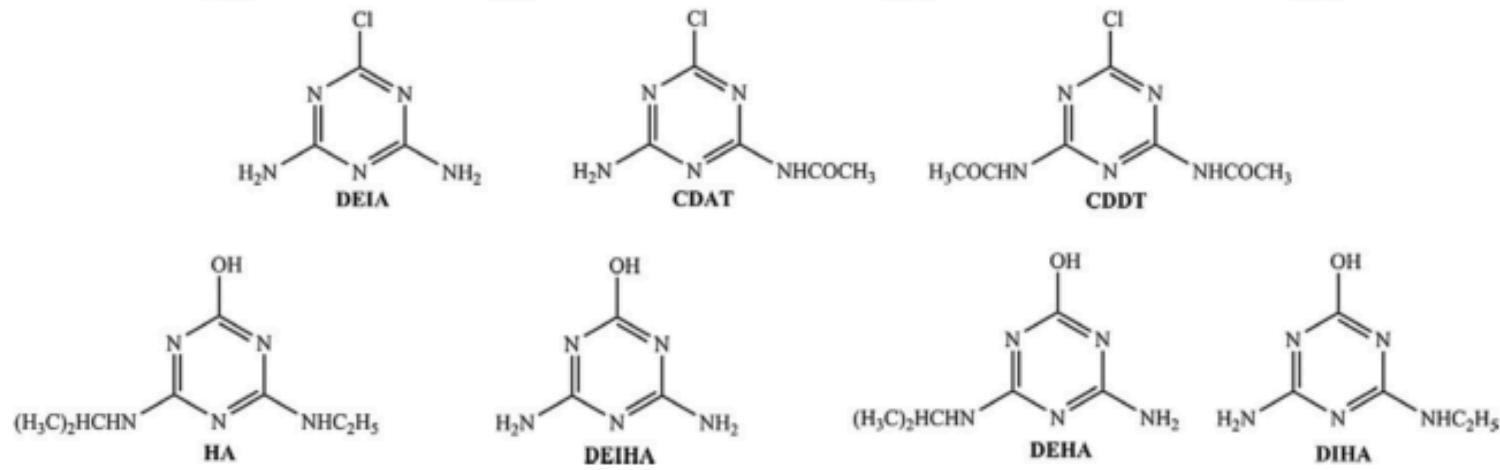

Figure 3: Structure of atrazine and its breakdown products from Fan et al. (2014).

In the experiments conducted by Fan et al. (2014), DEA, DIA, CDET, and CDIT were identified as the first generation of breakdown products. These breakdown products formed and reached their maximum concentration after 60 minutes before degrading via subsequent reactions. The second generation of breakdown products included DEIA, CDAT, and 2-chloro-4,6-diacetamido-1,3,5-triazine (CDDT) (Fan et al., 2014). Previous studies and the study by Fan et al. (2014) have identified DEIA as a terminal product for the breakdown of atrazine to DEA and DIA. The known atrazine breakdown products 2-chloro-4,6-diacetamido1,3,5-triazine (HA), desethyldeisopropylhydroxyatrazine (DEIHA), desethylhydroxyatrazine (DEHA), and deis-opropylhydroxyatrazine (DIHA) were not detected in the study by Fan et al. (2014). HA, DEIHA, DEHA, and DIHA form 
via the dechlorination of atrazine and their absence indicates this reaction pathway was not followed for the ozonation of atrazine (Fan et al., 2014). Rather, Fan et al. (2014) proposed the degradation pathway in Figure 4 for atrazine reacted with MWCNTs and ozone. Fan et al. (2014) found that the addition of MWCNTs to a system with ozone increased the reactivity of the first generation breakdown products. These first generation breakdown products were sorbed to the MWCNTs and easily reacted with ozone to form DEIA and CDAT (Fan et al., 2014).

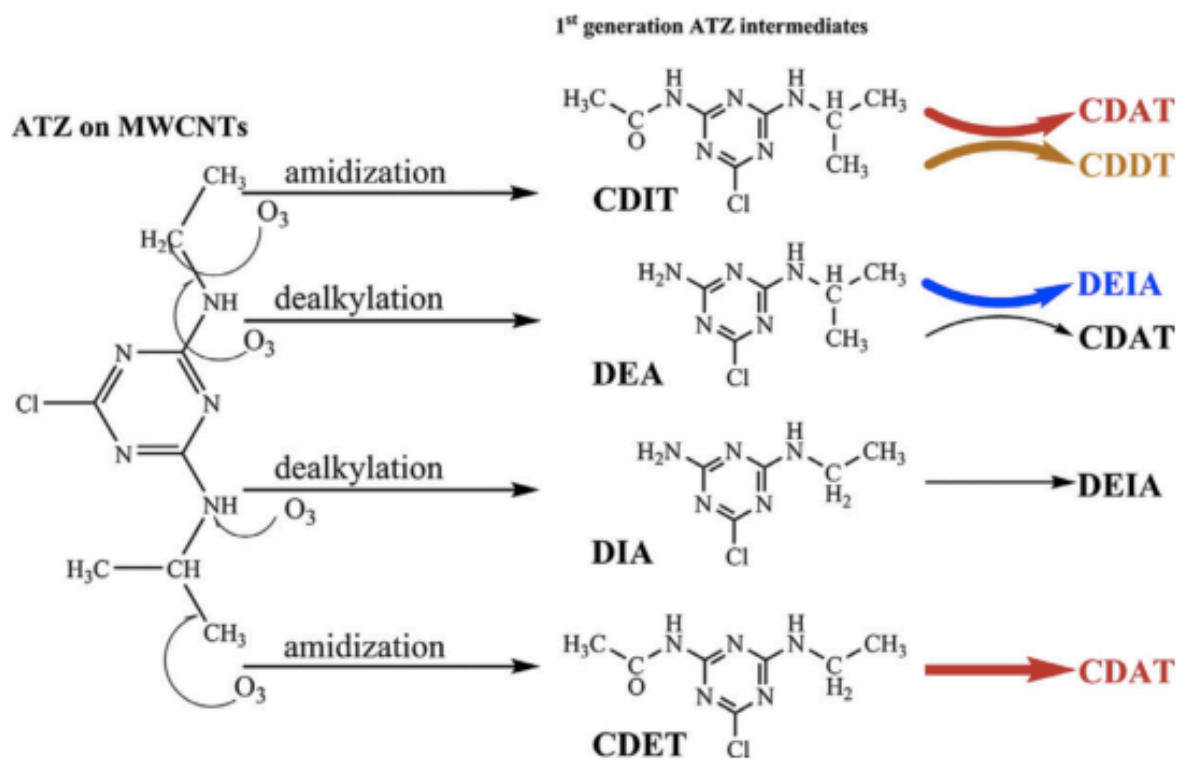

Figure 4: Proposed reaction mechanism of atrazine exposed to ozone and MWCNTs from Fan et al. (2014).

Complete removal of atrazine and its breakdown products is difficult to achieve because 1,3,5-triazine is known to resist degradation by ozone (Fan et al., 2014). The use of catalytic ozonation for removing atrazine can result in more toxic effluents because of the interaction between the different components in the 
system (Restivo et al., 2016). The study by Restivo et al. (2016) found that the treatment process with ozone and CNTs produced an effluent that inhibited the activity of bacteria by approximately $28 \%$ to $36 \%$. Compared to the effluent from treatment with ozone alone, the activity of bacteria was inhibited by approximately 18\% (Restivo et al., 2016).

\subsubsection{Reaction Rate Constants}

The reaction rate constants for atrazine have been determined as a result of several different studies. The $\mathrm{K}_{03}$ value for atrazine after exposure to ozone was found to be $6 \mathrm{M}^{-1} \mathrm{~s}^{-1}$ (Wert et al., 2009). From a study conducted by Wert et al. (2009), the $\mathrm{K}_{\mathrm{OH}}$ value for atrazine was $3 \times 10^{9} \mathrm{M}^{-1} \mathrm{~s}^{-1}$. In another study, the $\mathrm{KoH}_{\mathrm{OH}}$ value was found to be $2.4 \times 10^{9} \mathrm{M}^{-1} \mathrm{~s}^{-1}$ at $\mathrm{pH} 7.5$ and $20^{\circ} \mathrm{C}$ (Mandal, 2018). Variations in the reaction conditions used to measure the reaction rate constants for atrazine could cause the difference between the literature $\mathrm{K}_{\mathrm{OH}}$ values obtained. 


\section{Chapter 3 - Materials and Methods}

The materials and methods used to complete several phases of experiments are outlined in this chapter. The process used to prepare ozone and CNT solutions and the experimental procedure are included. This chapter also contains the methods used to analyze the samples and the quality assurance and quality control (QA/QC) measures used to ensure the reliability of the results.

Three phases of experiments were designed to address the research objectives of this study. The first objective was to explore the ability and limitations of the proposed AOP to improve removal of emerging contaminants. The contaminants were exposed to treatment with ozone only (direct oxidation), CNTs only (sorption), and the AOP with ozone and CNTs $(\cdot \mathrm{OH})$ to determine if increased contaminant removal was achieved by the AOP. Second, this study aimed to identify ubiquitous and recalcitrant contaminants that can serve as indicator compounds to represent the efficacy of an AOP. Three different contaminants were tested in this study and their response to treatment was used to evaluate their potential as indicator compounds. The third objective of this study was to determine if the reaction rate constants $\left(\mathrm{K}_{\mathrm{O}}\right.$ and $\left.\mathrm{K}_{\mathrm{OH}}\right)$ for a compound can be used to predict how that compound will respond to oxidative treatment in complex water mixtures. The experimental results were used to calculate the reaction rate constants for each compound tested and were compared to the expected degradation of the contaminants in mixed systems. 
To address the research objectives, three different contaminants were tested and three phases of experiments were performed. The contaminants - caffeine, atrazine, and phenytoin - were all know to be fairly ubiquitous in water and wastewater and relatively resistant to oxidative treatment via ozone. The first phase of experiments involved simple water systems with only one contaminant present. Caffeine was exposed to treatment with ozone only, and atrazine was exposed to treatment with ozone only, CNTs only, and the AOP with ozone and CNTs. In the second phase of testing, caffeine and atrazine were combined to simulate a more complex water system with increased competition for reactions. In the Phase 2 experiments, caffeine and atrazine were exposed to ozone only, CNTs only, and the AOP with ozone and CNTs. The results from the first two phases of experiments were used to evaluate the potential of caffeine and atrazine to be used as indicator compounds and to compare the second order $\mathrm{K}_{\mathrm{O}}$ and $\mathrm{K}_{\mathrm{OH}}$ values for caffeine and atrazine to their degradation results in more complex systems. In the final phase of testing, phenytoin was exposed to treatment with ozone only, CNTs only, and the AOP with ozone and CNTs. Phenytoin was evaluated for its potential as an indicator compound and the experimental results were compared to reaction rate constants found in literature.

\subsection{Preparation of Ozone Solution}

A $680 \mathrm{mg} / \mathrm{L}$ phosphate buffer solution adjusted to $\mathrm{pH} 7.0$ was prepared with potassium phosphate monobasic (Fisher Scientific) in deionized (DI) water. The phosphate buffer was bubbled with ozone produced from oxygen gas and a 
ClearWater Tech, LLC. CD1500P ozone generator for approximately 20 minutes. Prior to use, the phosphate buffer was allowed to deozonate for several hours.

For experimentation, an Erlenmeyer flask containing pre-ozonated phosphate buffer was placed in an ice bath and bubbled with ozone for approximately 15 minutes or until the dissolved ozone concentration stabilized. The dissolved ozone concentration was measured using a Thermo Scientific Genesys 10S UVVis spectrophotometer $\left(\varepsilon_{258}=2,900 \mathrm{M}^{-1} \mathrm{~cm}^{-1}\right)$. The ozone concentration ranged from $0.09 \mathrm{mM}$ to $0.25 \mathrm{mM}$ for all of the experiments conducted.

\subsection{Preparation of Carbon Nanotubes}

Multi-walled carbon nanotubes (MWCNTs) were functionalized via oxidation with concentrated nitric acid using a process followed by Oulton et al. (2015). The MWCNTs were suspended on a filter, dried, and then used to prepare a $1 \mathrm{~g} / \mathrm{L}$ solution in DI water. The solution was sonicated for approximately 20 hours using a Branson 2800 sonicator.

\subsection{Experimental Procedures}

To expose the compounds to ozone, ozonated phosphate buffer was added to a reactor containing a $10 \mathrm{mg} / \mathrm{L}$ solution of caffeine (Fisher Scientific), $10 \mathrm{mg} / \mathrm{L}$ solution of phenytoin (Fisher Scientific), and/or $10 \mathrm{mg} / \mathrm{L}$ solution of atrazine (Chem Service, Inc.), and a $0.32 \mathrm{mM}$ solution of tert-butanol (Fisher Scientific) as an $\cdot \mathrm{OH}$ competitor. To determine the sorption of the MWCNTs without ozone, the 
MWCNT solution was sonicated for approximately 30 minutes prior to experimentation. A $10 \mathrm{mg} / \mathrm{L}$ solution of sonicated MWCNTs was added to a reactor containing non-ozonated phosphate buffer and a $10 \mathrm{mg} / \mathrm{L}$ solution of caffeine, $10 \mathrm{mg} / \mathrm{L}$ solution of phenytoin, and/or $10 \mathrm{mg} / \mathrm{L}$ solution of atrazine, and a $0.32 \mathrm{mM}$ solution of tert-butanol. To expose the compounds to the AOP ozone and MWCNTs, a $10 \mathrm{mg} / \mathrm{L}$ solution of sonicated MWCNTs was added to a reactor containing ozonated phosphate buffer and $10 \mathrm{mg} / \mathrm{L}$ solution of caffeine, $10 \mathrm{mg} / \mathrm{L}$ solution of phenytoin, and/or $10 \mathrm{mg} / \mathrm{L}$ solution of atrazine, and a $0.32 \mathrm{mM}$ solution of tert-butanol.

The contents of the reactor were mixed on a stir plate. Samples were extracted after $5,10,15,30,60,90,120$, and 300 seconds and transferred to HPLC. For samples containing ozone, the HPLC vials contained a $20 \mathrm{mg} / \mathrm{L}$ solution of sodium sulfite (Fisher Scientific) to quench the ozone reaction. Samples containing MWCNTs were transferred to disposable vials and were filtered through $0.22 \mu \mathrm{m}$ nylon filters into the HPLC vials. The average amount of sorption to the filters and MWCNTs (determined separately) was used to adjust the final concentrations of the contaminants.

All experiments were performed in duplicate or triplicate and with the appropriate non-ozonated and/or non-MWCNT containing control. 
An additional experiment was conducted with double $(0.64 \mathrm{mM})$ and triple $(0.96$ $\mathrm{mM}$ ) the concentration of tert-butanol to determine the effect increased competition has on the direct oxidation of caffeine.

After analyzing the data for phenytoin, a majority of the sample was found to sorb to the nylon filters. Trials containing phenytoin were repeated using $0.22 \mu \mathrm{m}$ polytetrafluoroethylene (PFTE) filters which sorbed less of the sample. The average amount of sorption to the filters and MWCNTs (determined separately) was used to adjust the final concentrations of the contaminants.

\subsection{Analysis}

Samples were analyzed with an Agilent 1260 Infinity High Performance Liquid Chromatograph (HPLC) and an Aquasil C18 Column (150 mm x $4.6 \mathrm{~mm}, 3 \mu \mathrm{m}$ internal diameter). The injection volume for all samples was $200 \mu \mathrm{L}$. A calibration curve was developed for each compound (Appendix A) to verify the HPLC method and determine the detection limit of the equipment. The detection limit of the HPLC for all of the compounds tested was found to be $100 \mu \mathrm{g} / \mathrm{L}$.

For caffeine analysis, an application from Agilent Technologies for analyzing paracetamol, aspirin, and caffeine was adapted and used (Huesgen, n.d.). The eluent consisted of $69 \%$ DI water, $28 \%$ methanol, and $5 \%$ acetic acid. The HPLC ran at a flow rate of $1 \mathrm{~mL} / \mathrm{min}$ with a run time of 22 minutes, and the absorbance was measured at a wavelength of $275 \mathrm{~nm}$. 
A previously developed method for analyzing phenytoin was adjusted for use with the newer HPLC (Vance, 2017). The eluent consisted of $72 \%$ DI water, 23\% acetonitrile, and $5 \%$ methanol. The HPLC ran at a flow rate of $0.8 \mathrm{~mL} / \mathrm{min}$ for 45 minutes, and the absorbance was measured at a wavelength of $220 \mathrm{~nm}$.

To determine atrazine concentrations, a method was modified from Oulton, 2013. The eluent consisted of $60 \%$ acetonitrile and $40 \%$ DI water. The HPLC ran at a flow rate of $0.8 \mathrm{~mL} / \mathrm{min}$ for 11 minutes, and the absorbance was measured at a wavelength of $226 \mathrm{~nm}$.

\subsection{Quality Assurance and Quality Control}

Several QA/QC measures were incorporated into the experiment to confirm the accuracy and precision of the data and indicate any discrepancies in the results. QA/QC processes were also used to verify the methods used in the experiment.

Calibration curves were developed (Appendix A) for each contaminant analyzed on the HPLC to relate the results to known concentrations. A series of samples with known concentrations were analyzed on the HPLC and plotted against the measured abundance. A linear trendline for the calibration curve verified the response of the HPLC to different contaminant concentrations. The calibration curves also indicated the detection limits and sensitivity of the HPLC. At concentrations near the detection limit of the HPLC, the measured abundance could not be differentiated from the background noise of the results. 
Sample blanks were used as a QA/QC check. Vials of DI water were analyzed to observe any drifting in the baseline of the results and to indicate detection errors by the HPLC. Sample blanks for each contaminant were analyzed to determine the contaminant concentration in the reactor before exposure to treatment. The sample blanks were prepared using the same process as the experiments except without ozonating the phosphate buffer or the addition of CNTs. The measured concentrations from the sample blanks were used as the time zero reading for the different reactor conditions. Sample blanks were prepared and analyzed several times throughout the experimental process to confirm the consistency of the methods and compounds used and the detection by the HPLC. To measure the amount of a compound that sorbed to the filters, a sample blank was prepared and filtered. The concentration of the filtered sample blank was compared to the unfiltered sample blank, and the difference was estimated to be the amount of contaminant that sorbed to the filter. This amount was used to correct the other experimental results for the sorption effect with the filters.

Controls were performed as a QA/QC measure to test the experimental methods used. Reactors were prepared with the same concentration of compounds as the experimental trials but without ozonated phosphate buffer or CNTs. The control reactors were tested following the same experimental procedure of mixing and extracting samples. The samples were analyzed to verify the experimental procedure followed was not introducing error or giving unexpected results. The 
controls were also used to determine if any chemical interactions were causing the contaminants to degrade apart from exposure to the treatment processes.

As a QA/QC measure, all experiments were performed in duplicate and a few were performed in triplicate. The standard deviation of the data points was calculated and used to generate the error bars on the plots of the results. Large error bars on the plots indicate outliers caused by fluctuations in contaminant concentrations or a misreading by the HPLC.

\subsection{Determination of Reaction Rate Constants}

The rate constants for the reactions with ozone ( $\left.\mathrm{K}_{\mathrm{O}}\right)$ and ozone with CNTs $\left(\mathrm{K}_{\mathrm{OH}}\right)$ were analyzed for caffeine, phenytoin, and atrazine. The degradation of each compound and resulting concentration was determined through HPLC analysis. To measure ozone concentration, the direct oxidation and AOP experiments were replicated. Samples were taken from the reactor after 15, 30, 60, 90, 120, and 300 seconds, and the absorbance of ozone was measured with the UV-Vis spectrophotometer $\left(\varepsilon_{258}=2,900 \mathrm{M}^{-1} \mathrm{~cm}^{-1}\right)$ and used to determine the concentration. For the samples containing CNTs, the absorbance was adjusted by subtracting the average absorbance of CNTs in a sample of DI water. 


\section{Chapter 4 - Results and Discussion}

The results of the experiments performed with caffeine, atrazine, and phenytoin are presented and discussed in this chapter. A series of experiments was performed with the three different emerging contaminants and three different treatment conditions to address the research objectives outlined for this study. The first phase of experiments was performed with simple water systems to separately determine the response of caffeine and atrazine to treatment with ozone only, CNTs only, and the AOP with ozone and CNTs, to evaluate the compounds for their use as indicator compounds, and to determine the reaction rate constants for the compounds. In the second phase of experiments, more complex water systems with caffeine and atrazine combined were analyzed to determine the effect of increased competition on the degradation of the contaminants after exposure to ozone only, CNTs only, and the AOP. The potential for the contaminants to be indicator compounds was also analyzed, and the reaction rate constants for the compounds were determined to observe the effect of increased competition. The third phase of experiments utilized simple water systems to expose phenytoin to treatment with ozone only, CNTs only, and the AOP, to evaluate the potential of phenytoin to be an indicator compound, and to determine the reaction rate constant for the compound.

\subsection{Phase 1a - Caffeine Only}

Caffeine is widely prevalent in wastewater effluent because it is not completely removed by conventional treatment processes or exposure to ozone (Broséus et 
al., 2009; Rosal et al., 2009). After preliminary testing, caffeine was found to degrade easily with ozone. Therefore, a series of experiments were conducted with increasing competition to reduce the amount of degradation and rate of reaction of caffeine with ozone. In the first phase of testing (Phase 1a) caffeine was exposed to ozone with increasing concentration of tert-butanol, which acted as a competitor for the reaction. The results from these experiments were used to evaluate the potential for caffeine to be used as an indicator compound for AOPs and to determine the $\mathrm{K}_{\mathrm{O}}$ values for caffeine. Caffeine was exposed to ozone in experiments with initial tert-butanol concentrations of $0.32 \mathrm{mM}$ (Experiment 1), $0.64 \mathrm{mM}$ (Experiment 2), and $0.96 \mathrm{mM}$ (Experiment 3). Three trials were performed for Experiment 1, and two trials were performed for Experiments 2 and 3. A $680 \mathrm{mg} / \mathrm{L}$ phosphate buffer solution was used in all experiments to maintain a neutral $\mathrm{pH}$ of 7 . All of the experiments were performed at approximately $20^{\circ} \mathrm{C}$. The initial concentration of caffeine was $10 \mathrm{mg} / \mathrm{L}$ for all three experiments. The initial ozone concentration for all experiments was approximately $0.12 \mathrm{mM}$. The result showing degradation of caffeine for all three experiments are displayed in Figure 5. 


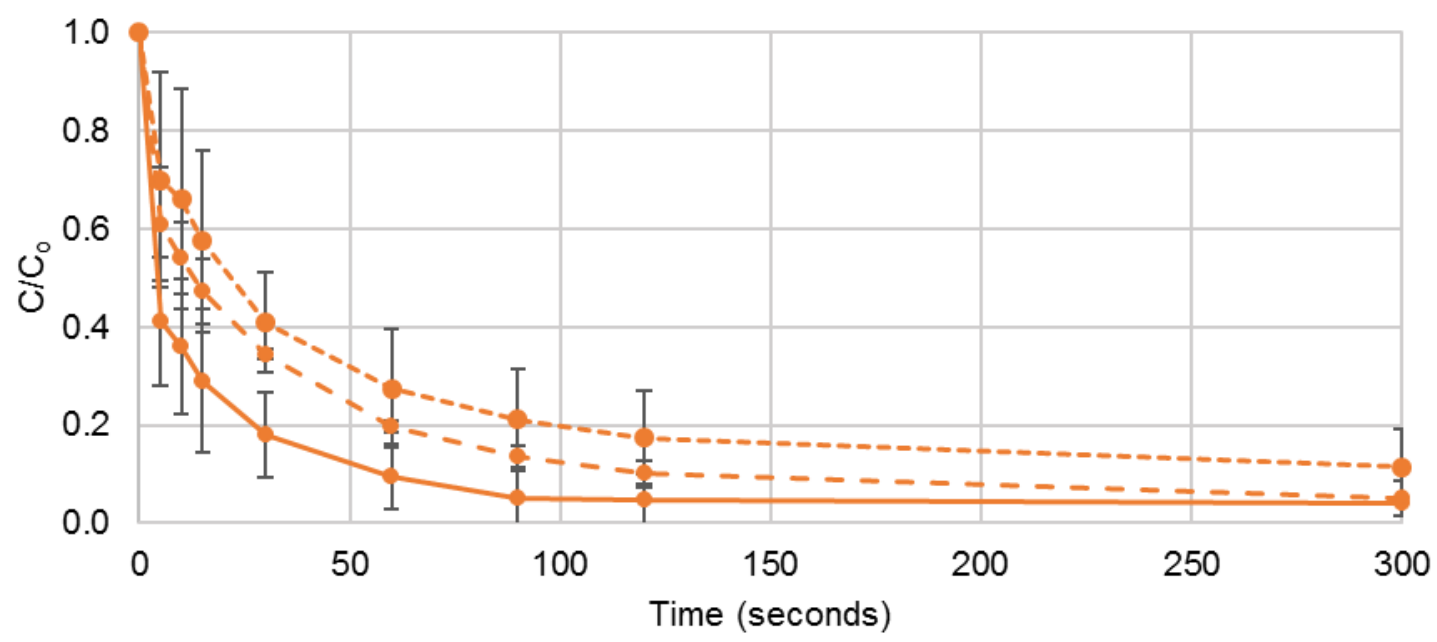

$\longrightarrow$ Experiment 1: [O3] $=0.17 \mathrm{mM}$, [tert-butanol $]=0.32 \mathrm{mM}$

- Experiment 2: [O3] $=0.10 \mathrm{mM}$, [tert-butanol $]=0.64 \mathrm{mM}$

- - - - Experiment 3: [O3] $=0.09 \mathrm{mM}$, [tert-butanol $]=0.96 \mathrm{mM}$

Figure 5: Caffeine concentration as a function of time in Experiment 1 (standard competition ratio), 2 (double competition), and 3 (triple competition). Data represent averages and standard deviation from triplicate or duplicate experiments. Experimental conditions: [caffeine] $=10$ $\mathrm{mg} / \mathrm{L}, \mathrm{pH} 7$ (680 $\mathrm{mg} / \mathrm{L}$ phosphate buffer), $T=20^{\circ} \mathrm{C}$.

For Experiment 1, the initial caffeine concentration was reduced by approximately $59 \%$ after 5 seconds, $82 \%$ after 30 seconds, and $91 \%$ after 60 seconds. After 5 minutes, approximately $4 \%$ of the initial caffeine concentration remained in the system.

For Experiment 2, caffeine degraded slower than in Experiment 1 as shown by the less steep degradation curve in Figure 5. After 5 seconds, the initial caffeine concentration was reduced by approximately $39 \%$ which is $20 \%$ less than Experiment 1 . The caffeine concentration was reduced by $66 \%$ and $80 \%$ after 30 and 60 seconds respectively. While caffeine displayed slower degradation with increased competition in Experiment 2, the initial concentration was reduced by 
$95 \%$ after 5 minutes which is within $1 \%$ of the reduction achieved in Experiment 1.

Experiment 3 contained triple the concentration of tert-butanol compared to Experiment 1. Caffeine degraded more slowly in Experiment 3 than in the other two experiments, as shown in Figure 5 . After 5 seconds, the initial caffeine concentration was reduced by $30 \%$ which is approximately half of the degradation experienced in Experiment 1. A reduction of $59 \%$ after 30 seconds and $73 \%$ after 60 seconds was observed. The reduction in caffeine at these time intervals was approximately $20 \%$ less than Experiment 1 and $7 \%$ less than Experiment 2. Ultimately, the remaining caffeine concentration was $11 \%$ at 5 minutes which is approximately $5 \%$ greater than the removal achieved by the other two reactors. However, an $89 \%$ reduction in the initial caffeine concentration can be considered an acceptable level of removal for the treatment process.

Despite the increased competition with tert-butanol, caffeine was still responsive to treatment via direct oxidation. Since caffeine was degraded by approximately $90 \%$ or greater after to exposure to ozone, even in the highly competitive environment created with Experiment 3, additional treatment with an AOP was not necessary. 
Based on the results of these experiments, caffeine cannot serve as an effective indicator compound for AOPs. Caffeine degraded by direct oxidation with ozone and did not require additional treatment with the AOP to be removed. Therefore, caffeine is likely to be removed by treatment systems with ozone and would not be detected after treatment with an AOP, unlike the ozone recalcitrant emerging contaminants of concern.

\subsubsection{Reaction Rate Constants}

To determine the reaction rate constants (Ko3 values) for caffeine exposed to ozone, the degradation of ozone was measured for Experiments 1, 2, and 3. In Experiment 1, ozone degraded slightly more quickly than the reactors with increased competition as shown in Figure 6. After 15 seconds the ozone concentration was reduced by $18 \%, 8 \%$, and $6 \%$ in Experiment 1,2 , and 3 respectively. For the time intervals between 30 and 120 seconds, the ozone concentrations varied by a maximum of $10 \%$ between the different reactors. The remaining ozone concentration after 5 minutes for Experiment 1 was 33\%, Experiment 2 was $43 \%$, and Experiment 3 was $46 \%$. 


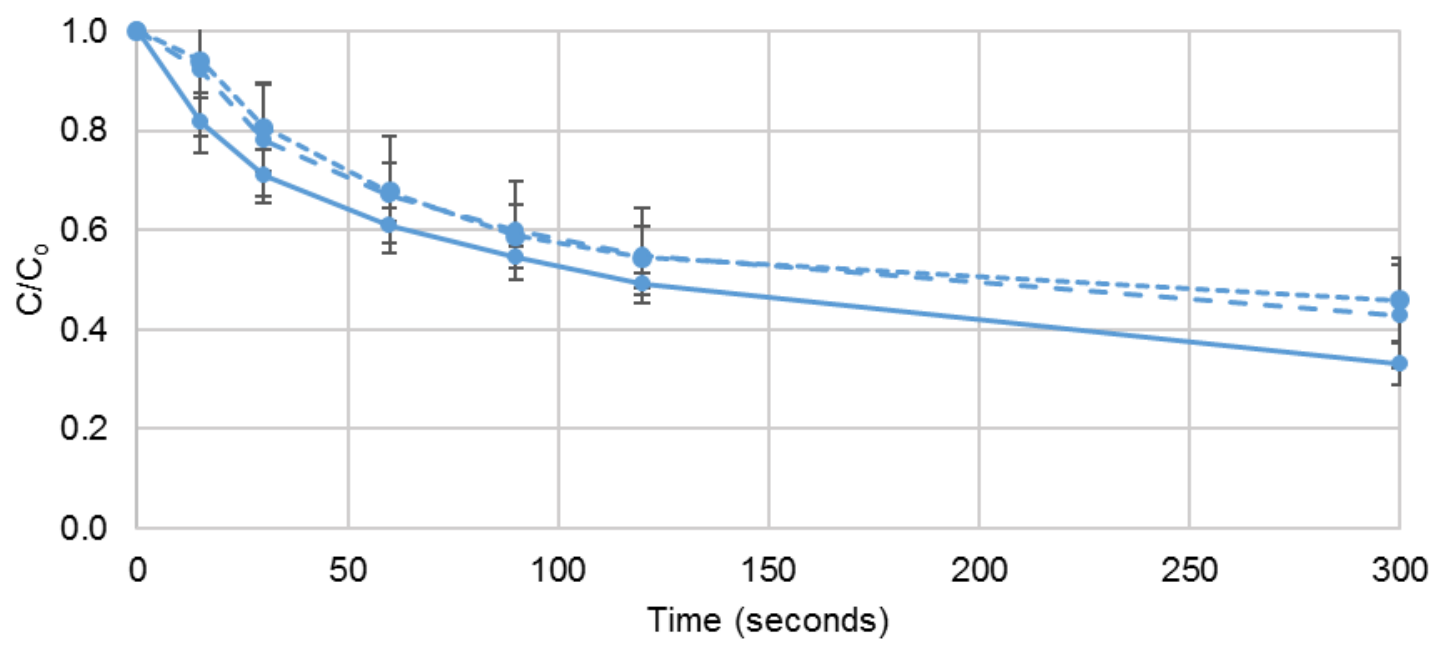

$\longrightarrow$ Experiment 1: [O3] $=0.17 \mathrm{mM}$, [tert-butanol $]=0.32 \mathrm{mM}$

- Experiment 2: [O3] $=0.10 \mathrm{mM}$, [tert-butanol $]=0.64 \mathrm{mM}$

--๑-- Experiment 3: [O3] $=0.09 \mathrm{mM}$, [tert-butanol] $=0.96 \mathrm{mM}$

Figure 6: Ozone concentration as a function of time in Experiment 1 (standard competition ratio), 2 (double competition), and 3 (triple competition). Data represent averages and standard deviation from duplicate experiments. Experimental conditions: [caffeine] $=10 \mathrm{mg} / \mathrm{L}, \mathrm{pH} 7$ (680 $\mathrm{mg} / \mathrm{L}$ phosphate buffer), $\mathrm{T}=20^{\circ} \mathrm{C}$.

The following equations represent the reaction taking place in the experiments, and they are used to determine the $\mathrm{K}_{03}$ values for caffeine specific to the reaction conditions used. The degradation of a compound after exposure to ozone is represented by Equation 1:

$$
-\frac{d C}{d t}=K_{O 3}[C]\left[O_{3}\right]
$$

Equation 1

Where $\mathrm{K}_{\mathrm{O} 3}=$ reaction rate constant with ozone and $\mathrm{C}=$ compound of interest (Broséus et al., 2009). 
Integration of Equation 1 gives Equation 2:

$$
\ln \left(\frac{C}{C_{o}}\right)=-K_{O 3} \int_{0}^{t}\left[O_{3}\right] d t
$$

Where $\int\left[\mathrm{O}_{3}\right] \mathrm{dt}=$ time integrated ozone concentration $(\mathrm{M} \bullet \mathrm{s})$ (Broséus et al., 2009).

The time integrated ozone concentration was determined by integrating the curve of ozone decay over time for each of the trials performed. The slope of the plot of the natural log of removal of the compound of interest versus the time integrated ozone concentration (Equation 2) represents the rate constant for each reaction (Broséus et al., 2009). This method was used to determine the $\mathrm{K}_{03}$ value for caffeine after exposure to various the treatment conditions in Experiments 1 through 3.

The plots used to determine the $\mathrm{K}_{03}$ value for each trial performed are displayed in Appendix $\mathrm{B}$. The $\mathrm{K}_{03}$ values from each trial were recorded and averaged in Table 1. The concurrent degradation of caffeine and ozone resulted in an average $\mathrm{K}_{03}$ value of $334 \pm 67 \mathrm{M}^{-1} \mathrm{~s}^{-1}$. The result of this experiment was compared to literature $\mathrm{K}_{03}$ values for caffeine; however, the $\mathrm{K}_{\mathrm{o}}$ values from literature vary by 5 orders of magnitude. The $\mathrm{K}_{03}$ value determined from the experimental results were within the same order of magnitude as the $\mathrm{K}_{03}$ value determined by Broséus et al. (2014). In the study conducted by Broséus et al. (2014), the calcualted $\mathrm{K}_{03}$ values ranged from $573-650 \mathrm{M}^{-1} \mathrm{~s}^{-1}$ for $\mathrm{pH} 8.10$ at 20 ${ }^{\circ} \mathrm{C}$. The higher $\mathrm{pH}$ in the experiment by Broséus et al. (2014) corresponds to the 
higher $\mathrm{K}_{03}$ value compared to the $\mathrm{K}_{03}$ value calculated from this experiment at $\mathrm{pH}$ 7. The $\mathrm{K}_{03}$ values determined in this experiment can be considered valid based on their similarity to the $\mathrm{K}_{03}$ values obtained by Broséus et al. (2014).

Table 1: Second-order Kоз values $\left(\mathrm{M}^{-1} \mathrm{~s}^{-1}\right)$ for caffeine exposed to ozone

\begin{tabular}{|c|c|c|c|}
\hline Trial & Experiment 1 & Experiment 2 & Experiment 3 \\
\hline $\mathbf{1}$ & 382 & 281 & 171 \\
\hline $\mathbf{2}$ & 363 & 217 & 272 \\
\hline $\mathbf{3}$ & 258 & - & - \\
\hline Average & $\mathbf{3 3 4} \pm \mathbf{6 7}$ & $\mathbf{2 4 9} \pm \mathbf{4 5}$ & $\mathbf{2 2 2} \pm \mathbf{7 1}$ \\
\hline
\end{tabular}

The $\mathrm{K}_{03}$ values for Experiment 2 were calculated, and the plots for each trial performed are displayed in Appendix B. The $\mathrm{K}_{03}$ values for each trial and the average are summarized in Table 1. For Experiment 2 with double the competition, the average $\mathrm{K}_{03}$ value was $249 \pm 45 \mathrm{M}^{-1} \mathrm{~s}^{-1}$ compared to Experiment 1 with an average $\mathrm{K}_{\mathrm{O} 3}$ value of $334 \pm 67 \mathrm{M}^{-1} \mathrm{~s}^{-1}$.

Appendix B contains the plots of the results from Experiment 3 . The average $\mathrm{K}_{\mathrm{o}}$ value from the gradient of the trendlines was $222 \pm 71 \mathrm{M}^{-1} \mathrm{~s}^{-1}$ for Experiment 3 with triple the competition. For Experiment 3, the $\mathrm{K}_{03}$ value continues the negative correlation between increasing competition and decreasing $\mathrm{K}_{03}$ values. However, the average $\mathrm{K}_{03}$ value in Experiment 3 does not display a linear relationship with the $\mathrm{K}_{03}$ values from the other two reactors. Compared to 
Experiment 1, the $\mathrm{K}_{03}$ value for Experiment 2 was $26 \%$ less and the $\mathrm{K}_{03}$ value for Experiment 3 was $34 \%$ less. While the correlation is not linear, conclusions can be drawn from the trend of decreasing $\mathrm{K}_{03}$ values with increasing competition in systems.

By comparing the $\mathrm{K}_{03}$ values as the conditions in the reactors were changed, the likelihood of caffeine to degrade when exposed to ozone can be predicted. Increased competition in the form of higher concentrations of tert-butanol was added to the reactors to slow the degradation of caffeine and effectively reduce the reaction rate. The $\mathrm{K}_{03}$ values obtained from the experimental data agree with the expected result for increasing competition in the reactors.

In the reactors with caffeine and tert-butanol, several competing reactions were taking place. The tert-butanol was more easily degraded than caffeine as shown by the slower reduction in caffeine concentration in reactors with increased competition. Ozone was also being consumed by the additional tert-butanol. Therefore, less ozone was available in the system to degrade caffeine which resulted in a lower $\mathrm{K}_{03}$ value for caffeine. As competition in the reactors was doubled and tripled, the $\mathrm{K}_{03}$ values decreased because less caffeine is degraded in the higher-competition environments.

This phenomenon is observed graphically as well. The lower Kо3 values for Experiments 2 and 3 represents the trend of slower degradation of caffeine 
observed in Figure 5. The $\mathrm{K}_{03}$ value is also a product of the degradation of ozone, and the ozone degradation curves in Figure 6 explain the decreasing $\mathrm{K}_{\mathrm{O} 3}$ values obtained from the data. Caffeine and ozone degraded slower in the reactors with increasing competition which is expected to result in a lower $\mathrm{K}_{03}$ value. A lower $\mathrm{K}_{03}$ value is expected because the smaller reduction in caffeine concentration and the larger time integrated ozone concentration results in a plot with a less steep trendline. Since the $\mathrm{K}_{03}$ value is the gradient of the trendline, a less steep trendline equates to a smaller $\mathrm{K}_{\mathrm{O} 3}$ value.

\subsection{Phase $1 \mathrm{~b}$ - Atrazine Only}

Atrazine is a ubiquitous contaminant in wastewater and surface water as a result of its resistance to conventional treatment methods (Benotti et al., 2009). A series of experiments was performed to determine the response of atrazine to treatment with direct oxidation, sorption on $\mathrm{CNTs}$, and $\bullet \mathrm{OH}$. The results from these experiments were used to determine the potential for atrazine to be used as an indicator compound for AOPs and to estimate the $\mathrm{K}_{\mathrm{O}}$ and $\mathrm{K}_{\mathrm{OH}}$ values for atrazine. Atrazine was exposed to treatment processes in experiments with ozone only (Experiment 4), CNTs only (Experiment 5), and the AOP with ozone and CNTs (Experiment 6). Two trials were performed for all three experiments. A $680 \mathrm{mg} / \mathrm{L}$ phosphate buffer solution was used in all experiments to maintain a neutral $\mathrm{pH}$ of 7 . All of the experiments were performed at approximately $20^{\circ} \mathrm{C}$. The initial concentration of atrazine was $10 \mathrm{mg} / \mathrm{L}$ and tert-butanol was $0.32 \mathrm{mM}$ for all three experiments. For experiments 4 and 6 , the initial ozone concentration 
was approximately $0.21 \mathrm{mM}$. For experiments 5 and 6 , CNTs had a concentration of $10 \mathrm{mg} / \mathrm{L}$. The samples containing CNTs were filtered through $0.22 \mu \mathrm{m}$ nylon filter prior to analysis by the HPLC. The average amount of atrazine that sorbed to the filters was measured to be approximately $17 \%$ of the initial concentration. All of the data presented in this discussion were corrected to account for sorption to the filters.

To determine if exposure to the AOP improved the removal of atrazine, the response of atrazine to direct oxidation with ozone alone and sorption by CNTs alone was determined first. Then, atrazine was exposed to the AOP and the removal achieved by the presence of $\bullet \mathrm{OH}$ was calculated. The concentration of atrazine was measured and the results of the three experiments are displayed in Figure 7. 


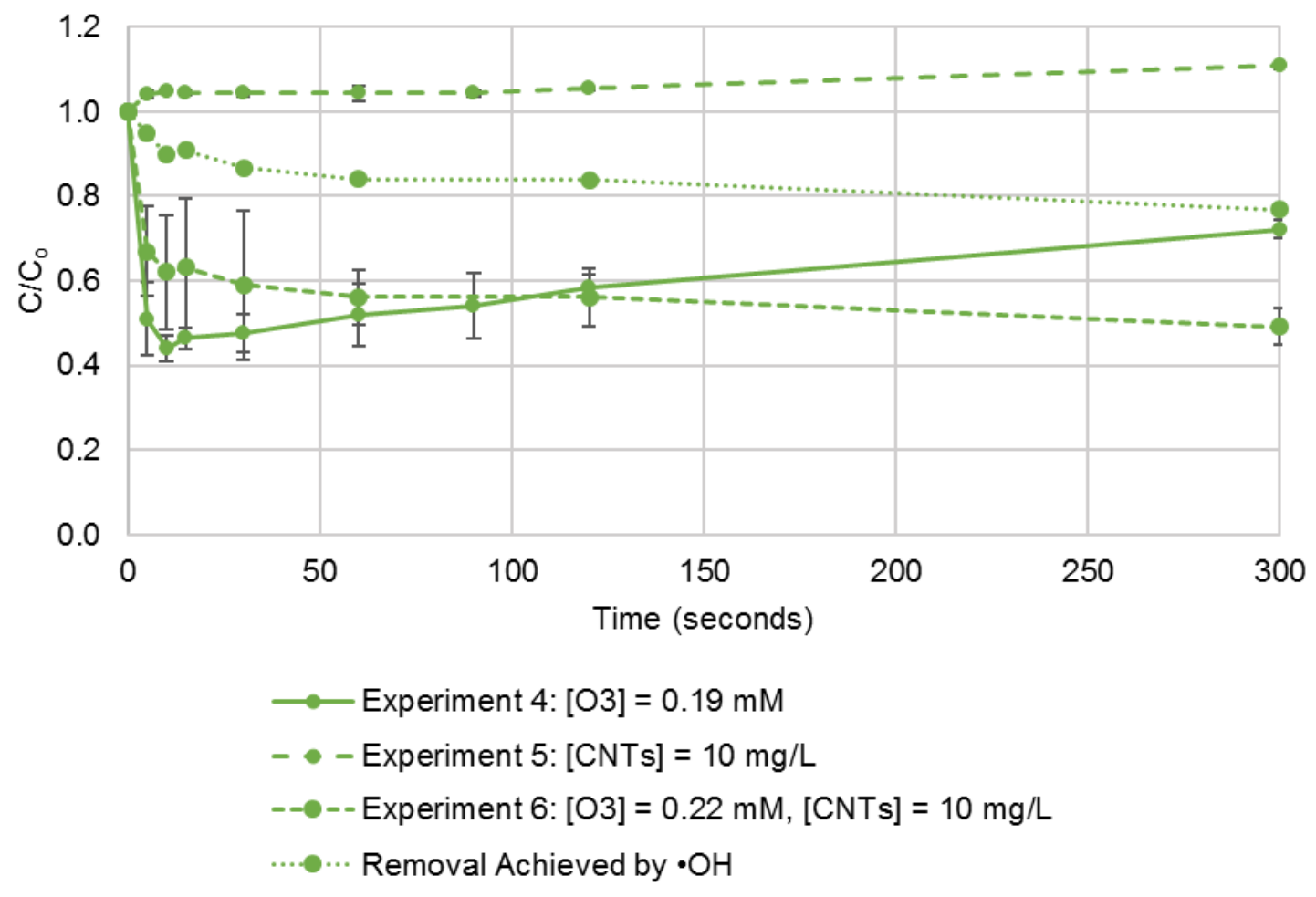

Figure 7: Atrazine concentration as a function of time in Experiment 4 (ozone only), 5 (CNTs only), and 6 (AOP with ozone and CNTs), and the removal achieved by the AOP via $\bullet O H$. Data represent averages and standard deviation from duplicate experiments. Experimental conditions: [atrazine] $=10 \mathrm{mg} / \mathrm{L}$, [tert-butanol] $=0.32 \mathrm{mM}, \mathrm{pH} 7(680 \mathrm{mg} / \mathrm{L}$ phosphate buffer $), T$ $=20^{\circ} \mathrm{C}$.

In Experiment 4, atrazine showed limited response to treatment with ozone within 5 minutes. After 15 seconds, atrazine was reduced by $54 \%$. From 30 seconds to 5 minutes, the atrazine concentration showed an increasing trend which is not reasonable considering the contaminant is being exposed to a treatment process. The formation of breakdown products could have affected the concentration of atrazine detected by the HPLC. This possible detection error is further discussed below. The final concentration of atrazine was $72 \%$ of the initial concentration after 5 minutes. Since the atrazine concentration was not 
significantly removed by ozone, the compound can be considered recalcitrant to ozone treatment.

Atrazine was also exposed to CNTs in Experiment 5 to determine if any sorption effects would occur. After 5 minutes, atrazine was present in the same concentration as the initial concentration. Therefore, none of the atrazine was removed by sorption onto the CNTs. For Experiment 5, the error introduced by correcting the data for sorption to the filters could have contributed to the slight increase in concentration observed over 5 minutes.

To determine the efficacy of the AOP, atrazine was exposed to ozone and CNTs in Experiment 6. The atrazine concentration experienced a greater reduction after treatment by the AOP compared to ozone alone. The greatest reduction occurred during the first 15 seconds of treatment where the atrazine concentration reduced by $37 \%$. After 60 seconds, the atrazine concentration was reduced by $44 \%$. The remaining atrazine concentration after exposure to treatment for 5 minutes was $49 \%$ of the initial concentration. The AOP resulted in a $23 \%$ greater reduction in atrazine concentration in Experiment 6 compared to Experiment 4. Since sorption losses to CNTs were minimal, this additional removal can be attributed to reaction with $\cdot \mathrm{OH}$.

The AOP with ozone and CNTs targets the generation of $\bullet \mathrm{OH}$ to increase the removal of recalcitrant compounds such as atrazine. The amount of removal 
achieved by treatment with ozone alone was subtracted from the concentration of atrazine after exposure to the AOP. The resulting degradation curve in Figure 7 represents the reduction in atrazine concentration achieved by the addition of -OH. After 15 seconds, $\bullet \mathrm{OH}$ contributed to a $9 \%$ reduction in atrazine concentration. The addition of $\cdot \mathrm{OH}$ resulted in a $23 \%$ reduction in atrazine concentration after 5 minutes in addition to the $28 \%$ reduction from the ozone in the system.

\subsubsection{Detection Error}

When analyzing the results for atrazine from the HPLC, a detection error for the results from Experiment 4 may have occurred. Using standard analysis methods, the peak for atrazine had an expected elution time of approximately 7 minutes (Ross, Adam, \& Dittmann, n.d.). In the chromatograph of the sample blank for atrazine (Figure 8), atrazine is the only compound detected, as indicated by the single peak.

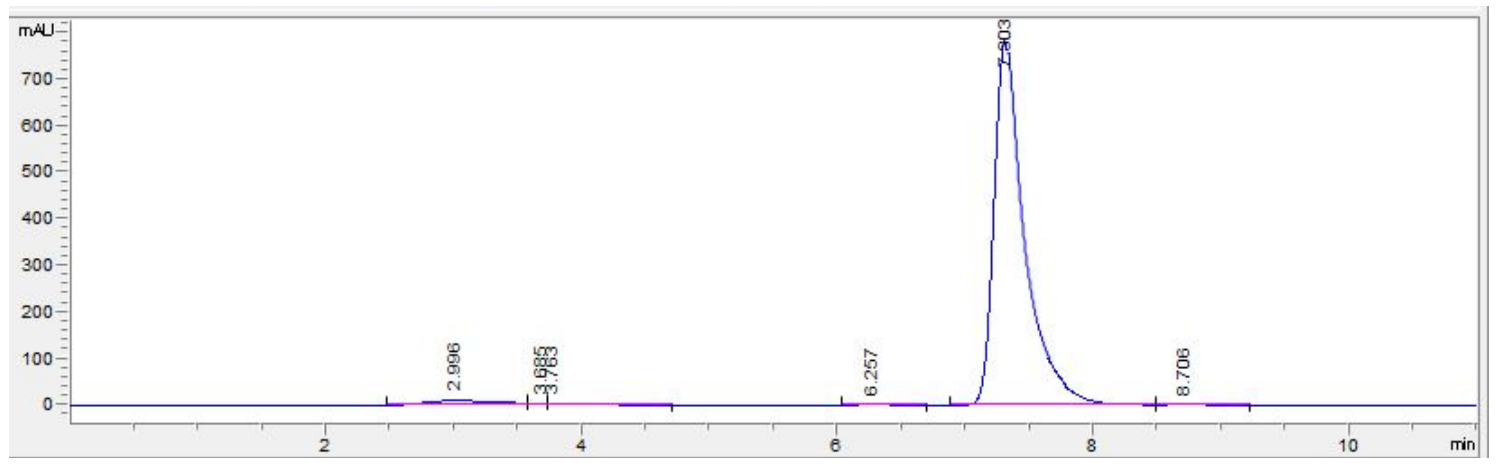

Figure 8: Chromatograph of atrazine sample blank (not exposed to treatment). Experimental conditions: $[$ atrazine] $=10 \mathrm{mg} / \mathrm{L}$, [tert-butanol] $=0.32 \mathrm{mM}, \mathrm{pH} 7(680 \mathrm{mg} / \mathrm{L}$ phosphate buffer $), T$ $=20^{\circ} \mathrm{C}$. 
Figure 9 contains the chromatograph of atrazine after exposure to ozone for 5 seconds. Several peaks other than the peak for atrazine at 7 minutes are present in the chromatograph. The additional peaks are suspected to be breakdown products associated with the degradation of atrazine, desisopropylatrazine (DIA) and desethylatrazine (DEA). DIA and DEA are expected to elute approximately 2.5 minutes before atrazine (Ross et al., n.d.), so it is likely that the peaks at approximately 5 minutes in Figure 9 show the detection of DIA and DEA.

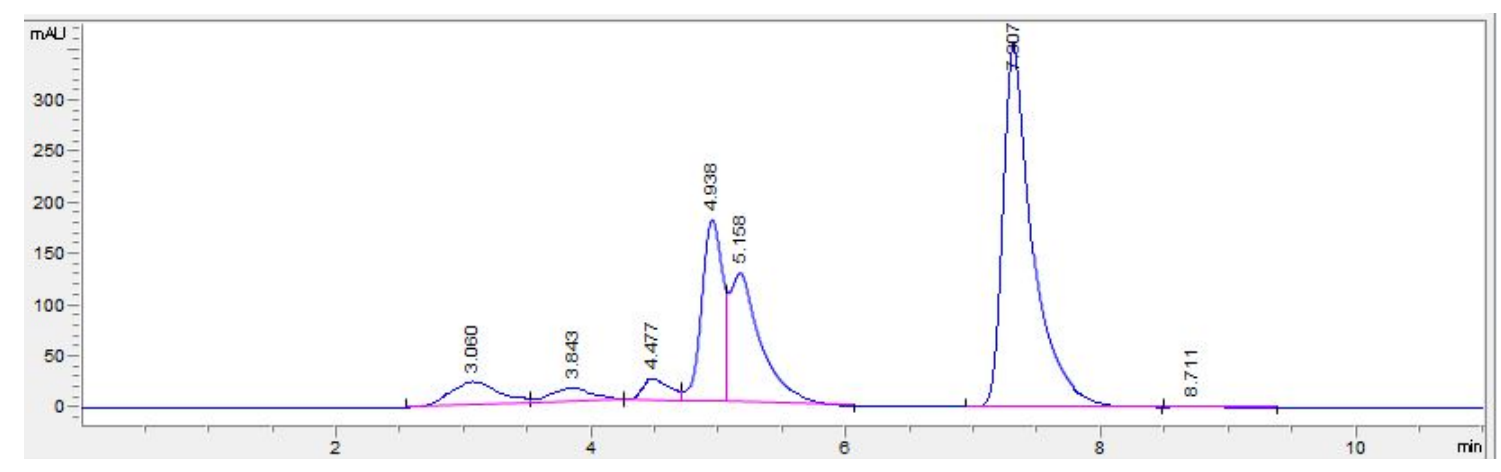

Figure 9: Chromatograph of atrazine in Experiment 4 (ozone only) after 5 seconds. Experimental conditions: [atrazine] $=10 \mathrm{mg} / \mathrm{L}$, [tert-butanol] $=0.32 \mathrm{mM}$, [ozone] $=0.22 \mathrm{mM}, \mathrm{pH}$ 7 (680 $\mathrm{mg} / \mathrm{L}$ phosphate buffer), $T=20^{\circ} \mathrm{C}$.

Figure 10 contains the chromatograph of atrazine after exposure to ozone for 5 minutes. The peak for atrazine increased while the peaks for the suspected breakdown products decreased. A possible explanation for the results seen in Figure 10 is the formation of subsequent breakdown products that were detected at the same elution time as the atrazine peak. The varying peaks detected in the chromatographs display the interference present that could have affected the detection of the atrazine peak. The interference of the breakdown products or other compounds detected on the chromatograph may have caused a misreading of the atrazine concentration. The appearance of these breakdown 
products occurred consistently on the chromatographs from both of the trials performed for this experiment.

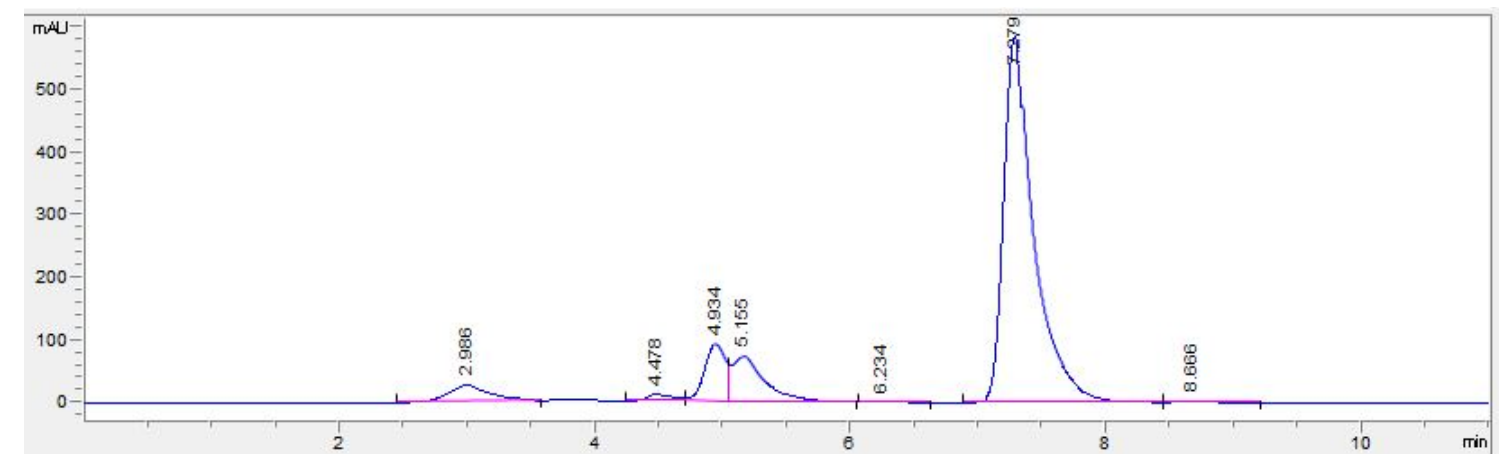

Figure 10: Chromatograph of atrazine in Experiment 4 (ozone only) after 5 minutes.

Experimental conditions: [atrazine] $=10 \mathrm{mg} / \mathrm{L}$, [tert-butanol] $=0.32 \mathrm{mM}$, [ozone] $=0.22 \mathrm{mM}, \mathrm{pH}$ 7 (680 $\mathrm{mg} / \mathrm{L}$ phosphate buffer), $T=20^{\circ} \mathrm{C}$.

Atrazine was also exposed to the AOP, and the chromatograph after 5 seconds is displayed in Figure 11. Compared to the chromatograph for atrazine after exposure to ozone only for 5 seconds, the additional peaks in Figure 11 appear at slightly different times and magnitudes. The additional peaks in Figure 11 are suspected to be the breakdown products for atrazine after exposure to the AOP.

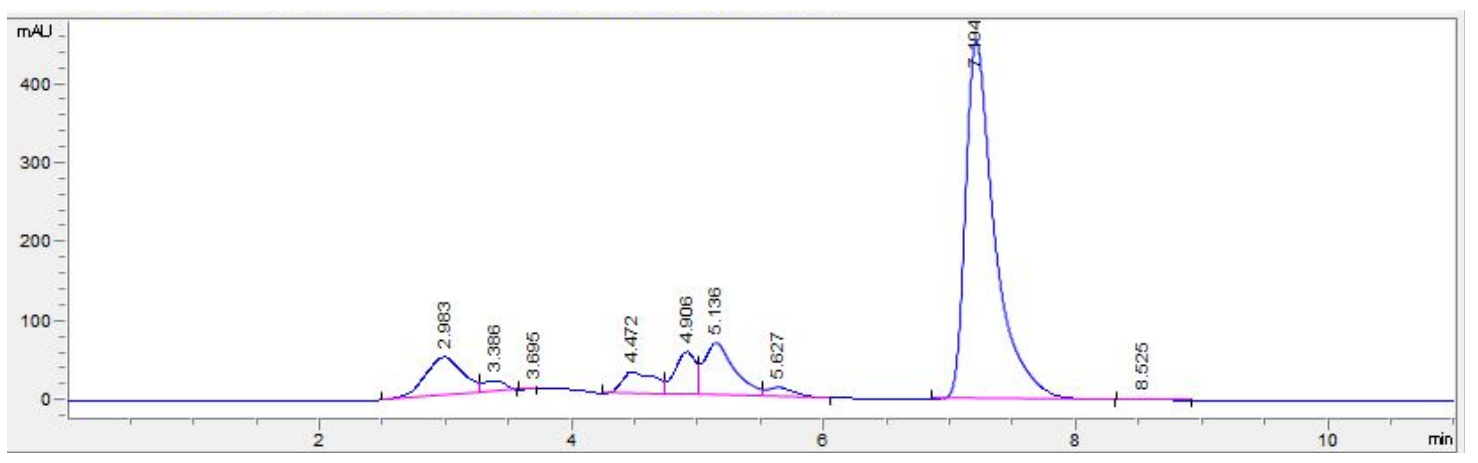

Figure 11: Chromatograph of atrazine in Experiment 6 (AOP with ozone and CNTs) after 5 seconds. Experimental conditions: [atrazine] $=10 \mathrm{mg} / \mathrm{L}$, [tert-butanol] $=0.32 \mathrm{mM}$, [ozone] = $0.19 \mathrm{mM},[\mathrm{CNTs}]=10 \mathrm{mg} / \mathrm{L}, \mathrm{pH} 7$ (680 mg/L phosphate buffer), $T=20^{\circ} \mathrm{C}$. 
Figure 12 contains the chromatograph of atrazine after exposure to the AOP for 5 minutes. The peak for atrazine decreased while the additional peaks increased. Overall, the chromatographs for atrazine exposed to the AOP display the expected trend of decreasing atrazine concentration over time. The reduction in the atrazine peak corresponds with an increase in the other peaks. This trend supports the theory that the additional peaks are caused by the detection of atrazine breakdown products. Interestingly, in the chromatographs for atrazine exposed to the AOP, the additional peaks do not appear to interfere with the detection of the atrazine peak. From the literature review, the breakdown pathway for atrazine exposed to the AOP was the only reaction mechanism studied. For ozone alone, atrazine is expected to degrade following different breakdown pathways. The different reaction mechanisms for ozone alone compared to the AOP resulted in the formation of different breakdown products as shown by different peak location and sizes for the chromatographs from Experiments 4 and 6.

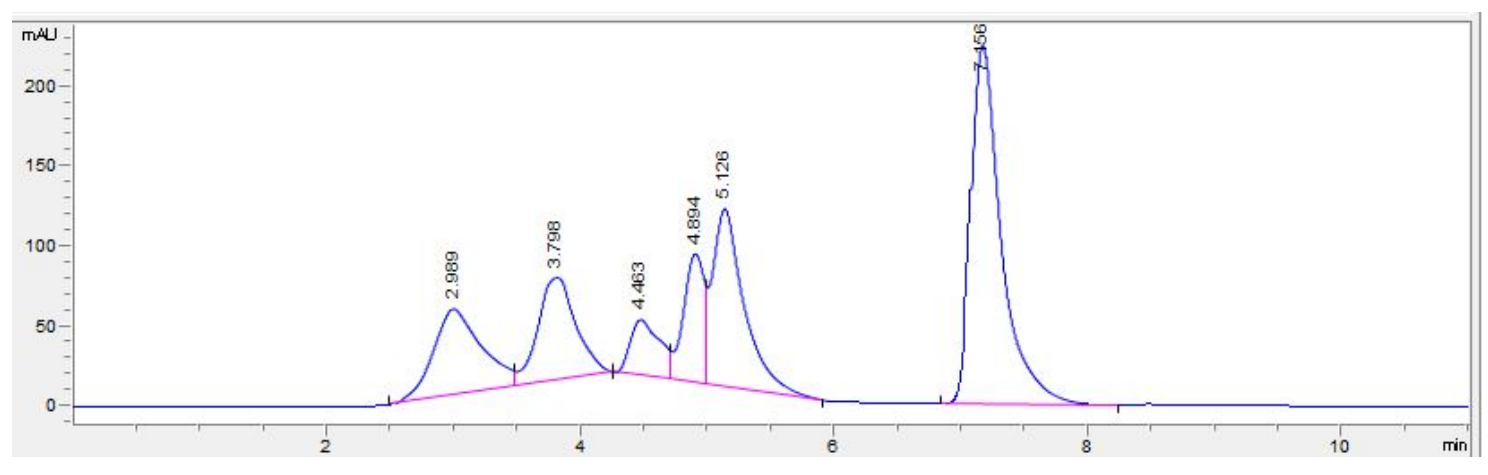

Figure 12: Chromatograph of atrazine in Experiment 6 (AOP with ozone and CNTs) after 5 minutes. Experimental conditions: [atrazine] $=10 \mathrm{mg} / \mathrm{L}$, [tert-butanol] $=0.32 \mathrm{mM},[$ ozone $]=$ $0.19 \mathrm{mM},[\mathrm{CNTs}]=10 \mathrm{mg} / \mathrm{L}, \mathrm{pH} 7(680 \mathrm{mg} / \mathrm{L}$ phosphate buffer $), T=20^{\circ} \mathrm{C}$. 
The chromatograph results from Experiments 4 and 6 (Figure 8 through Figure 12 above) suggest that as the concentration of atrazine is reduced, the concentration of the breakdown products increases. Ultimately, the peaks representing breakdown products preceding the atrazine peak constituted a significant area compared to the area of the atrazine peak. In Figure 13, the area of the additional peaks was added to the area of the atrazine peak at each time interval, representing an approximate mass balance for the systems. Any reduction in peak area represents complete removal of atrazine and its breakdown products.

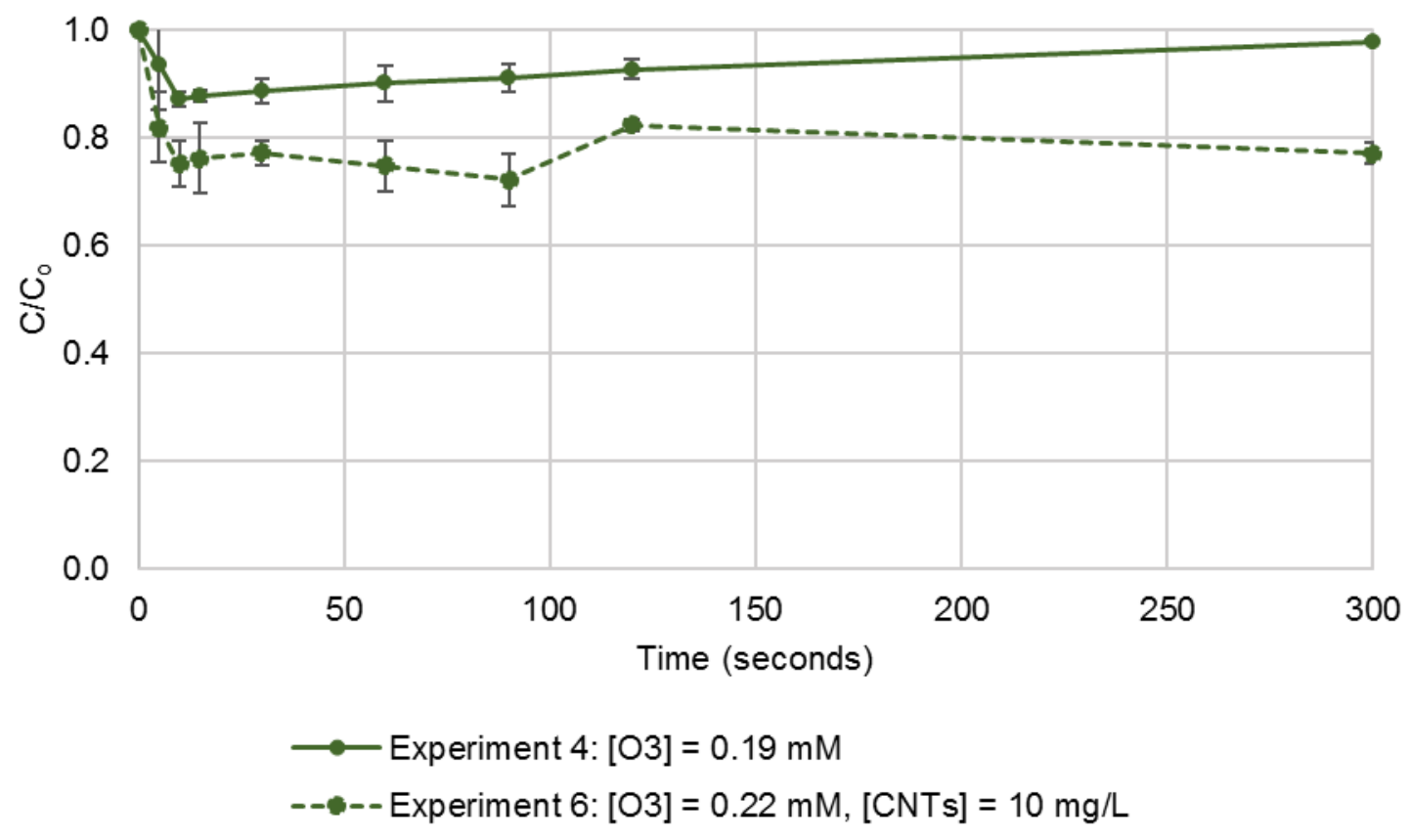

Figure 13: Atrazine concentration added to unknown identified breakdown products in Experiment 4 (ozone only) and 6 (AOP with ozone and CNTs). Experimental conditions: [atrazine] $=10 \mathrm{mg} / \mathrm{L}$, [tert-butanol] $=0.32 \mathrm{mM}, \mathrm{pH} 7(680 \mathrm{mg} / \mathrm{L}$ phosphate buffer $), T=20^{\circ} \mathrm{C}$.

The total concentration of atrazine and its breakdown products is equal to approximately $100 \%$ from time zero to 5 minutes after exposure to ozone in 
Experiment 4. After 5 minutes, none of the atrazine or breakdown products were completely removed from the system; therefore, the total mass of the system remained at $100 \%$ of the initial concentration. In Experiment 6 , the total mass of atrazine was reduced by $18 \%$ after 5 seconds. After exposure to treatment for 5 minutes, the remaining total mass of atrazine was $77 \%$ of the initial concentration. The AOP used in Experiment 6 was able to achieve an overall removal of $23 \%$ of the combined atrazine concentration and breakdown product mass in the system after 5 minutes which is an improvement over treatment with ozone alone. The $23 \%$ of overall removal of atrazine and breakdown products after exposure to the AOP can be attributed to the addition of $\bullet \mathrm{OH}$ because ozone alone and CNTs alone did not result in any degradation after 5 minutes of treatment. This result suggests that the AOP may be able to achieve partial mineralization of atrazine.

According to Figure 7, the atrazine concentration in Experiment 4 reduced initially then increased to $72 \%$ of the initial concentration after 5 minutes. A misreading of the peaks for atrazine and the breakdown products on the chromatograph from the HPLC could have occurred and caused the increasing concentration reading. The breakdown products could have been detected at the same time as atrazine and contributed to the area of the atrazine peak. The inconsistent detection of the additional peaks in the chromatographs for atrazine exposed to ozone indicates the potential interference caused by these additional peaks for detecting the atrazine peak. To allow for further analysis of the data, the final atrazine 
concentration after exposure to ozone for 5 minutes in Experiment 4, $72 \%$ of the initial concentration, was used to calculate the reaction rate constants.

Based on the response of atrazine to the different treatment processes, it has potential to serve as an indicator compound for AOPs. Atrazine displayed a limited response to treatment by direct oxidation and increased degradation with the AOP.

\subsubsection{Reaction Rate Constants}

To determine the reaction rate constants (Kо3 values) for atrazine exposed to ozone and the AOP, the degradation of ozone was measured for Experiments 4 and 6. In Experiment 6, ozone degraded more quickly than in Experiment 4, as displayed in Figure 14. After 15 seconds, the ozone concentration in both reactors was reduced by $13 \%$. The ozone concentration was reduced by $19 \%$ for Experiment 4 and $33 \%$ for Experiment 6 after 60 seconds. From 90 seconds to 5 minutes the ozone concentrations varied by approximately $20 \%$ between the two different reactors. After 5 minutes, the remaining ozone concentration was $48 \%$ and $26 \%$ of the initial concentration for Experiment 4 and 6 respectively. The addition of CNTs to Experiment 6 consumed the ozone to generate $\cdot \mathrm{OH}$ causing the ozone concentration to decrease more rapidly than in Experiment 4. 


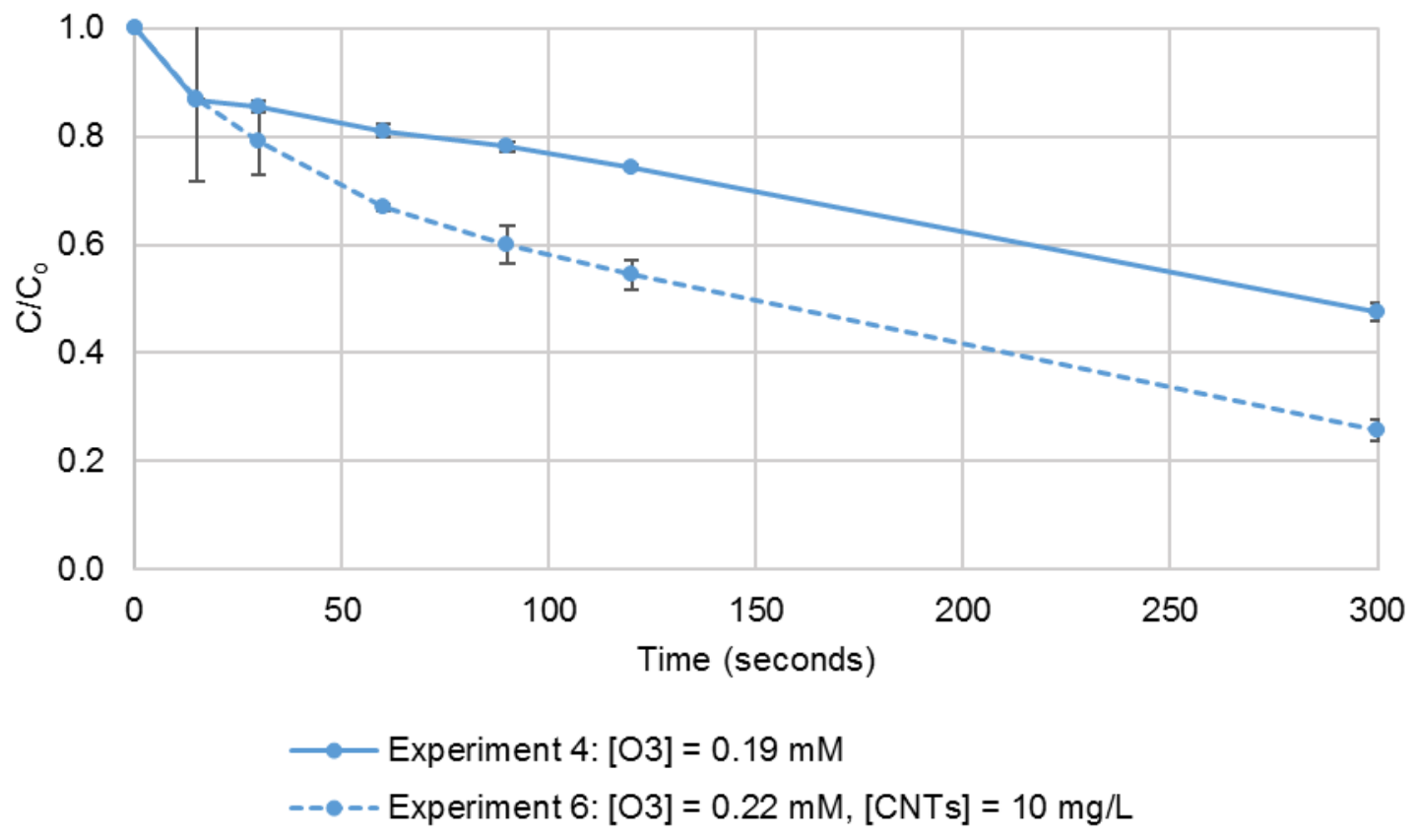

Figure 14: Ozone concentration as a function of time in Experiment 4 (ozone only) and 6 (AOP with ozone and CNTs). Data represent averages and standard deviation from duplicate experiments. Experimental conditions: [atrazine] $=10 \mathrm{mg} / \mathrm{L}$, [tert-butanol] $=0.32 \mathrm{mM}, \mathrm{pH} 7$ (680 $\mathrm{mg} / \mathrm{L}$ phosphate buffer), $\mathrm{T}=20^{\circ} \mathrm{C}$.

Following the same procedure used to calculate the $\mathrm{K}_{03}$ values for caffeine, the measured atrazine and ozone concentrations were used to generate the plots (in Appendix B) which display the $\mathrm{K}_{03}$ values for the reactors containing atrazine and ozone (Experiment 4). The $\mathrm{K}_{\mathrm{O}}$ values from each trial were recorded and averaged in Table 2. 
Table 2: Second-order Kоз values $\left(\mathrm{M}^{-1} \mathrm{~s}^{-1}\right)$ for atrazine exposed to ozone

\begin{tabular}{|c|c|}
\hline Trial & Experiment 4 \\
\hline $\mathbf{1}$ & 7.6 \\
\hline $\mathbf{2}$ & 9.0 \\
\hline Average & $\mathbf{8 . 3} \pm \mathbf{1 . 0}$ \\
\hline
\end{tabular}

The resulting average $\mathrm{K}_{03}$ value from the reactor with atrazine and ozone was $8.3 \pm 1.0 \mathrm{M}^{-1} \mathrm{~s}^{-1}$. The literature $\mathrm{K}_{03}$ value for atrazine was found to be $6 \mathrm{M}^{-1} \mathrm{~s}^{-1}$ at $\mathrm{pH} 7$ and $20^{\circ} \mathrm{C}$ (Wert et al., 2009). The experimental results produced a $\mathrm{K}_{\mathrm{O}}$ value similar to the $\mathrm{K}_{03}$ value from literature. Therefore, the methods and results of this experiment can be considered valid because they essentially replicate the findings of a previous study.

For the AOP tested, the system becomes increasingly complicated to analyze. Two simultaneous reactions may be occurring in a system with ozone and CNTs. Ozone reacts with contaminants via direct oxidation and also with CNTs to form - $\mathrm{OH}$ that react with contaminants via indirect oxidation. There is a reaction rate constant associated with the degradation of a contaminant via direct oxidation $\left(\mathrm{K}_{\mathrm{O} 3}\right)$ and indirect oxidation with $\cdot \mathrm{OH}\left(\mathrm{K}_{\mathrm{OH}}\right)$. The two simultaneous reactions consume both ozone and atrazine. The degradation of the compounds after exposure to ozone and CNTs $(\cdot \mathrm{OH})$ is represented by Equation 3:

$$
\frac{d C}{d t}=K_{O 3}[C]\left[O_{3}\right]+K_{\bullet \mathrm{OH}}[C][\bullet \mathrm{OH}] \quad \text { Equation } 3
$$


Where $\mathrm{K}_{\mathrm{OH}}=$ reaction rate constant with $\bullet \mathrm{OH}, \mathrm{C}$ represents atrazine, and the other values were previously defined.

Integration of Equation 3 results in Equation 4:

$$
\ln \left(\frac{C}{C_{o}}\right)=K_{O 3} \int_{0}^{t}\left[O_{3}\right] d t+K_{\bullet \mathrm{OH}} \int_{0}^{t}[\bullet \mathrm{OH}] d t \quad \text { Equation } 4
$$

Where $\int[\cdot \mathrm{OH}] \mathrm{dt}=$ time integrated $\bullet \mathrm{OH}$ concentration $(\mathrm{M} \cdot \mathrm{s})$.

The $\mathrm{K}_{\mathrm{OH}}$ value for a compound cannot be predicted without measuring the $\cdot \mathrm{OH}$ concentration in the reactor. Cal Poly does not have the equipment to directly measure $\cdot \mathrm{OH}$ concentration. Therefore, $\mathrm{K}_{\mathrm{OH}}$ values were not calculated and Equation 4 could not be used to determine the $\mathrm{K}_{03}$ value for atrazine. Instead, Equation 2 and the method in Phase 1 were used to determine a second-order $\mathrm{K}_{03}$ value $\left(\mathrm{K}^{\prime}\right)$ for atrazine exposed to direct and indirect oxidation by the AOP. The measured degradation of atrazine and ozone resulting from exposure to the AOP was used to calculate $K^{\prime}$. The $K^{\prime}$ value reflects the competing reaction in Experiment 6 and can be compared to the $\mathrm{K}_{03}$ values from the previous experiments to determine how the addition of $\bullet \mathrm{OH}$ affected the rate of a reaction. To further evaluate the reaction rate constants of the contaminants studied, the experimental results were also compared to literature $\mathrm{K}_{\mathrm{OH}}$ values for the compounds of interest. 
The plots used to determine the $\mathrm{K}^{\prime}$ values for each trial for Experiment 6 are displayed in Appendix B. Table 3 contains the $K^{\prime}$ values for each trial and the average with the standard deviation.

Table 3: Second-order $K^{\prime}$ values $\left(M^{-1} s^{-1}\right)$ for atrazine exposed to $\cdot \mathrm{OH}$

\begin{tabular}{|c|c|}
\hline Trial & Experiment 6 \\
\hline $\mathbf{1}$ & 20.3 \\
\hline $\mathbf{2}$ & 32.5 \\
\hline Average & $\mathbf{2 6 . 4} \pm \mathbf{8 . 7}$ \\
\hline
\end{tabular}

The $\mathrm{K}^{\prime}$ value for atrazine exposed to the AOP in Experiment 6 was $26.4 \pm 8.7$ $\mathrm{M}^{-1} \mathrm{~s}^{-1}$ compared to $8.3 \pm 1.0 \mathrm{M}^{-1} \mathrm{~s}^{-1}$ for atrazine exposed to ozone alone. The higher $\mathrm{K}^{\prime}$ value in Experiment 6 correlates with the increased degradation of atrazine and ozone observed in Figure 7 and Figure 14. The increased K' value indicates atrazine was reacting more quickly when exposed to $\cdot \mathrm{OH}$. In Experiment 6, the degradation of the contaminant exposed to $\cdot \mathrm{OH}$ is expected to increase compared to systems with ozone alone. The increased K' values in Experiment 6 indicate the reaction with ozone and atrazine is occurring at a faster rate than in Experiment 4 , as a result of the $\cdot \mathrm{OH}$ formation.

The generation of $\cdot \mathrm{OH}$ by the AOP contributes to the increased degradation of atrazine. The $\mathrm{K}_{\mathrm{OH}}$ value can be used to predict the rate of the reaction between atrazine and $\bullet \mathrm{OH}$. The $\mathrm{K}_{\mathrm{OH}}$ values for atrazine from literature ranged from $2.4 \mathrm{x}$ 
$10^{9} \mathrm{M}^{-1} \mathrm{~s}^{-1}$ at pH 7.5 and $20^{\circ} \mathrm{C}$ (Mandal, 2018) to $3 \times 10^{9} \mathrm{M}^{-1} \mathrm{~s}^{-1}$ (Wert et al., 2009). The $\mathrm{K}_{\mathrm{OH}}$ value for atrazine is 9 orders of magnitude higher than the $\mathrm{K}_{\mathrm{O}}$ value which explains the rapid rate of reaction with $\cdot \mathrm{OH}$ and the faster degradation of atrazine and ozone observed with the AOP. This result supports that reaction rate constants can be useful tools in predicting the response of emerging contaminants to oxidative treatment.

\subsection{Phase 2 - Atrazine and Caffeine}

To model a more realistic water system, atrazine was exposed to treatment in conditions with increased competition. Caffeine was added to act as a competitor for the reaction. As displayed in the results of the caffeine experiments, caffeine was easily degraded by ozone within 5 minutes. Caffeine is also a ubiquitous contaminant in wastewater effluent and surface water; therefore, it will likely be present when treating other contaminants such as atrazine (Rosal et al., 2009). Atrazine showed a limited response to treatment with ozone and an improved response to the AOP. Since atrazine is known to be resistant to treatment, conditions with increased competition are likely to further reduce the degradation of atrazine by ozone and the AOP (Benotti et al., 2009). The addition of caffeine represents a more complex water system with increased competition for reactions. The series of experiments from Phase $1 \mathrm{~b}$ were repeated in this phase of experiments to determine the response of the atrazine/caffeine mixture to treatment with direct oxidation, sorption on $\mathrm{CNTs}$, and $\bullet \mathrm{OH}$. The results from these experiments were used to further evaluate the potential for atrazine to be 
used as an indicator compound for AOPs and for the reaction rate constants to predict the response of atrazine to treatment in systems with increased competition.

Atrazine and caffeine were exposed to treatment processes in experiments with ozone only (Experiment 7), CNTs only (Experiment 8), and the AOP with ozone and CNTs (Experiment 9). Two trials were performed for all three experiments. A $680 \mathrm{mg} / \mathrm{L}$ phosphate buffer solution was used in all experiments to maintain a neutral $\mathrm{pH}$ of 7 . All of the experiments were performed at approximately $20^{\circ} \mathrm{C}$. The initial concentration of caffeine was $10 \mathrm{mg} / \mathrm{L}$, atrazine was $10 \mathrm{mg} / \mathrm{L}$, and tertbutanol was $0.32 \mathrm{mM}$ for all three experiments. For experiments 7 and 9 , the initial ozone concentration was an average of $0.24 \mathrm{mM}$. Experiments 8 and 9 used a CNT concentration of $10 \mathrm{mg} / \mathrm{L}$. As with Phase $1 \mathrm{~b}$, results presented below were corrected to account for atrazine lost to sorption on the filter. The samples containing CNTs were filtered through $0.22 \mu \mathrm{m}$ nylon filter prior to analysis by the HPLC. The average amount of atrazine and caffeine that sorbed to the filters was measured. All of the data presented in Figure 15 and in the following discussion were corrected with the average sorption to the filters.

To determine the degradation of atrazine and caffeine by the AOP in a system with increased competition, the response of the contaminants to direct oxidation with ozone alone and sorption by CNTs alone was determined first. Then, atrazine and caffeine were exposed to the AOP and the removal achieved by the 
presence of $\cdot \mathrm{OH}$ was determined. The concentration of atrazine was measured, and the degradation of atrazine after exposure to the different treatments is displayed in Figure 15.

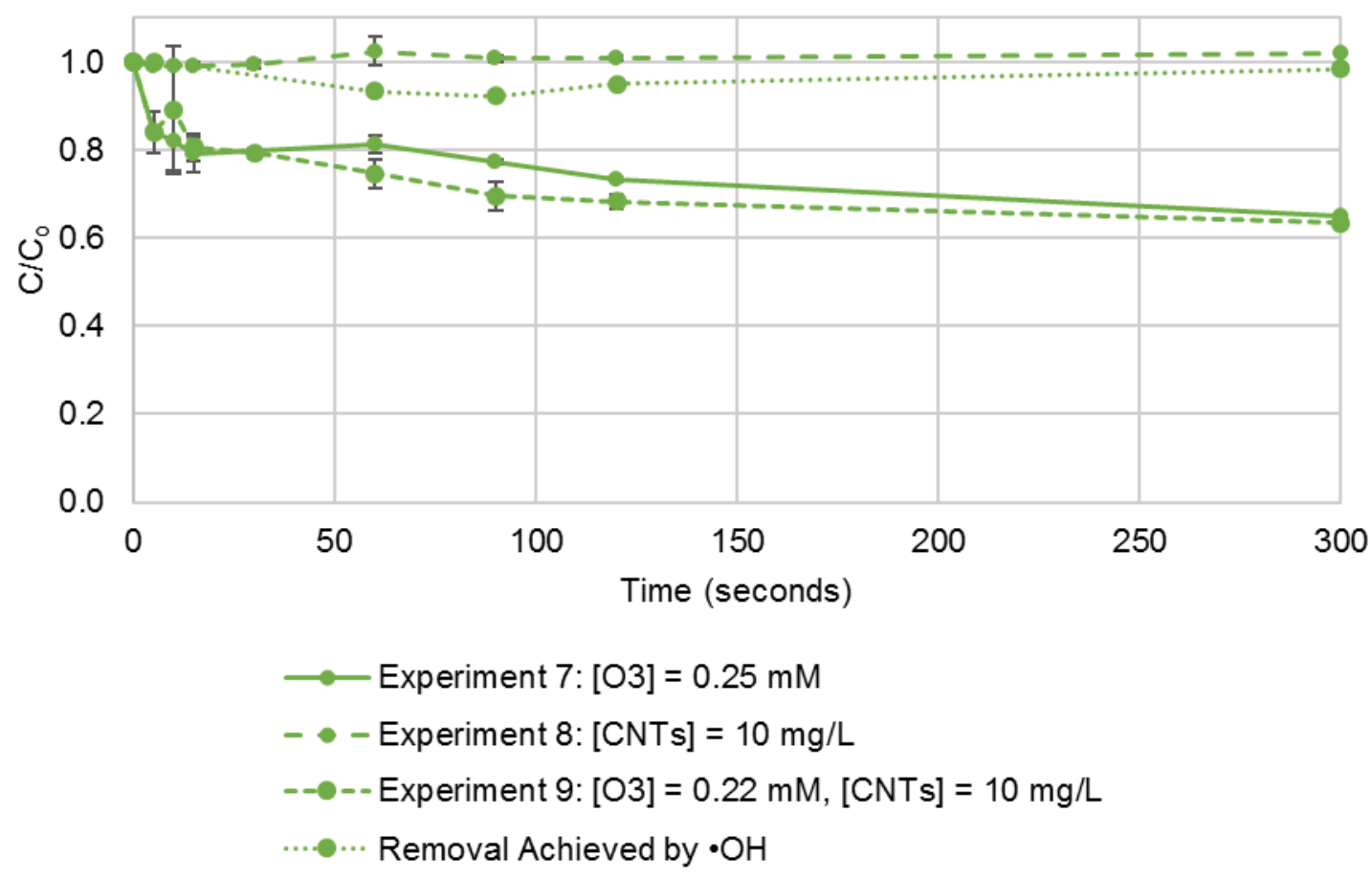

Figure 15: Atrazine concentration as a function of time in Experiment 7 (ozone only), 8 (CNTs only), and 9 (AOP with ozone and CNTs), and the removal achieved by the AOP via $\cdot O H$ with increased competition. Data represent averages and standard deviation from duplicate experiments. Experimental conditions: [atrazine] $=10 \mathrm{mg} / \mathrm{L}$, [caffeine] $=10 \mathrm{mg} / \mathrm{L}$, [tert-butanol] $=0.32 \mathrm{mM}, \mathrm{pH} 7(680 \mathrm{mg} / \mathrm{L}$ phosphate buffer $), T=20^{\circ} \mathrm{C}$.

After 15 seconds, the atrazine concentration was reduced by $21 \%$. The atrazine concentration was reduced by $27 \%$ after 120 seconds. The remaining atrazine concentration after exposure to treatment for 5 minutes was $65 \%$ of the initial concentration.

After 10 seconds, the atrazine concentration was reduced by $56 \%$ in Experiment 4 and was reduced by $18 \%$ in Experiment 7 . The increased competition in 
Experiment 7 reduced the degradation of atrazine via direct oxidation with ozone by $38 \%$. Compared to Experiment 4 with atrazine only, a higher overall removal of atrazine was achieved in Experiment 7 with atrazine and caffeine. Adding caffeine to the reactor was expected to reduce the degradation of atrazine, as caffeine provided competition for the reaction with ozone. However, in Experiment 7 with atrazine and caffeine, a $7 \%$ greater reduction of atrazine was observed. This unexpected result could be attributed to the misreading of the atrazine concentration in Experiment 4 because of the interference with breakdown products, from the previous section of results.

In Experiment 8, atrazine and caffeine were exposed to CNTs to determine if any sorption effects would occur. After 5 minutes, the atrazine concentration was $100 \%$ of the initial concentration. Therefore, none of the atrazine was removed by sorption onto the CNTs. This result matches that of Experiment 5 with atrazine only.

Atrazine and caffeine were exposed to ozone and CNTs in Experiment 9, to determine the efficacy of the AOP in a system with increased competition. All of the samples taken from Experiment 9 were filtered, and the data were corrected with the average sorption to the filters. After 5 minutes, the remaining atrazine concentration was $63 \%$ of the initial concentration. Overall, the AOP increased the degradation of atrazine in Experiment 9 by $2 \%$ compared to the ozone-only system in Experiment 7. 
When comparing the AOP systems in Experiments 6 and 9, atrazine was degraded to a greater extent in the reactor without increased competition. The increased competition was expected to reduce the degradation of atrazine, and the expected result was observed in the measured data. After 5 minutes of exposure to the AOP, atrazine was degraded by $51 \%$ in Experiment 6 and by $37 \%$ in Experiment 9. The addition of caffeine resulted in a $14 \%$ increase in the remaining atrazine concentration. Therefore, the introduction of increased competition can significantly affect the ability of a compound to degrade in a treatment system.

Since the AOP did not result in a significant increase in the degradation of atrazine from Experiment 7 to Experiment 9, the removal achieved by the $\cdot \mathrm{OH}$ alone was minimal. The increased competition reduced the removal of atrazine achieved by $\cdot \mathrm{OH}$. The removal from ozone alone was subtracted from the concentration of atrazine after exposure to the AOP, and the degradation curve representing the additional removal achieved by $\bullet \mathrm{OH}$ was included in Figure 15. After 5 minutes, $\bullet \mathrm{OH}$ contributed to a $2 \%$ reduction in atrazine concentration, while ozone alone contributed to the $35 \%$ reduction in atrazine concentration. In Experiment 6 without caffeine, $\cdot \mathrm{OH}$ contributed to a $23 \%$ reduction in atrazine concentration compared to the $2 \%$ reduction achieved by $\bullet \mathrm{OH}$ in Experiment 9 with caffeine. The additional competition with caffeine significantly reduced the amount of removal achieved by $\cdot \mathrm{OH}$, likely because caffeine consumed the ozone leaving it unavailable to react with $\mathrm{CNTs}$ to form $\bullet \mathrm{OH}$. 
The results of this experiment further justify the use of atrazine as an indicator compound. With the increased competition, atrazine displayed a limited response to treatment by direct oxidation and a slightly increased degradation with the AOP. Based on these results, atrazine has shown to be recalcitrant to treatment and is increasingly resistant to treatment with increased competition. Therefore, atrazine has the potential to be representative of contaminants in more complex real water systems and their response to AOPs.

\subsubsection{Reaction Rate Constants}

To determine the reaction rate constants (Kо3 values) for atrazine exposed to ozone with increased competition, the degradation of ozone was measured for Experiments 7 and 9 . Figure 16 shows ozone degrading more quickly in Experiment 9 compared to Experiment 7 . The ozone concentration was reduced by $35 \%$ for Experiment 7 and by $47 \%$ for Experiment 9 after 60 seconds. The remaining ozone concentration after 5 minutes was $38 \%$ and $30 \%$ of the initial concentration for Experiment 7 and 9 respectively. The presence of CNTs with ozone in Experiment 9 resulted in a faster degradation of ozone, likely due to the reactions with CNTs to form $\cdot \mathrm{OH}$. 


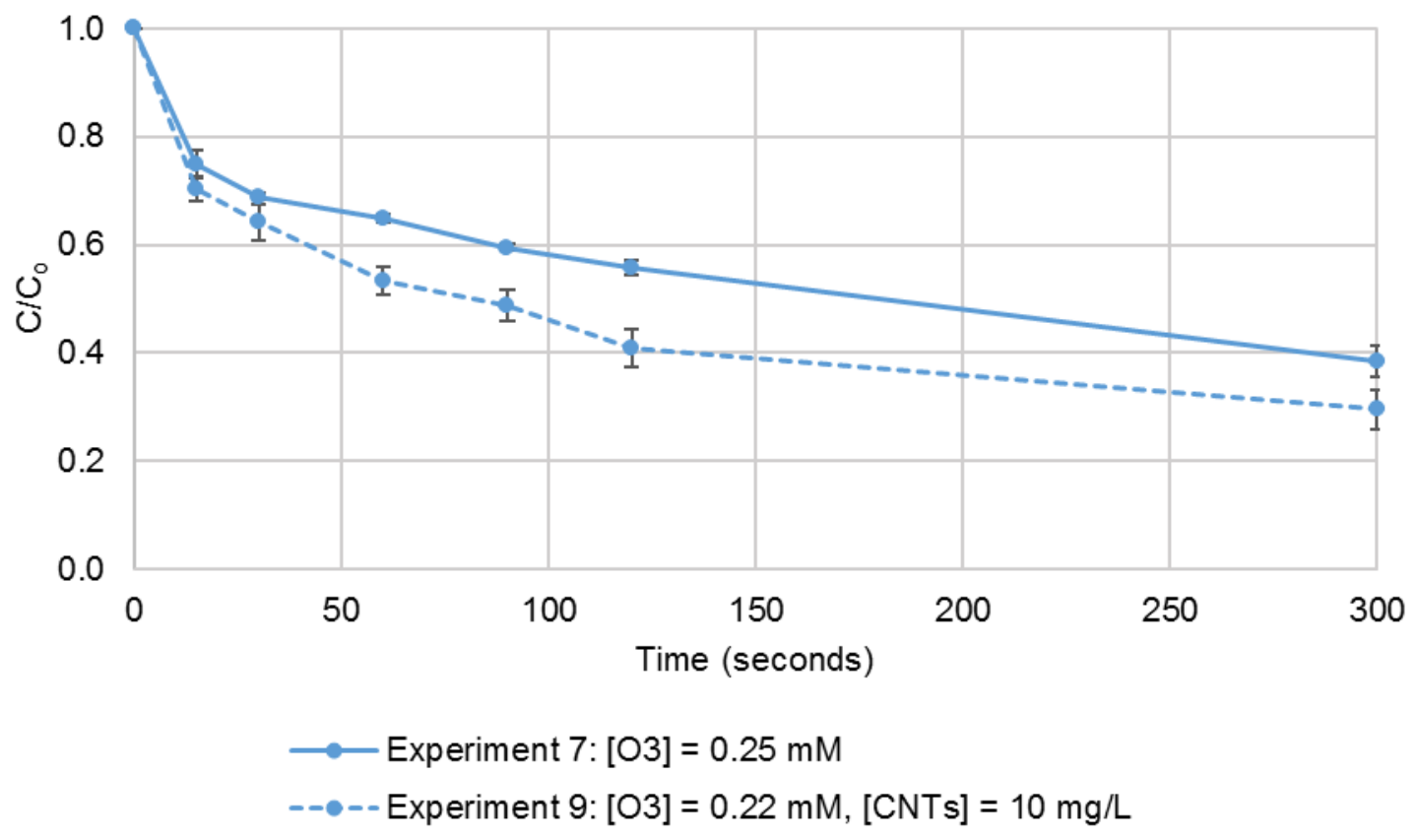

Figure 16: Ozone concentration as a function of time in Experiment 7 (ozone only) and 9 (AOP with ozone and CNTs) with increased competition. Data represent averages and standard deviation from duplicate experiments. Experimental conditions: [atrazine] $=10 \mathrm{mg} / \mathrm{L}$, [caffeine] $=10 \mathrm{mg} / \mathrm{L}$, [tert-butanol] $=0.32 \mathrm{mM}, \mathrm{pH} 7(680 \mathrm{mg} / \mathrm{L}$ phosphate buffer $), T=20^{\circ} \mathrm{C}$

From the reactors with increased competition, the measured atrazine and ozone concentrations were used to generate the plots in Appendix B. The $\mathrm{K}_{03}$ and $\mathrm{K}^{\prime}$ values for atrazine were obtained from the gradient of the trendlines in the plots. These $\mathrm{K}_{03}$ values are specific to the degradation of atrazine after exposure to ozone in a reactor with caffeine. Comparing these $\mathrm{K}_{03}$ values to the $\mathrm{K}_{03}$ values for atrazine without competition will give an indication of the reaction rate of atrazine in a system with increased competition.

Table 4 contains the $\mathrm{K}_{03}$ values from each trial and the average with the standard deviation. The average $\mathrm{K}_{03}$ value for the degradation of atrazine in Experiment 7 was $9.2 \pm 0.8 \mathrm{M}^{-1} \mathrm{~s}^{-1}$. Compared to Experiment 4 without 
competition, the average $\mathrm{K}_{03}$ value with competition was $0.9 \mathrm{M}^{-1} \mathrm{~s}^{-1}$ higher. With increased competition, atrazine was expected to degrade less and have a lower $\mathrm{K}_{\mathrm{O} 3}$ value. From the measured data, atrazine experienced an overall greater reduction in the system with caffeine which was an unexpected result. This unexpected result could be attributed to the inaccurate estimation of the atrazine concentration by the HPLC detection in the reactor without increased competition. However, the higher $\mathrm{K}_{03}$ value for atrazine in the system with increased competition is likely to have been caused by the increased degradation of ozone. The more rapid degradation of ozone resulted in a smaller time integrated ozone concentration and more steep trendline for the plots used to calculate the $\mathrm{K}_{03}$ values which equates to a higher $\mathrm{K}_{03}$ value for atrazine.

Table 4: Second-order Kоз values $\left(M^{-1} \mathrm{~s}^{-1}\right)$ for atrazine and caffeine exposed to ozone

\begin{tabular}{|c|c|}
\hline Trial & Experiment 7 \\
\hline 1 & 9.7 \\
\hline 2 & 8.6 \\
\hline Average & $9.2 \pm 0.8$ \\
\hline
\end{tabular}

Determining the $\mathrm{K}_{03}$ value for atrazine independently in a system containing caffeine introduces a level of uncertainty. This method of calculating $\mathrm{K}_{\mathrm{O}}$ values does not account for the ozone degradation caused by the reaction with caffeine which affects the reaction rate obtained for atrazine. The $\mathrm{K}_{03}$ values were calculated for each trial to be compared to the trials for the other reactors. Using 
the calculated $\mathrm{K}_{03}$ values provides a valid means of comparing the degradation of atrazine and ozone from the different treatment systems.

Following the procedure in Phase 1b, the $\mathrm{K}^{\prime}$ value for atrazine in Experiment 9 was calculated to represent the degradation of atrazine after exposure to $\cdot \mathrm{OH}$. The plots for Experiment 9 are displayed in Appendix B. The K' values from the gradient of the trendline for each trial and the average with the standard deviation were summarized in Table 5. After exposure to the AOP in Experiment 9, the average $\mathrm{K}^{\prime}$ value for atrazine was $13.0 \pm 0.4 \mathrm{M}^{-1} \mathrm{~s}^{-1}$. Compared to the $\mathrm{K}_{\mathrm{O} 3}$ value from Experiment 7 with ozone only, the $\mathrm{K}^{\prime}$ value was $3.8 \mathrm{M}^{-1} \mathrm{~s}^{-1}$ higher for the AOP. The system in Experiment 9 was expected to increase the degradation of atrazine compared to Experiment 7 which corresponds to the increased $K^{\prime}$ value. While the AOP in Experiment 9 did not result in a significant reduction in atrazine concentration compared to ozone alone in Experiment 7, the $\mathrm{K}^{\prime}$ value is higher which indicates a faster reaction rate. The increased degradation of ozone in Experiment 9 also contributed to the increased $\mathrm{K}^{\prime}$ value for atrazine.

Table 5: Second-order $K^{\prime}$ values $\left(M^{-1} s^{-1}\right)$ for atrazine and caffeine exposed to $\cdot \mathrm{OH}$

\begin{tabular}{|c|c|}
\hline Trial & Experiment 9 \\
\hline $\mathbf{1}$ & 12.8 \\
\hline $\mathbf{2}$ & 13.3 \\
\hline Average & $\mathbf{1 3 . 0 \pm 0 . 4}$ \\
\hline
\end{tabular}


The $\mathrm{K}^{\prime}$ value for atrazine exposed to the AOP was $26.4 \pm 8.7 \mathrm{M}^{-1} \mathrm{~s}^{-1}$ in Experiment 6 compared to $13.0 \pm 0.4 \mathrm{M}^{-1} \mathrm{~s}^{-1}$ in Experiment 9. The addition of caffeine was expected to reduce the reaction rate for atrazine, and the $\mathrm{K}^{\prime}$ value was reduced by $13.4 \mathrm{M}^{-1} \mathrm{~s}^{-1}$. The lower $\mathrm{K}^{\prime}$ value corresponds with the lower reduction in atrazine concentration observed for Experiment 9. Caffeine competes with atrazine for the reaction with ozone, and since caffeine is more easily degraded than atrazine, it is more likely to react with ozone first. While the K' values calculated from the experimental results are unique to the specific conditions of the reactors tested, they can be used to predict how a contaminant will respond to treatment in a system with increasing competition.

Compared to the $\mathrm{K}_{03}$ value for caffeine exposed to ozone, the $\mathrm{K}_{03}$ value for atrazine was significantly lower. The average $\mathrm{K}_{03}$ value for caffeine was $334 \pm 67$ $\mathrm{M}^{-1} \mathrm{~s}^{-1}$ which was more than $300 \mathrm{M}^{-1} \mathrm{~s}^{-1}$ higher than the $\mathrm{K}_{03}$ values calculated for atrazine. When comparing the $\mathrm{K}_{03}$ values for caffeine and atrazine, caffeine is more reactive with ozone and is expected to degrade before atrazine. The experimental results support this hypothesis because the addition of caffeine caused atrazine to degrade to lesser extent. In the system with caffeine and atrazine, caffeine was degraded completely when exposed to ozone, as displayed in Figure 17. 


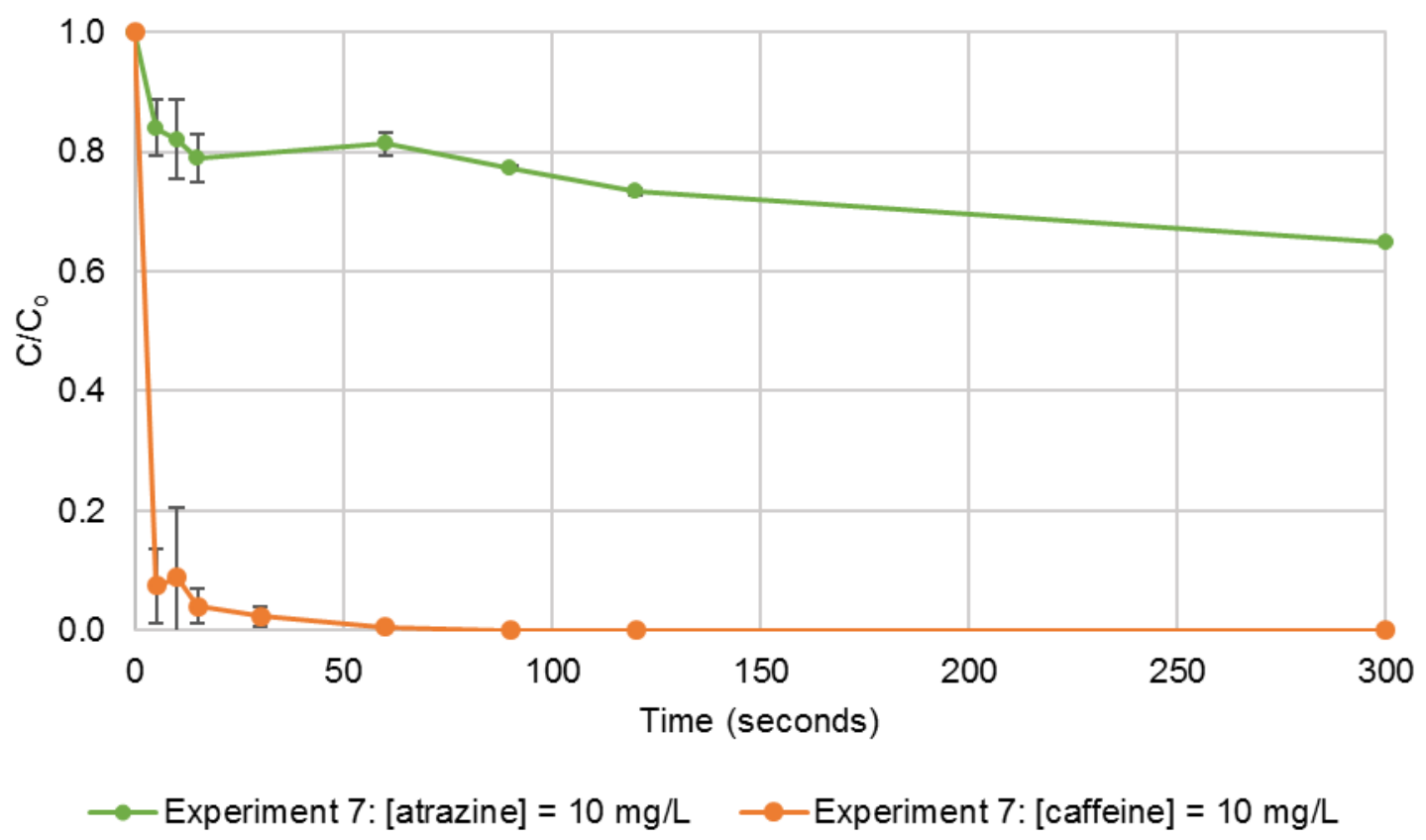

Figure 17: Atrazine and caffeine concentration as a function of time in Experiment 7 (ozone only) with increased competition. Data represent averages and standard deviation from duplicate experiments. Experimental conditions: [atrazine] $=10 \mathrm{mg} / \mathrm{L}$, [caffeine] $=10 \mathrm{mg} / \mathrm{L}$, [tert-butanol] $=0.32 \mathrm{mM},\left[\mathrm{O}_{3}\right]=0.25 \mathrm{mM}, \mathrm{pH} 7(680 \mathrm{mg} / \mathrm{L}$ phosphate buffer $), T=20^{\circ} \mathrm{C}$.

Caffeine created competition for the reaction with ozone which left it unavailable to form $\cdot \mathrm{OH}$ to degrade atrazine. Ozone was consumed to reduce the caffeine concentration to $0 \%$ of the initial concentration. Atrazine was degraded by approximately $35 \%$, but remained in the system after 5 minutes of exposure to treatment. Both the experimental results and the calculated $\mathrm{K}_{03}$ values for caffeine and atrazine reflect the expected degradation for these compounds in a combined system. The combination of caffeine and atrazine is more representative of real water systems where many compounds will be present and competing for reactions. In this system with increased competition, the more easily degraded compound, caffeine, degraded first leaving the more difficult to degrade compound, atrazine, untreated. The results of this experiment display 
the effect increased competition has on the efficacy of treatment processes for removing recalcitrant compounds such as atrazine.

\subsection{Phase 3 - Phenytoin Only}

Phenytoin is known to be recalcitrant to ozone treatment, and therefore, has potential to serve as an indicator compound for AOPs (Benotti et al., 2009; Oulton et al., 2010). In this phase of experiments, phenytoin was exposed to ozone alone (Experiment 10), CNTs alone (Experiment 11), and the AOP with ozone and CNTs (Experiment 12) to determine its response to treatment. Two trials were performed for all three experiments. A $680 \mathrm{mg} / \mathrm{L}$ phosphate buffer solution was used in all experiments to maintain a neutral $\mathrm{pH}$ of 7 . All of the experiments were performed at approximately $20^{\circ} \mathrm{C}$. The initial concentration of phenytoin was $10 \mathrm{mg} / \mathrm{L}$ and tert-butanol was $0.32 \mathrm{mM}$ for all three experiments. For Experiments 10 and 12, the initial ozone concentration was an average of $0.19 \mathrm{mM}$. Experiments 11 and $12 \mathrm{had}$ a CNT concentration of $10 \mathrm{mg} / \mathrm{L}$.

The samples containing CNTs were filtered through $0.22 \mu \mathrm{m}$ nylon filter prior to analysis by the HPLC. The average amount of phenytoin that sorbed to the filters was measured to be approximately $78 \%$ of the initial concentration. Since a majority of the phenytoin sample was sorbed to the filter, a large degree of error was introduced which reduced the reliability of the results. 
In an attempt to reduce the error introduced by the sorption effect for phenytoin, $0.22 \mu \mathrm{m}$ PFTE filters were used. The PFTE filters are designed to be nonreactive with compounds; however, $63 \%$ of the initial phenytoin concentration was sorbed. The sorption to the PFTE filters was reduced compared to the nylon filters, but the reduction was not significant enough to greatly improve the phenytoin results. This experiment demonstrated the reactivity of phenytoin with two different and supposedly non-reactive filter materials. The sorption of phenytoin to the filters suggests that filtration could be a more feasible treatment method than AOPs for removing this emerging contaminant from water. According to the reaction mechanisms of phenytoin explained in Chapter 2, phenytoin is broken down via metabolism, then the metabolites are absorbed from the intestinal tract of humans (Ohnmacht et al., 2006). Since phenytoin functions effectively as a pharmaceutical by being absorbed by human tissues, the compound is suspected to have a high sorptive capacity (Ohnmacht et al., 2006). The results of this experiment demonstrate the high sorptive capacity of phenytoin to the filters which supports the findings on the reaction mechanisms of phenytoin in literature.

With the sizeable error caused by the sorption effect, the results of this experiment do not definitively quantify the removal of phenytoin achieved by oxidative treatment. The results from these experiments are presented in Appendix C. 
Based on the findings of this experiment, phenytoin was not degraded by ozone, and a $\mathrm{K}_{\mathrm{O} 3}$ value could not be calculated. After reviewing the literature, a $\mathrm{K}_{\mathrm{O} 3}$ value for phenytoin was not found because other studies have found phenytoin to be recalcitrant to ozone treatment. The literature $\mathrm{K}_{\mathrm{OH}}$ value found for phenytoin is $6.28 \times 10^{9} \mathrm{M}^{-1} \mathrm{~s}^{-1}$ (Yuan et al., 2009). Compared to the $\mathrm{KoH}_{\mathrm{oH}}$ value for atrazine, the $\mathrm{K}_{\mathrm{OH}}$ value for phenytoin is higher by approximately $3 \times 10^{9} \mathrm{M}^{-1} \mathrm{~s}^{-1}$. The lower $\mathrm{K}_{\mathrm{OH}}$ value for atrazine compared to phenytoin does not reflect the experimental data obtained because atrazine was more responsive to treatment by $\cdot \mathrm{OH}$ than phenytoin. Since the $\mathrm{K}_{\mathrm{OH}}$ values found in literature do not correspond to the trends of the experimental results, these values might not be accurate indicators of the reactivity of the compounds tested. 


\section{Chapter 5 - Conclusions and Future Work}

Conclusions were drawn based on the results of this study and were evaluated for their ability to address the original research objectives. Areas of further study were also identified and recommendations for future work were made.

\subsection{Conclusions}

Overall, exposing caffeine to ozone resulted in a reduction in caffeine concentration by approximately $90 \%$ or better. Increased competition caused the caffeine and ozone concentrations to degrade more slowly with average $\mathrm{K}_{\mathrm{O} 3}$ values for caffeine decreasing from $334 \pm 67 \mathrm{M}^{-1} \mathrm{~s}^{-1}$ to $222 \pm 71 \mathrm{M}^{-1} \mathrm{~s}^{-1}$ as tertbutanol concentrations increased and ozone was consumed by the other compounds present. Tert-butanol was more easily degraded than caffeine as indicated by the reduced degradation and lower $\mathrm{K}_{03}$ values for caffeine. The $\mathrm{K}_{03}$ values were within the range of literature values (Broséus et al., 2009) which validates the experimental methods. Therefore, these $\mathrm{K}_{03}$ values reflect the likelihood of caffeine to degrade when exposed to ozone.

Atrazine was exposed to treatment with ozone and the AOP. After exposure to ozone, the atrazine concentration was reduced by approximately $28 \%$. A large concentration of breakdown products appeared to form when atrazine was exposed to ozone. The detection of those breakdown products could have interfered with the measurement of the atrazine concentration and affected further results. When exposed to the AOP, atrazine degraded by $51 \%$, and $\cdot \mathrm{OH}$ 
were calculated to have contributed to $23 \%$ of the reduction. The degradation of ozone was also increased from $52 \%$ with ozone alone to $72 \%$ with the AOP. The increased degradation of ozone in the presence of CNTs indicates the formation of $\bullet \mathrm{OH}$ and the more rapid degradation of contaminants compared to ozone alone.

Caffeine was added to the reactor with atrazine to reflect a more complex water system with increased competition. Atrazine was degraded by $35 \%$ after exposure to ozone which was a $7 \%$ increase compared to the system without caffeine. This unexpected result is likely the outcome of the misreading of the atrazine concentration caused by the interference with the breakdown products. After exposure to ozone and CNTs, the atrazine concentration was reduced by $37 \%$, approximately the same as the ozone-only system. The addition of caffeine reduced the degradation of atrazine by the AOP by $14 \%$ compared to the system without caffeine. In the experiment with the AOP, ozone degraded by $70 \%$ compared to the $62 \%$ reduction with ozone alone. Therefore, caffeine likely consumed a portion of the ozone leaving it unavailable for reaction to form sufficient $\bullet \mathrm{OH}$ to degrade atrazine.

The average $\mathrm{K}_{03}$ values for atrazine were calculated for the different reactor condition and compared to literature values. For the reactor with ozone alone, the average $\mathrm{K}_{03}$ value for atrazine was $8.3 \pm 1.0 \mathrm{M}^{-1} \mathrm{~s}^{-1}$. The experimental $\mathrm{K}_{03}$ value was approximately $2.3 \mathrm{M}^{-1} \mathrm{~s}^{-1}$ higher than the literature value (Wert et al., 2009) 
which further confirms the validity of the methods used. In the reactor with caffeine, the $\mathrm{K}_{03}$ value for atrazine was $9.2 \pm 0.8 \mathrm{M}^{-1} \mathrm{~s}^{-1}$ which is unexpectedly higher than the system without increased competition. The increase in $\mathrm{K}_{03}$ value is a result of the suspected misreading of the atrazine concentration in the reactor without caffeine or from the increased degradation of ozone. The $\mathrm{K}^{\prime}$ values for atrazine were calculated for the systems exposed to the AOP to predict the degradation achieved by ozone and to determine if a trend in the reaction rate constants could be seen. In the systems with $\bullet \mathrm{OH}$, the $\mathrm{K}^{\prime}$ values were higher than the reactors with ozone alone, as expected. Compared to the ozone-only systems, the $\mathrm{K}^{\prime}$ values were higher for the AOP systems because ozone was reacting with $\mathrm{CNTs}$ to form $\bullet \mathrm{OH}$ and with atrazine. The addition of caffeine to the reactor with the AOP caused the $\mathrm{K}^{\prime}$ value for atrazine to decrease as a result of caffeine consuming ozone leaving it unavailable to react with CNTs to form $\bullet \mathrm{OH}$ and degrade atrazine.

Phenytoin was also exposed to ozone and the AOP with ozone and CNTs to determine its response to treatment. After 5 minutes of exposure to ozone, phenytoin was not degraded; therefore, a Ko3 value could not be calculated. The results of this experiment support the theory that phenytoin is recalcitrant to treatment with ozone. Phenytoin was exposed to CNTs alone and the AOP; however, a large sorption effect between phenytoin and the filters used to remove the suspended CNTs from the samples was discovered. Correcting the data for the sorption effect introduced a sizeable error into the data. 
Consequently, the results of the phenytoin experiment were inconclusive because the reduction in the phenytoin concentration for the AOP may have been caused by both the $\cdot \mathrm{OH}$ and the sorption effect.

\subsection{Research Objectives}

One objective of this study was to explore the ability and limitation of the AOP with ozone and CNTs to remove recalcitrant emerging contaminants. Caffeine was found to be easily degraded by ozone and was not exposed to the AOP. Atrazine was not fully degraded by ozone alone, and a greater level of removal was achieved by the AOP. The result of the experiments with atrazine demonstrate the ability of the AOP to improve effluent water quality and remove a contaminant that would not be removed through direct oxidation. Phenytoin was found to be recalcitrant to treatment with ozone and slightly responsive to treatment with the AOP. However, the results for phenytoin contained a large degree of error. Overall, the AOP tested through this experiment proved to be effective and shows promise for treating recalcitrant emerging contaminants.

Another goal of this study was to determine if specific ubiquitous and recalcitrant emerging contaminants can serve as indicator compounds that represent the efficacy of an AOP. Caffeine, atrazine, and phenytoin were selected as potential indicator compounds based on their ubiquity and recalcitrance to direct oxidation. Since caffeine was easily degraded by ozone alone, it cannot serve as an indicator for compounds that are resistant to treatment with ozone. Atrazine has 
potential to be a representative indicator compound based on its response to treatment observed in this experiment. Phenytoin has limited potential to be used as an indicator compound to represent the efficacy of an AOP. Based on the results of this experiment, phenytoin resisted treatment by ozone, experienced minimal treatment by the AOP, and sorbed easily to the filters used to remove CNTs from the samples. The sorption effect for phenytoin suggests that filtration may be a more appropriate treatment method for removing phenytoin than an AOP.

The third objective of this study was to determine if the reaction rate constant for a compound reflects how it will respond to treatment and how it will react in a system with a variety of contaminants present. Since wastewater, surface water, and drinking water contain a number of contaminants that compete for the reaction with a treatment process like ozone, increased competition was added to the reactors to simulate more realistic water systems. The observed trend in $\mathrm{K}_{03}$ values reflects the experimental results and demonstrates the ability of $\mathrm{K}_{03}$ values to predict how contaminants will respond in a system with increased competition. Based on the findings of this study, $\mathrm{K}_{03}$ values can be used to predict the progression in which different contaminants will degrade when exposed to ozone in a real water system with competition for the reaction.

The results of this study did not find a similar correlation between the degradation of contaminants after exposure to $\cdot \mathrm{OH}$ and the $\mathrm{K}_{\mathrm{OH}}$ values found in literature. 
Previous studies using simple systems had found a positive correlation between $\mathrm{K}_{\mathrm{OH}}$ values and response to AOPs (Oulton, 2013). However, in complex water systems, $\mathrm{K}_{\mathrm{OH}}$ values may not be accurate indicators of how a contaminant will respond to treatment with $\cdot \mathrm{OH}$.

\subsection{Future Work}

Several recommendations for future work resulted from the completion of this study. One area in need of further study is how to modify the AOP studied to be implemented on a larger scale. The experiments performed in this study were conducted in small reactors which were not representative of full-scale treatment systems. A continuous reactor with a constant ozone concentration would more accurately represent the functioning of the AOP and could help optimize the conditions for removing contaminants. The method of incorporating CNTs into the treatment process could also be further refined. In this study, the CNTs were suspended in the reactor which required filtration of the effluent. The suspended CNTs also aggregated as the contents of the reactor were mixed, which could have reduced their effectiveness. Developing a method of exposing contaminants to CNTs without suspending them in water would be essential for the implementation of this AOP in full scale systems. Oulton (2013) recommended the use of a hybrid CNT/ceramic filter system that would retain CNTs while allowing water to pass through. A filter system would simultaneously expose water to CNTs and ozone creating a $\cdot \mathrm{OH}$-rich environment for treatment (Oulton, 2013). 
Another aspect of this study that could be further researched are the breakdown products formed by the degradation of emerging contaminants. In the experiments with atrazine, a large concentration of breakdown products was suspected to have formed. Standards are available for the breakdown products of atrazine which could be used to identify the compounds and measure their concentration after exposure to treatment. A study could be conducted to determine if the AOP achieves complete removal of a contaminant such as atrazine and its associated breakdown products. Studying the removal of breakdown products will give a better understanding of the overall removal efficacy achieved by the treatment process.

Based on the results obtained for phenytoin in this study, further sorption studies could be conducted with phenytoin. Since phenytoin easily sorbed to both the nylon and PFTE filters, it is likely to respond to treatment with standard water filters. A further literature review could be conducted on the removal of phenytoin achieved by filtration processes. Phenytoin also has the potential to sorb to other media such as activated carbon. An additional study could be performed with activated carbon to determine the likelihood of phenytoin to be removed through sorption.

The different responses to treatment displayed by the compounds in this study are a product of the wide range of complex properties associated with emerging contaminants. Different types of emerging contaminants will respond better to 
some treatment technologies than others. Therefore, there is not one treatment solution that can be implemented to address all of the various emerging contaminants that may be present in water. Further studies could be conducted to determine if a correlation between emerging contaminants from the same class (i.e. pharmaceuticals or pesticides) exists. The results of this type of study could be used to implement appropriate treatment processes based on the class of emerging contaminants being targeted.

Additionally, reaction rate constants for emerging contaminants and their ability to predict how a compound will respond to treatment could be further studied. Following the methods used in this experiment, different compounds could be exposed to treatment and their $\mathrm{K}_{\mathrm{O} 3}$ values could be calculated. The $\cdot \mathrm{OH}$ concentration could be measured and used to calculate $\mathrm{K}_{\mathrm{OH}}$ values for different emerging contaminants. An experiment could also be designed to isolate the $\cdot \mathrm{OH}$ effect to determine if there is improved removal of recalcitrant compounds. Further study of specific compounds and their reaction rate constants could be used to determine if there is a correlation between $\mathrm{K}_{03}$ or $\mathrm{K}_{\mathrm{OH}}$ values and the degradation after exposure to treatment with ozone and $\bullet \mathrm{OH}$. Contaminants that support the correlation between responsiveness to treatment and their corresponding reaction rate constant could be tested in complex water systems with increased competition to determine which contaminants will degrade first or resist treatment. In the absence of effective indicator compounds, developing the 
ability to predict how compounds will respond to treatment could be used to determine the expected removal efficiency of AOPs for real water systems. 


\section{References}

Almomani, F. A., Shawaqfah, M., Bhosale, R. R., \& Kumar, A. (2016). Removal of Emerging Pharmaceuticals from Wastewater by Ozone-Based Advanced Oxidation Processes. Environmental Progress \& Sustainable Energy, 35(4), 982-995. https://doi.org/10.1002/ep

Aymerich, I., Acuna, V., Barcelo, D., Garcia, M. J., Petrovic, M., Poch, M., ... Corominas, L. (2016). Attenuation of pharmaceuticals and their transformation products in a wastewater treatment plant and its receiving river ecosystem. Water Research, 100, 126-136.

https://doi.org/10.1016/j.watres.2016.04.022

Belgiorno, V., Rizzo, L., Fatta, D., Della Rocca, C., Lofrano, G., Nikolaou, A., ... Meric, S. (2007). Review on endocrine disrupting-emerging compounds in urban wastewater: occurrence and removal by photocatalysis and ultrasonic irradiation for wastewater reuse. Desalination, 215(1-3), 166-176.

https://doi.org/10.1016/j.desal.2006.10.035

Bell, K., Antolovich, A., Funk, D., Hooper, J., Minton, J., \& Schimmoller, L. (2016). Ozone biologically active filtration - an alternative treatment for potable reuse. World Water: Water Reuse \& Desalination, 27-30.

Benotti, M. J., Trenholm, R. A., Vanderford, B. J., Holady, J. C., Stanford, B. D., \& Snyder, S. A. (2009). Pharmaceuticals and Endocrine Disrupting Compounds in U.S. Drinking Water. Environmental Science \& Technology, 43(3), 597-603. https://doi.org/10.1021/es801845a

Boleda, M. R., Galceran, M. T., \& Ventura, F. (2011). Behavior of 
pharmaceuticals and drugs of abuse in a drinking water treatment plant (DWTP) using combined conventional and ultrafiltration and reverse osmosis (UF/RO) treatments. Environmental Pollution, 159(6), 1584-1591. https://doi.org/10.1016/j.envpol.2011.02.051

Bolong, N., Ismail, A. F., Salim, M. R., \& Matsuura, T. (2009). A review of the effects of emerging contaminants in wastewater and options for their removal. Desalination, 238(1-3), 229-246.

https://doi.org/10.1016/j.desal.2008.03.020

Broséus, R., Vincent, S., Aboulfadl, K., Daneshvar, A., Sauvé, S., Barbeau, B., \& Prévost, M. (2009). Ozone oxidation of pharmaceuticals, endocrine disruptors and pesticides during drinking water treatment. Water Research, 43(18), 4707-4717. https://doi.org/10.1016/j.watres.2009.07.031

Clara, M., Strenn, B., Gans, O., Martinez, E., Kreuzinger, N., \& Kroiss, H. (2005). Removal of selected pharmaceuticals, fragrances and endocrine disrupting compounds in a membrane bioreactor and conventional wastewater treatment plants. Water Research, 39(19), 4797-4807. https://doi.org/10.1016/j.watres.2005.09.015

Dalmazio, I., Santos, L. S., Lopez, R. P., Eberlin, M. N., \& Augusti, R. (2005). Advanced Oxidation of Caffeine in Water: On-Line and Real-Time Monitoring by Electrospray Ionization Mass Spectrometry. Environmental Science and Technology, 39(16), 5982-5988. https://doi.org/10.1021/es047985v

Deeb, A. A., Stephan, S., Schmitz, O. J., \& Schmidt, T. C. (2017). Suspect 
screening of micropollutants and their transformation products in advanced wastewater treatment. Science of The Total Environment, 601-602, 12471253. https://doi.org/10.1016/j.scitotenv.2017.05.271

Esplugas, S., Bila, D. M., Krause, L. G. T., \& Dezotti, M. (2007). Ozonation and advanced oxidation technologies to remove endocrine disrupting chemicals (EDCs) and pharmaceuticals and personal care products (PPCPs) in water effluents. Journal of Hazardous Materials, 149(3), 631-642.

https://doi.org/10.1016/j.jhazmat.2007.07.073

Fan, X., Restivo, J., Órfão, J. J. M., Pereira, M. F. R., \& Lapkin, A. A. (2014). The role of multiwalled carbon nanotubes (MWCNTs) in the catalytic ozonation of atrazine. Chemical Engineering Journal, 241, 66-76.

https://doi.org/10.1016/j.cej.2013.12.023

Garcia-Ivars, J., Dura-Maria, J., Moscardo-Carreno, C., Carbonell-Alcaina, C., Alcaina-Miranda, M. I., \& Iborra-Clar, M. I. (2017). Rejection of trace pharmaceutically active compounds present in municipal wastewaters using ceramic fine ultrafiltration membranes: Effect of feed solution $\mathrm{pH}$ and fouling phenomena. Separation and Purification Technology, 175, 58-71. https://doi.org/10.1016/j.seppur.2016.11.027

Glassmeyer, S. T., Furlong, E. T., Kolpin, D. W., Batt, A. L., Benson, R., Boone, J. S., ... Wilson, V. S. (2017). Science of the Total Environment Nationwide reconnaissance of contaminants of emerging concern in source and treated drinking waters of the United States. Science of the Total Environment, 581582, 909-922. https://doi.org/10.1016/j.scitotenv.2016.12.004 
Hernández, F., Sancho, J. V., Ibáñez, M., \& Grimalt, S. (2008). Investigation of pesticide metabolites in food and water by LC-TOF-MS. TrAC - Trends in Analytical Chemistry, 27(10), 862-872.

https://doi.org/10.1016/j.trac.2008.08.011

Huerta-Fontela, M., Galceran, M. T., \& Ventura, F. (2011). Occurrence and removal of pharmaceuticals and hormones through drinking water treatment. Water Research, 45(3), 1432-1442.

https://doi.org/10.1016/j.watres.2010.10.036

Huesgen, A. G. (n.d.). Agilent 1220 Infinity LC Application Compendium.

Jelic, A., Gros, M., Ginebreda, A., Cespedes-Sánchez, R., Ventura, F., Petrovic, M., \& Barcelo, D. (2011). Occurrence, partition and removal of pharmaceuticals in sewage water and sludge during wastewater treatment. Water Research, 45(3), 1165-1176.

https://doi.org/10.1016/j.watres.2010.11.010

Karelid, V., Larsson, G., \& Bjorlenius, B. (2017). Pilot-scale removal of pharmaceuticals in municipal wastewater: Comparison of granular and powdered activated carbon treatment at three wastewater treatment plants. Journal of Environmental Management, 193, 491-502. https://doi.org/10.1016/j.jenvman.2017.02.042

Klavarioti, M., Mantzavinos, D., \& Kassinos, D. (2009). Removal of residual pharmaceuticals from aqueous systems by advanced oxidation processes. Environment International, 35(2), 402-417. https://doi.org/10.1016/j.envint.2008.07.009 
Knopp, G., Prasse, C., Ternes, T. A., \& Cornel, P. (2016). Elimination of micropollutants and transformation products from a wastewater treatment plant effluent through pilot scale ozonation followed by various activated carbon and biological filters. Water Research, 100, 580-592. https://doi.org/10.1016/j.watres.2016.04.069

Lee, Y., \& von Gunten, U. (2010). Oxidative transformation of micropollutants during municipal wastewater treatment: Comparison of kinetic aspects of selective (chlorine, chlorine dioxide, ferrateVI, and ozone) and non-selective oxidants (hydroxyl radical). Water Research, 44(2), 555-566. https://doi.org/10.1016/j.watres.2009.11.045

Liu, Z. hua, Kanjo, Y., \& Mizutani, S. (2009). Removal mechanisms for endocrine disrupting compounds (EDCs) in wastewater treatment - physical means, biodegradation, and chemical advanced oxidation: A review. Science of the Total Environment, 407(2), 731-748.

https://doi.org/10.1016/j.scitotenv.2008.08.039

Mandal, S. (2018). Reaction Rate Constants of Hydroxyl Radicals with Micropollutants and Their Significance in Advanced Oxidation Processes. Journal of Advanced Oxidation Technologies, 21(1). https://doi.org/10.26802/jaots.2017.0075

Mompelat, S., Le Bot, B., \& Thomas, O. (2009). Occurrence and fate of pharmaceutical products and by-products, from resource to drinking water. Environment International, 35(5), 803-814. https://doi.org/10.1016/j.envint.2008.10.008 
Ohnmacht, C. M., Chen, S., Tong, Z., \& Hage, D. S. (2006). Studies by biointeraction chromatography of binding by phenytoin metabolites to human serum albumin. Journal of Chromatography, 836, 83-91. https://doi.org/10.1016/j.jchromb.2006.03.043

Oulton. (2013). Development of nanomaterial-enabled advanced oxidation techniques for treatment of organic micropollutants, (August), 232.

Oulton, R., Haase, J. P., Kaalberg, S., Redmond, C. T., Nalbandian, M. J., \& Cwiertny, D. M. (2015). Hydroxyl radical formation during ozonation of multiwalled carbon nanotubes: Performance optimization and demonstration of a reactive CNT filter. Environmental Science and Technology, 49(6), 3687-3697. https://doi.org/10.1021/es505430v

Oulton, Kohn, T., \& Cwiertny, D. M. (2010). Pharmaceuticals and personal care products in effluent matrices: A survey of transformation and removal during wastewater treatment and implications for wastewater management. Journal of Environmental Monitoring, 12(11), 1929-2188.

https://doi.org/10.1039/c0em00068j

Pal, A., He, Y., Jekel, M., Reinhard, M., \& Yew-Hoong Gin, K. (2014). Emerging contaminants of public health significance as water quality indicator compounds in the urban water cycle indicator compounds in the urban water cycle. Environment International, 71(June), 46-62. https://doi.org/10.1016/j.envint.2014.05.025

Petrie, B., Barden, R., \& Kasprzyk-Hordern, B. (2014). A review on emerging contaminants in wastewaters and the environment: Current knowledge , 
understudied areas and recommendations for future monitoring. Water Research, 72(0), 3-27. https://doi.org/10.1016/j.watres.2014.08.053

Quintana, J. B., Weiss, S., \& Reemtsma, T. (2005). Pathways and metabolites of microbial degradation of selected acidic pharmaceutical and their occurrence in municipal wastewater treated by a membrane bioreactor. Water Research, 39(12), 2654-2664. https://doi.org/10.1016/j.watres.2005.04.068 Radjenović, J., Petrović, M., \& Barceló, D. (2009). Fate and distribution of pharmaceuticals in wastewater and sewage sludge of the conventional activated sludge (CAS) and advanced membrane bioreactor (MBR) treatment. Water Research, 43(3), 831-841. https://doi.org/10.1016/j.watres.2008.11.043

Radjenović, Petrović, M., Ventura, F., \& Barceló, D. (2008). Rejection of pharmaceuticals in nanofiltration and reverse osmosis membrane drinking water treatment. Water Research, 42(14), 3601-3610.

https://doi.org/10.1016/j.watres.2008.05.020

Restivo, J., Garcia-bordejé, E., Órfão, J. J. M., \& Pereira, M. F. R. (2016). Carbon nanofibers doped with nitrogen for the continuous catalytic ozonation of organic pollutants. Chemical Engineering Journal, 293, 102-111.

Rey, A., Carbajo, J., Adán, C., Faraldos, M., Bahamonde, A., Casas, J. A., \& Rodriguez, J. J. (2011). Improved mineralization by combined advanced oxidation processes. Chemical Engineering Journal, 174(1), 134-142. https://doi.org/10.1016/j.cej.2011.08.061

Rosal, R., Rodriguez, A., Perdigon-Melon, J. A., Petre, A., Garcia-Calvo, E., 
Gomez, M. J., ... Fernandez-Alba, A. R. (2010). Occurrence of emerging pollutants in urban wastewater and their removal through biological treatment followed by ozonation. Water Research, 44(2), 578-588. https://doi.org/10.1016/j.watres.2009.07.004

Rosal, R., Rodríguez, A., Perdigón-melón, J. A., Petre, A., García-Calvo, E., José, M., ... Fernández-Alba, A. R. (2009). Degradation of caffeine and identification of the transformation products generated by ozonation. Chemosphere, 74(6), 825-831. https://doi.org/10.1016/j.chemosphere.2008.10.010

Ross, G., Adam, T., \& Dittmann, M. (n.d.). Gradient LC analysis of herbicides and polyaromatic hydrocarbons by isocratic Capillary Electrochromatography, 1-2.

Sánchez-Polo, M., Salhi, E., Rivera-Utrilla, J., \& Von Gunten, U. (2006). Combination of ozone with activated carbon as an alternative to conventional advanced oxidation processes. Ozone: Science and Engineering, 28(4), 237-245. https://doi.org/10.1080/01919510600714170

Schaar, H., Clara, M., Gans, O., \& Kreuzinger, N. (2010). Micropollutant removal during biological wastewater treatment and a subsequent ozonation step. Environmental Pollution, 158(5), 1399-1404.

https://doi.org/10.1016/j.envpol.2009.12.038

Schonherr, J., Buchheim, J., Scholz, P., \& Stelter, M. (2017). Oxidation of carbon nanotubes with ozone and hydroxyl radicals. Carbon, 111, 631-640. https://doi.org/10.1016/j.carbon.2016.10.013 
Sipma, J., Osuna, B., Collado, N., Monclús, H., Ferrero, G., Comas, J., \& Rodriguez-Roda, I. (2010). Comparison of removal of pharmaceuticals in MBR and activated sludge systems. Desalination, 250(2), 653-659. https://doi.org/10.1016/j.desal.2009.06.073

Sotelo, J. L., Rodriguez, A. R., Mateos, M. M., Hernandez, S. D., Torrellas, S. A., \& Rodriguez, J. G. (2012). Adsorption of pharmaceutical compounds and an endocrine disruptor from aqueous solutions by carbon materials. Journal of Environmental Science and Health, 47, 640-652.

https://doi.org/10.1080/03601234.2012.668462

Vance, L. E. (2017). Potential of Ozone and Hydroxyl Radicals to Degrade Emerging Organic Contaminants, (October).

Wert, E. C., Rosario-Ortiz, F. L., \& Snyder, S. A. (2009). Effect of ozone exposure on the oxidation of trace organic contaminants in wastewater. Water Research, 43(4), 1005-1014.

https://doi.org/10.1016/j.watres.2008.11.050

Yuan, F., Hu, C., Hu, X., Qu, J., \& Yang, M. (2009). Degradation of selected pharmaceuticals in aqueous solution with UV and UV / H 2 O 2. Water Research, 43(6), 1766-1774. https://doi.org/10.1016/j.watres.2009.01.008 


\section{Appendices}

\section{Appendix A - Calibration Curves}

Figure A.1 contains the calibration curve for the caffeine data obtained by the HPLC.

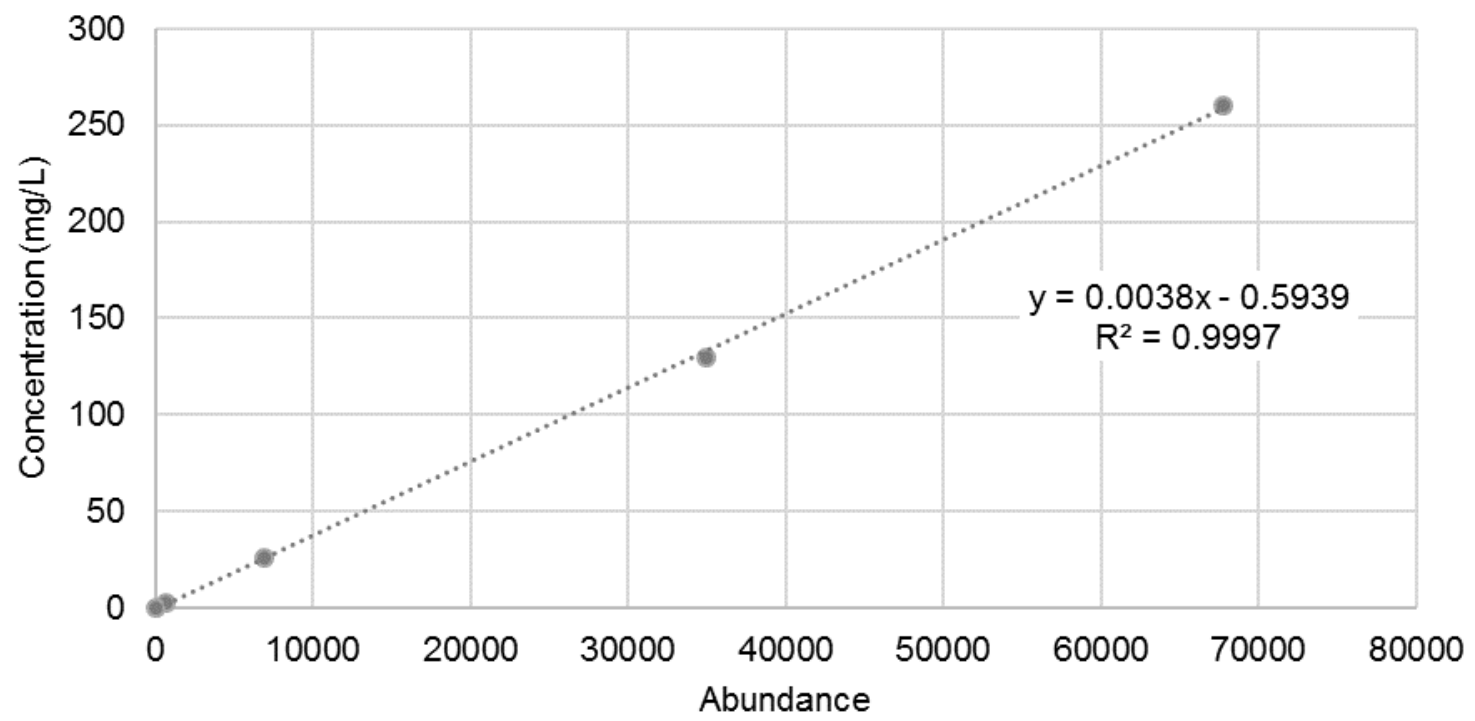

Figure A.1: Calibration curve for known caffeine concentrations and absorbance measured by the HPLC.

Figure A. 2 contains the calibration curve for the atrazine data obtained by the HPLC. 


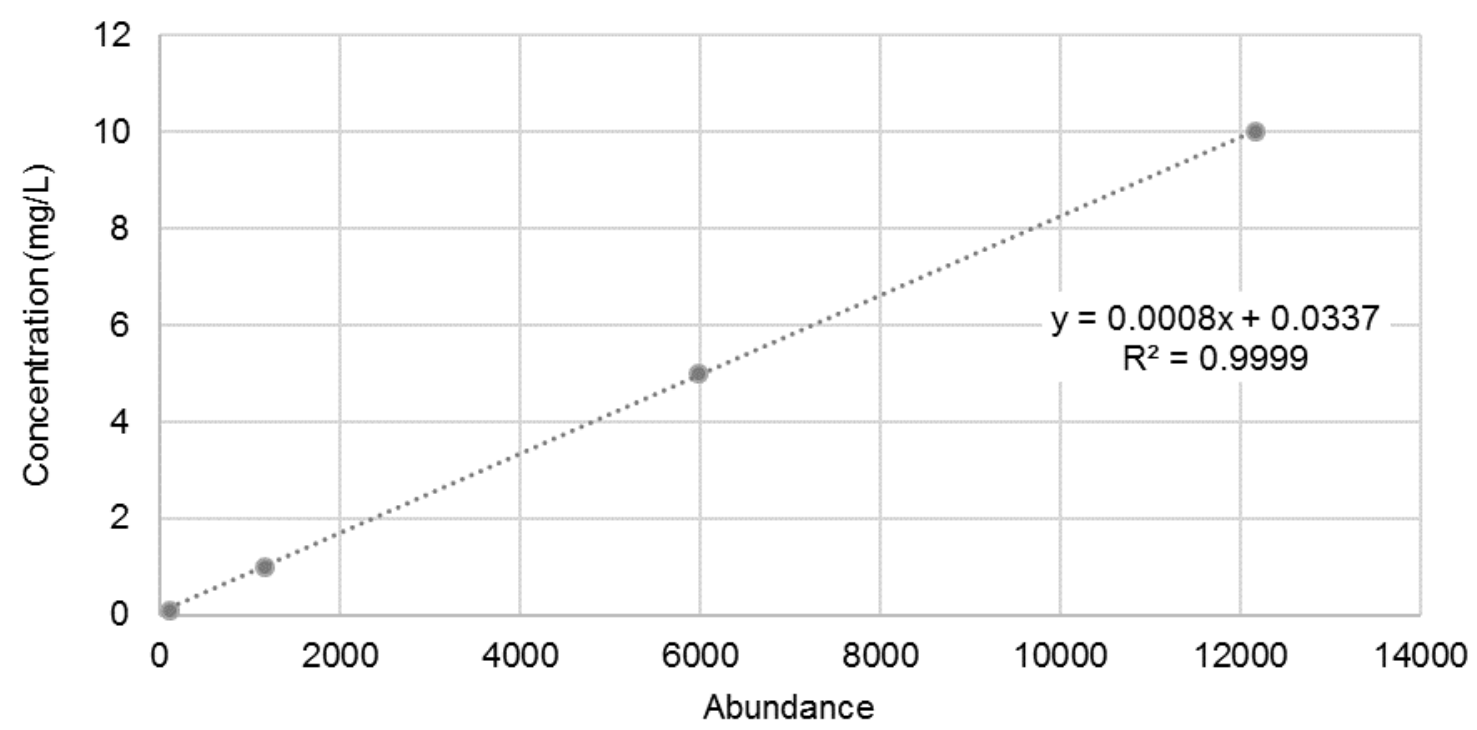

Figure A.2: Calibration curve for known atrazine concentrations and absorbance measured by the HPLC.

Figure A. 3 contains the calibration curve for the phenytoin data obtained by the HPLC.

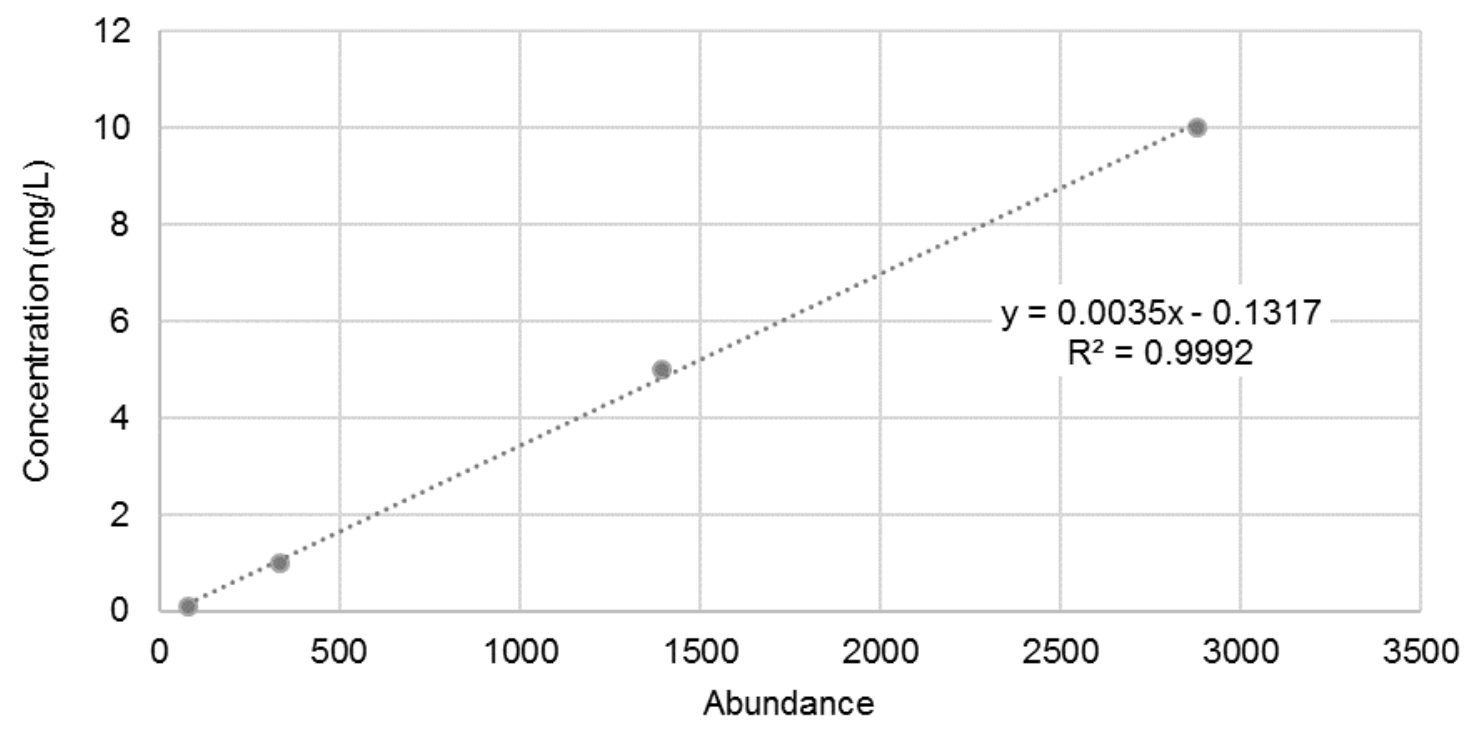

Figure A.3: Calibration curve for known phenytoin concentrations and absorbance measured by the HPLC. 
Appendix B - Calculation of $\mathrm{K}_{\circ 3}$ Values

Figure B.1 contains the graphs for each trial of Experiment 1 used to calculate the $\mathrm{K}_{\mathrm{O} 3}$ values for caffeine exposed to ozone with standard competition.

(a)

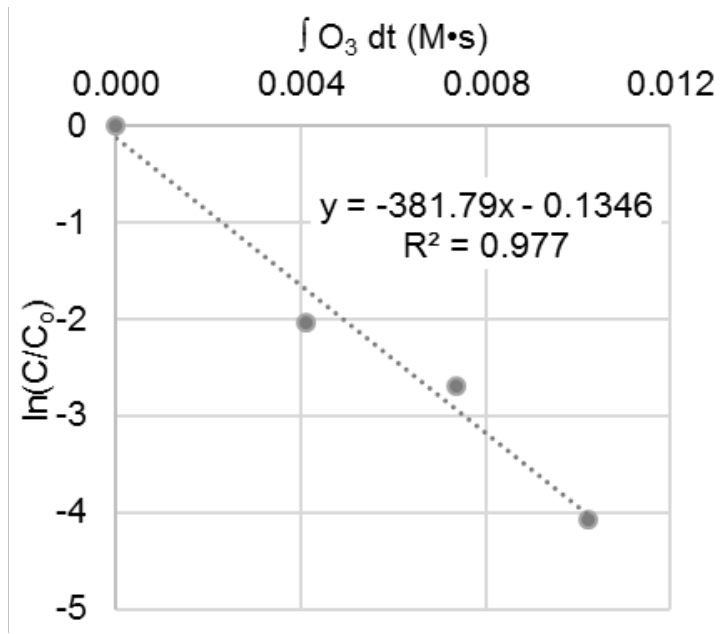

(b)

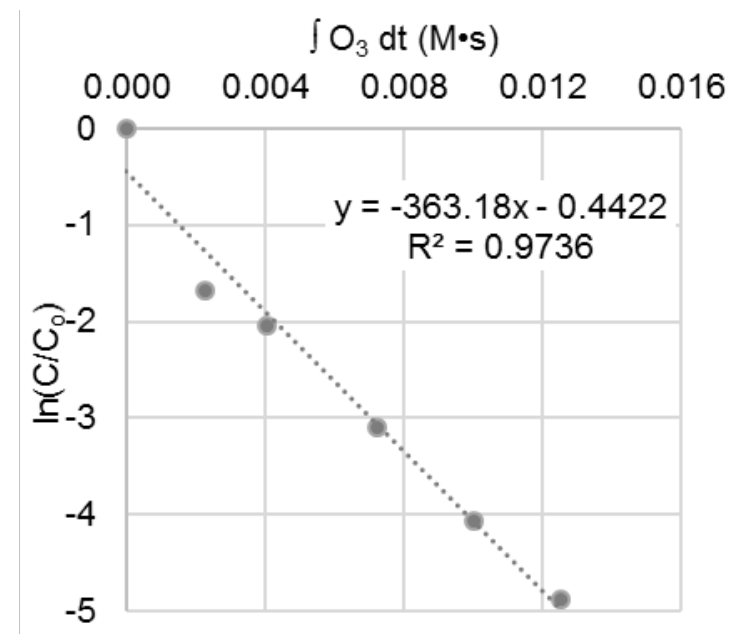

(c)

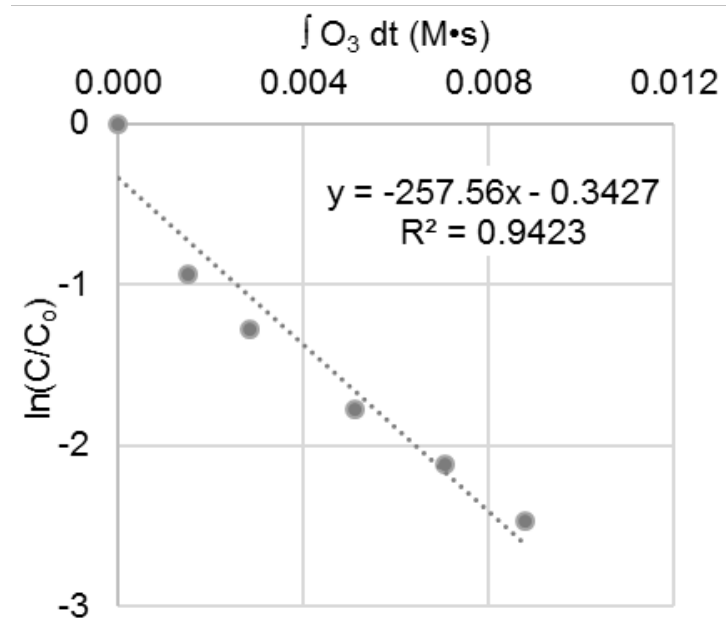

Figure B.1: Natural log of removal of caffeine versus the time integrated ozone concentration for (a) Trial 1, (b) Trial 2, and (c) Trial 3 in Experiment 1.

Figure B. 2 contains the graphs for each trial of Experiment 2 used to calculate the $\mathrm{K}_{03}$ values for caffeine exposed to ozone with double competition. 
(a)

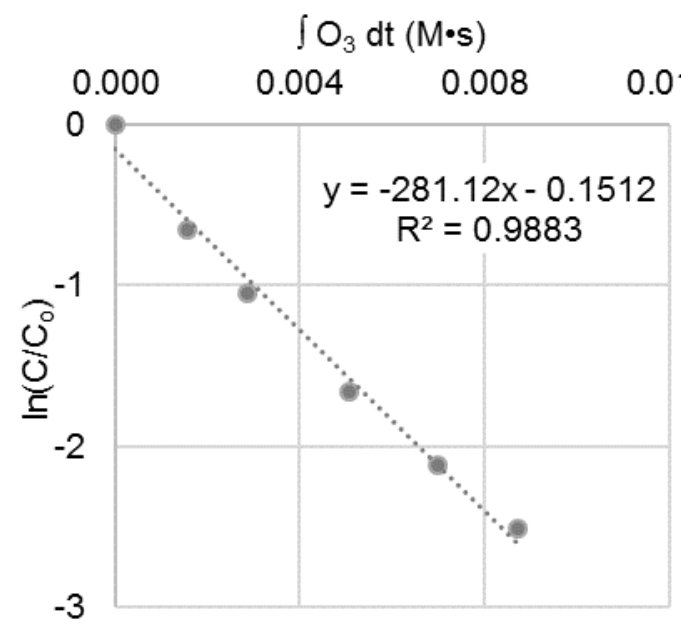

(b)

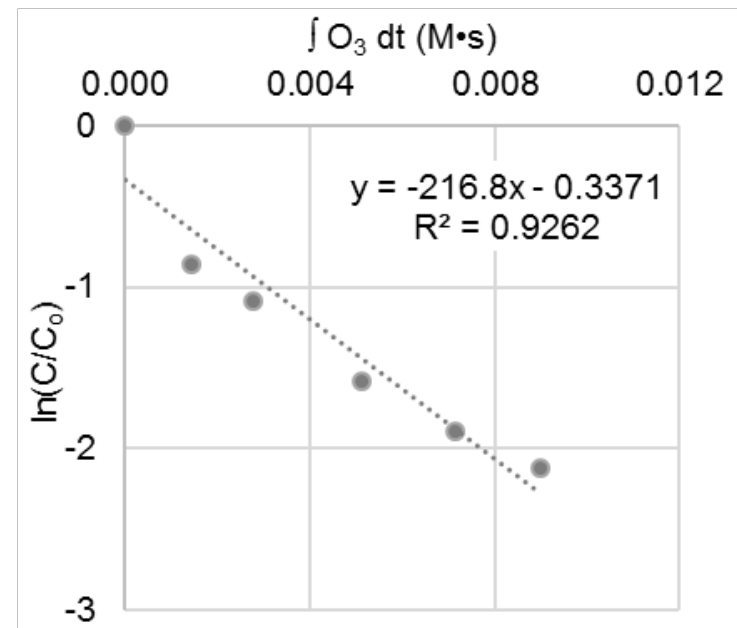

Figure B.2: Natural log of removal of caffeine versus the time integrated ozone concentration for (a) Trial 1 and (b) Trial 2 in Experiment 2.

Figure B.3 contains the graphs for each trial of Experiment 3 used to calculate the $\mathrm{K}_{\mathrm{O}}$ values for caffeine exposed to ozone with triple competition.

(a)

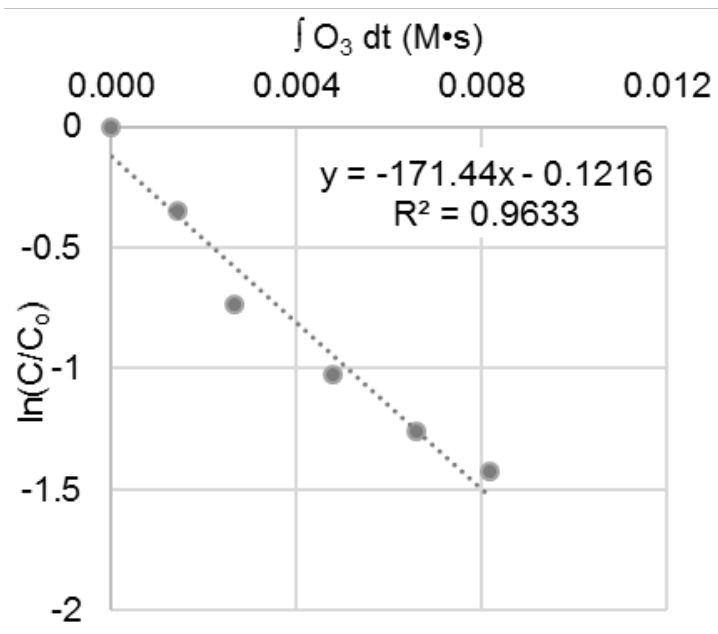

(b)

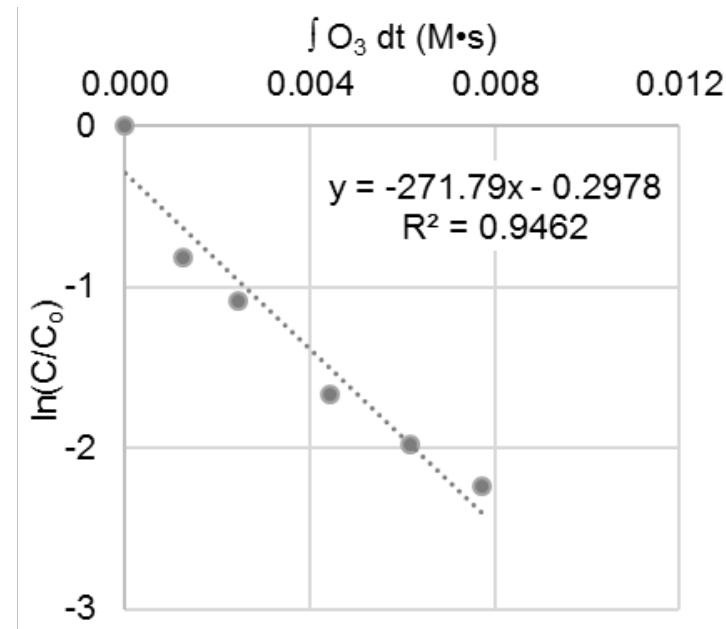

Figure B.3: Natural log of removal of caffeine versus the time integrated ozone concentration for (a) Trial 1 and (b) Trial 2 in Experiment 3.

Figure B.4 contains the graphs for each trial of Experiment 4 used to calculate 
the $\mathrm{K}_{03}$ values for atrazine exposed to ozone alone.

(a)

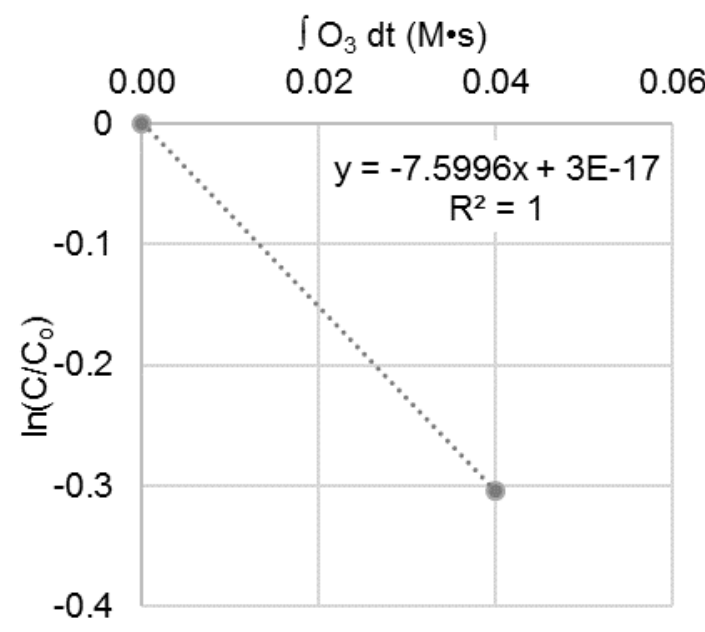

(b)

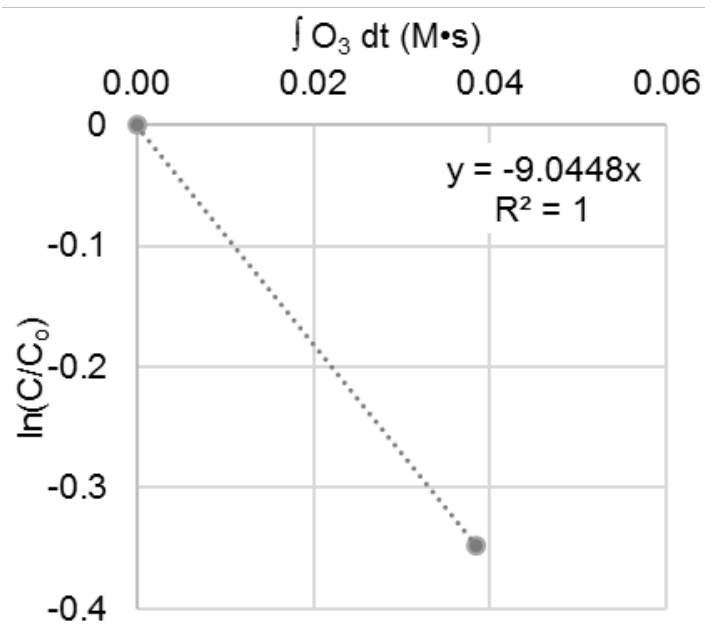

Figure B.4: Natural log of removal of atrazine versus the time integrated ozone concentration for (a) Trial 1 and (b) Trial 2 in Experiment 4.

Figure B.5 contains the graphs for each trial of Experiment 6 used to calculate the K' values for atrazine exposed to the AOP with ozone and CNTs.

(a)

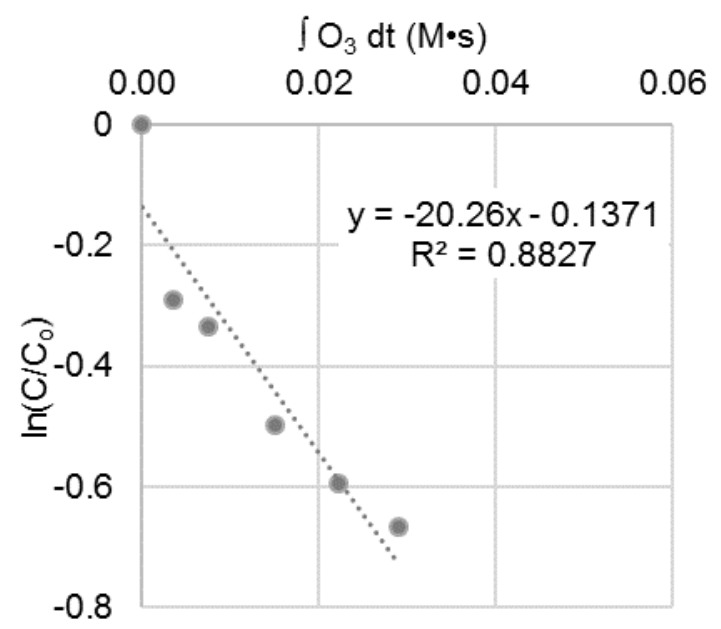

(b)

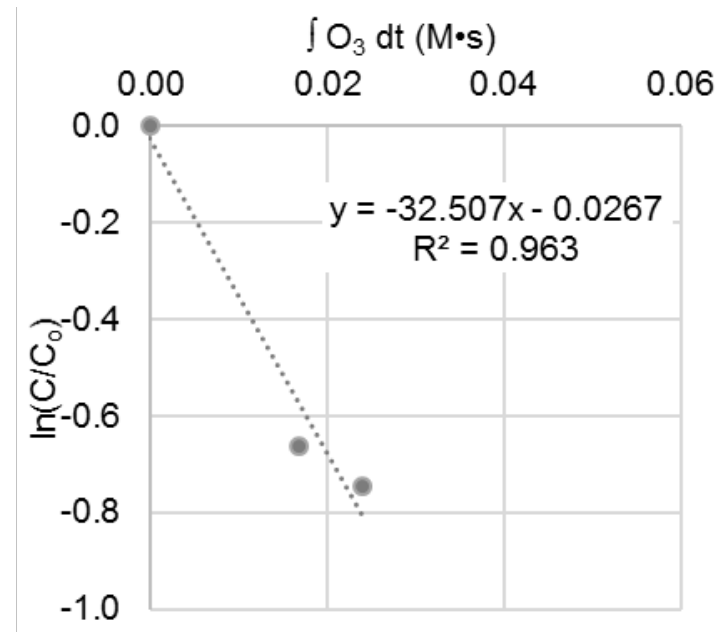

Figure B.5: Natural log of removal of atrazine versus the time integrated ozone concentration for (a) Trial 1 and (b) Trial 2 in Experiment 6. 
Figure B. 6 contains the graphs for each trial of Experiment 7 used to calculate the $\mathrm{K}_{\mathrm{O} 3}$ values for atrazine and caffeine exposed to ozone alone.

(a)

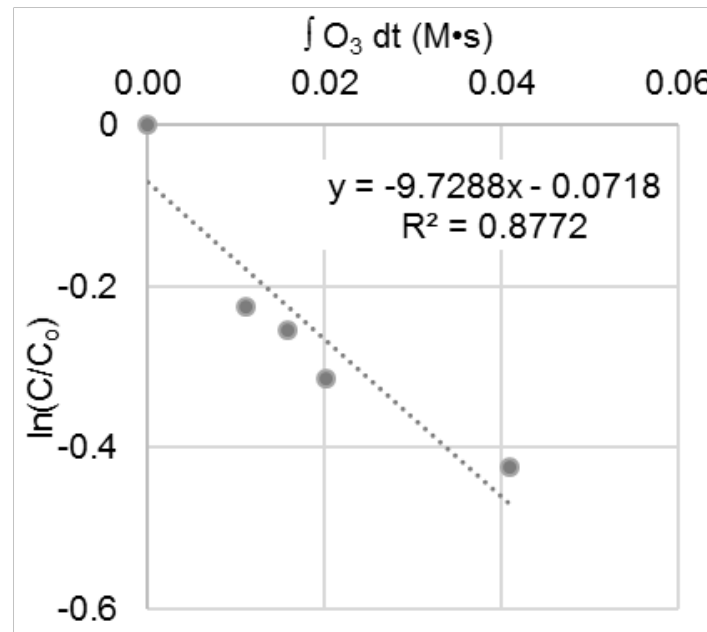

(b)

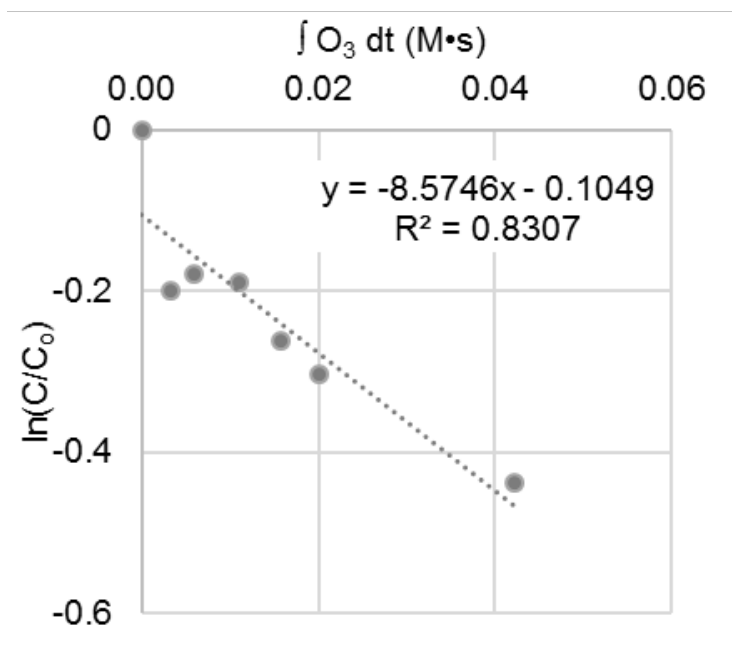

Figure B.6: Natural log of removal of atrazine versus the time integrated ozone concentration for (a) Trial 1 and (b) Trial 2 in Experiment 7.

Figure B.7 contains the graphs for each trial of Experiment 9 used to calculate the $\mathrm{K}^{\prime}$ values for atrazine and caffeine exposed to the AOP with ozone and CNTs. 
(a)

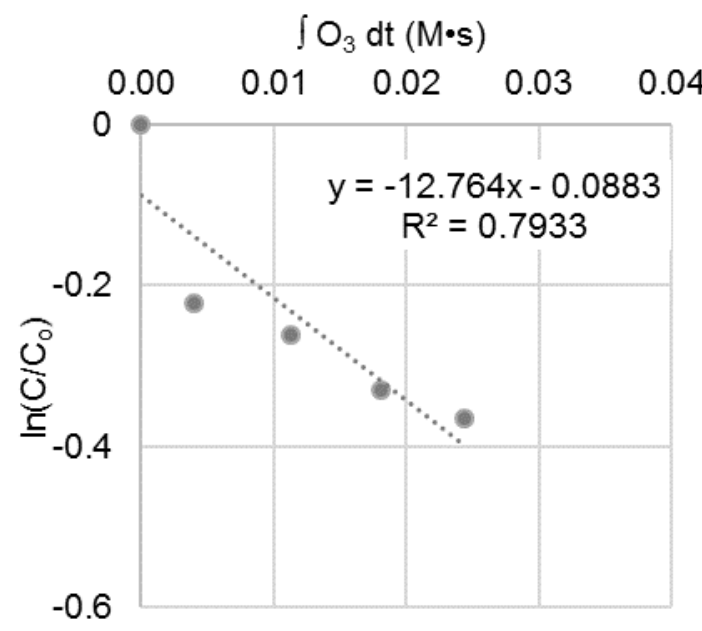

(b)

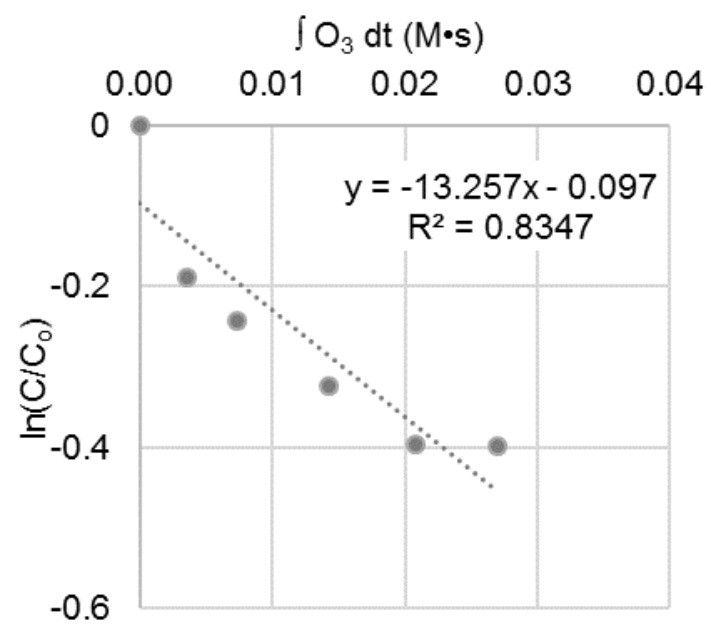

Figure B.7: Natural log of removal of atrazine versus the time integrated ozone concentration for (a) Trial 1 and (b) Trial 2 in Experiment 9. 
Appendix C - Phenytoin Results

To determine if exposure to the AOP improved the removal of phenytoin, the response of phenytoin to direct oxidation with ozone alone and sorption by CNTs alone was determined first. Then, phenytoin was exposed to the AOP. The concentration of phenytoin was measured and the results of the three experiments are displayed in Figure C.1.

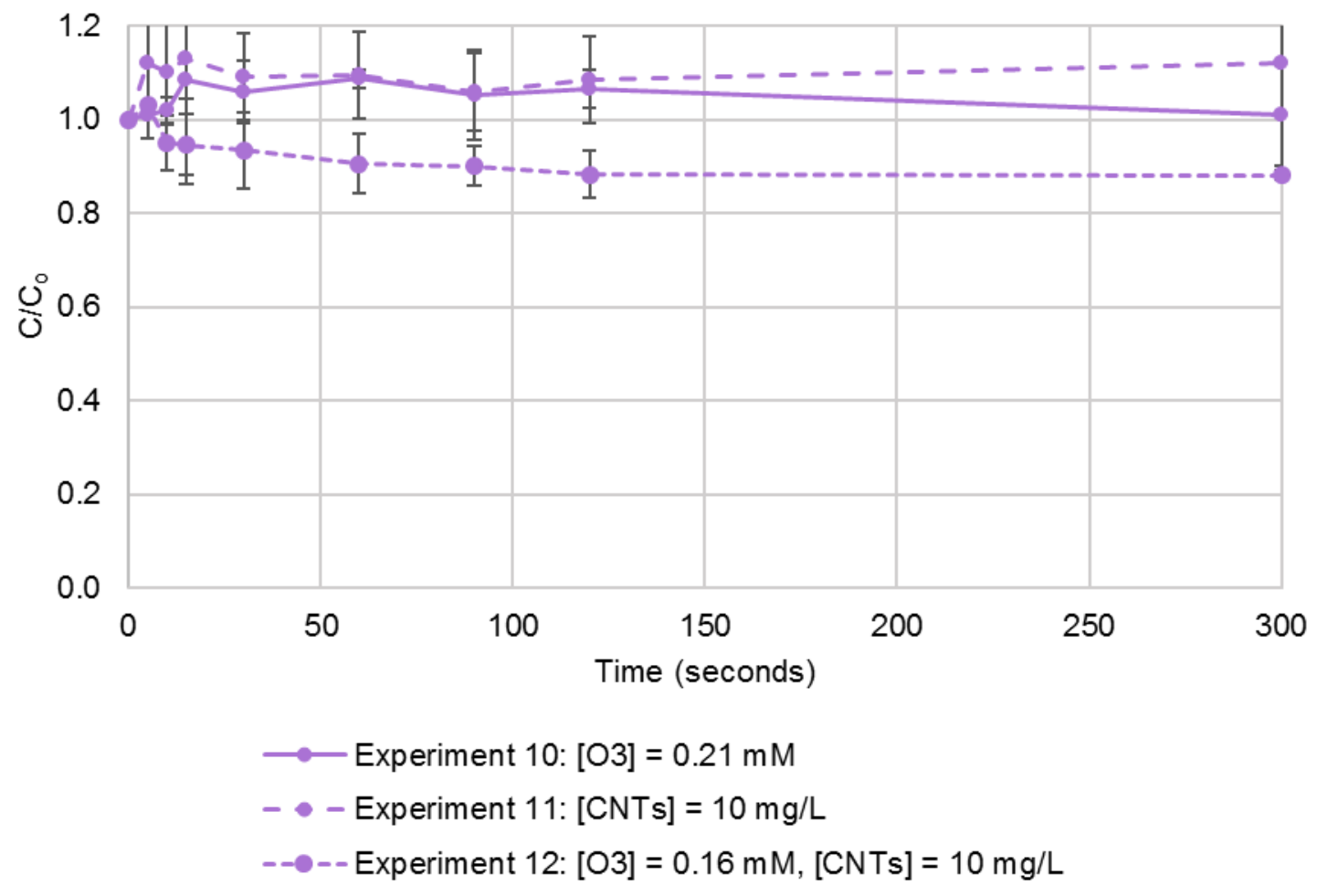

Figure C.1: Phenytoin concentration as a function of time in Experiment 10 (ozone only), 11 (CNTs only), and 12 (AOP with ozone and CNTs). Data represent averages and standard deviation from duplicate experiments. Experimental conditions: [phenytoin] $=10 \mathrm{mg} / \mathrm{L}$, [tertbutanol] $=0.32 \mathrm{mM}, \mathrm{pH} 7(680 \mathrm{mg} / \mathrm{L}$ phosphate buffer $), T=20^{\circ} \mathrm{C}$.

When exposed to ozone for 5 minutes in Experiment 10, phenytoin did not display any degradation. The $0 \%$ reduction in phenytoin concentration demonstrates the resistance of phenytoin to degrade by treatment with ozone. 
In Experiment 11, phenytoin was exposed to CNTs to determine if any sorption effects exist between the phenytoin and CNTs. After 5 minutes, $100 \%$ of the initial concentration of phenytoin remained in Experiment 11, indicating that sorption to CNTs is not significant.

Phenytoin was also exposed to the AOP with ozone and CNTs in Experiment 12 and experienced a slight reduction in concentration over 5 minutes. The phenytoin concentration was reduced by approximately $5 \%$ after 15 seconds and by $9 \%$ after 60 seconds. After 5 minutes, approximately $88 \%$ of the initial phenytoin concentration remained in Experiment 12.

Since phenytoin demonstrated recalcitrance to ozone, the reduction in phenytoin concentration can be attributed to the addition of $\cdot \mathrm{OH}$ from the AOP. The degradation curve for Experiment 12 in Figure C.1 also represents the degradation by $\cdot \mathrm{OH}$. Overall, $\cdot \mathrm{OH}$ contributed to a $12 \%$ reduction in phenytoin concentration. The response of phenytoin to $\cdot \mathrm{OH}$ demonstrates the benefit the AOP can provide for degrading ozone recalcitrant compounds. Without the addition of highly reactive $\cdot \mathrm{OH}$ via the AOP, phenytoin would not experience any degradation when exposed to direct oxidation with ozone alone.

The data presented in Figure C.1 were corrected with the average sorption to the filters. For Experiment 11 and 12, the error introduced by correcting the data for sorption could contribute to the slight increase and variation in concentration 
observed over 5 minutes. The method used to correct the data tested the precision limits of the analytical methods used. The low initial concentration of phenytoin was susceptible to the error associated with correcting the data for sorption. The $12 \%$ reduction of phenytoin achieved by $\cdot \mathrm{OH}$ may be slightly more or less depending on the error introduced by the sorption effect. With the sizeable error caused by the sorption effect, the source of the slight reduction in phenytoin concentration is unknown. Therefore, results of this experiment do not definitively quantify the removal of phenytoin achieved by the AOP.

Phenytoin has limited potential as an indicator compound for AOPs because of its minimal response to treatment and the sorption effect with filter materials. In this study, phenytoin was degraded by approximately $10 \%$ after exposure to the AOP. The lack of response to treatment with the AOP limits the potential for phenytoin to be used as an indicator compound. The sorption effect of phenytoin to filters poses a challenge for further study with CNTs. 